\title{
WestVirginiaUniversity
}

THE RESEARCH REPOSITORY @ WVU

Graduate Theses, Dissertations, and Problem Reports

2021

\section{Technical Direction Process for King Lear}

Ashley Noel Hungerford

anh0051@mix.wvu.edu

Follow this and additional works at: https://researchrepository.wvu.edu/etd

Part of the Fine Arts Commons

\section{Recommended Citation}

Hungerford, Ashley Noel, "Technical Direction Process for King Lear" (2021). Graduate Theses,

Dissertations, and Problem Reports. 8071.

https://researchrepository.wvu.edu/etd/8071

This Thesis is protected by copyright and/or related rights. It has been brought to you by the The Research Repository @ WVU with permission from the rights-holder(s). You are free to use this Thesis in any way that is permitted by the copyright and related rights legislation that applies to your use. For other uses you must obtain permission from the rights-holder(s) directly, unless additional rights are indicated by a Creative Commons license in the record and/ or on the work itself. This Thesis has been accepted for inclusion in WVU Graduate Theses, Dissertations, and Problem Reports collection by an authorized administrator of The Research Repository @ WVU. For more information, please contact researchrepository@mail.wvu.edu. 
Graduate Theses, Dissertations, and Problem Reports

2021

Technical Direction Process for King Lear

Ashley Noel Hungerford

Follow this and additional works at: https://researchrepository.wvu.edu/etd

Part of the Fine Arts Commons 


\title{
Technical Direction Process for King Lear
}

\author{
Ashley Noel Hungerford \\ Thesis submitted to the \\ College of Creative Arts \\ at West Virginia University \\ in partial fulfillment of the requirements \\ for the degree of \\ Master of Fine Arts \\ In \\ Technical Direction \\ Steven Neuenschwander, MFA, Chair \\ Alan McEwen, MFA \\ Jerry McGonigle, MFA
}

School of Theatre and Dance

Morgantown, WV 2021

Keywords: Technical Direction, Technical Director, Technical Design, Technical Theatre, King Lear

(C) 2021 Ashley Noel Hungerford 
ABSTRACT

\title{
Technical Direction Process of King Lear
}

\author{
Ashley Noel Hungerford
}

This thesis is my account as the Technical Director of King Lear filmed at West Virginia University, College of Creative Arts, School of Theatre \& Dance in collaboration with West Virginia Public Broadcasting. This production took place during the COVID-19 pandemic from September 2020 - March 2021. This document will take you through budgeting, drafting, build, load in, filming, and strike processes, including how COVID-19 affected these processes. This thesis is supported by images, schedules, drafting, and paperwork. 


\section{ACKNOWLEDGMENTS}

I would like to express my great appreciation and thanks to Dan \& Suzette Hungerford for their unending support and belief in me throughout my academic career. Without it, I would not be where I am today. I would also like to express my deepest thanks and appreciation to the faculty and staff of WVU School of Theatre \& Dance, especially Steven Neuenschwander, Alan McEwen, Mary McClung, and Robert Klingelhoefer. Thank you for taking a chance on me and pushing me beyond what I thought I could do.

Thank you! 


\section{TABLE OF CONTENTS}

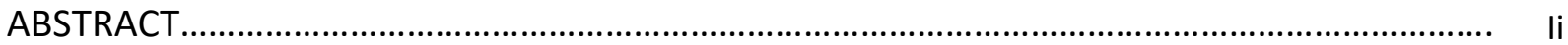

AKNOWLEDGMENTS................................................................................................................... lii

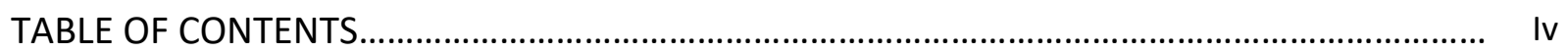

TABLE OF FIGURES ............................................................................................

INTRODUCTION ........................................................................................................

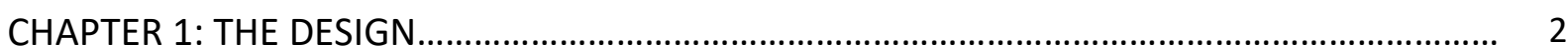

CHAPTER 2: BUDGETING \& PLANNING .................................................................... 6

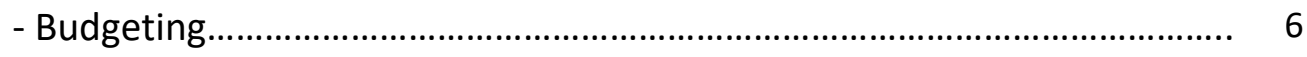

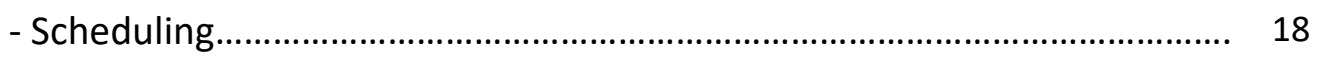

- Ordering Materials................................................................................ 22

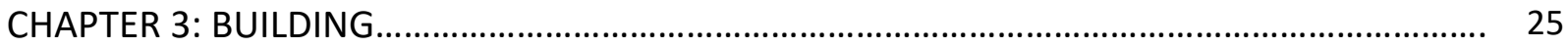

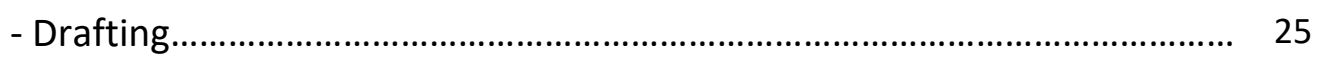

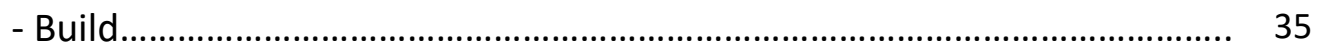

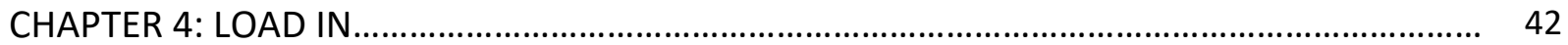

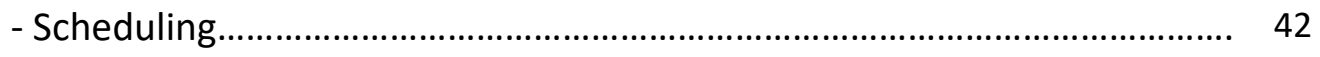

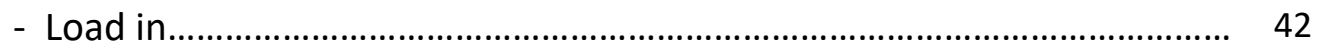

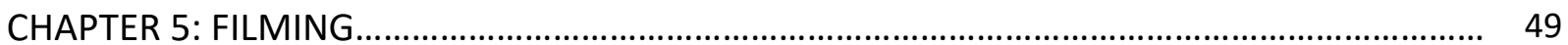

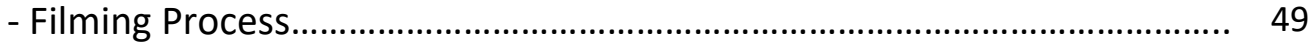

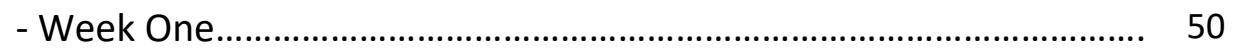

- Week Two............................................................................... 53

- Week Three.............................................................................. 56

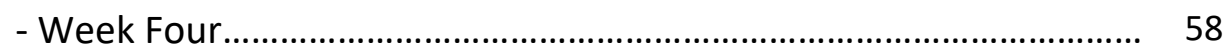

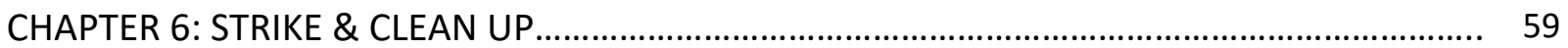

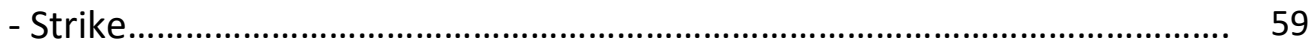

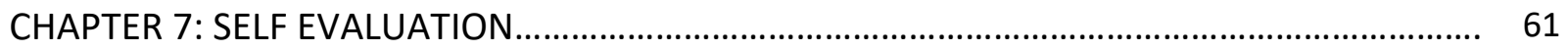

- What I would keep and what I would change.......................................................... 61

- What I learned................................................................................................... 62

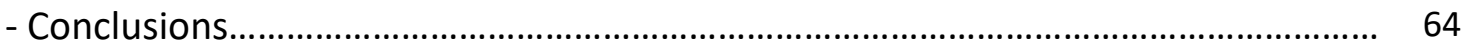

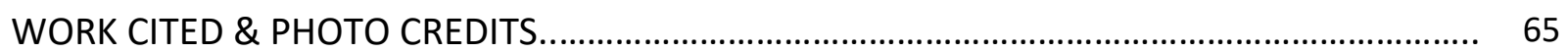

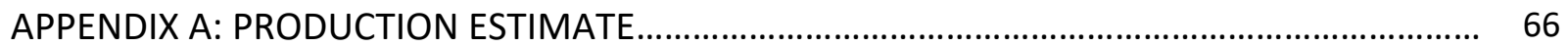

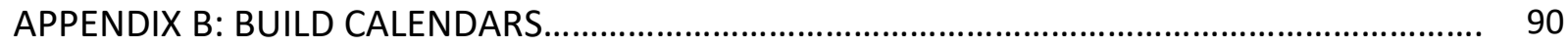

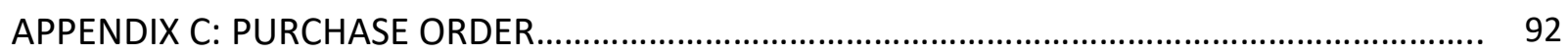

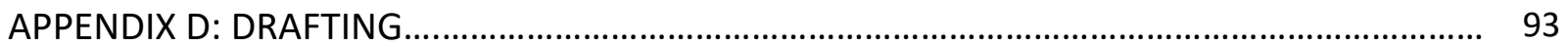

APPENDIX E: DESIGNER RENDERINGS .................................................................. 107

APPENDIX F: STRIKE PLAN...................................................................................... 110 


\section{TABLE OF FIGURES}

Figure $1 \quad$ Act 1 Scene 1 - Lear's Palace ......................................................................... 2

Figure $2 \quad$ Act 1 Scene 2 - Gloucester's castle............................................................... 3

Figure $3 \quad$ Act 2 Scenes 1-4 - Outside Gloucester's Castle.............................................. 4

Figure $4 \quad$ Act 3 Scenes 1 \& 2 - Heath \& Storm............................................................. 4

Figure $5 \quad$ Act 3 Scene 3 Inside the Hovel....................................................................... 4

Figure $6 \quad$ Budget Form A for Rain Machine................................................................ 9

Figure $7 \quad$ Mr. Sheriff's form for Rotating Walls............................................................. 10

Figure $8 \quad$ Miss. Johnsons Form A for Large Arches....................................................... 11

Figure $9 \quad$ Department Budget Break Down...................................................................... 13

Figure $10 \quad$ Screen capture of instruction video............................................................. 14

Figure 11 Revised Form A for Rain Machine............................................................. 14

Figure 12 Build Calendar for Fall Semester.................................................................. 20

Figure 13 Build Calendar for Spring Semester............................................................ 21

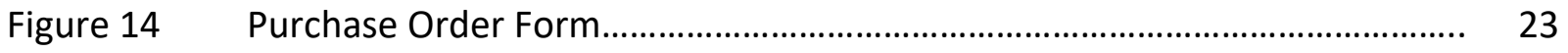

Figure 15 3D Model of Tent Rig shown in AutoCAD..................................................... 26

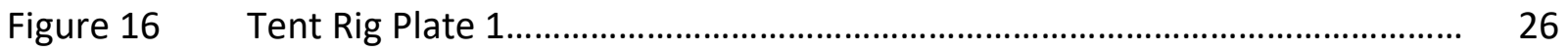

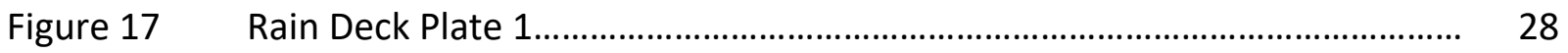

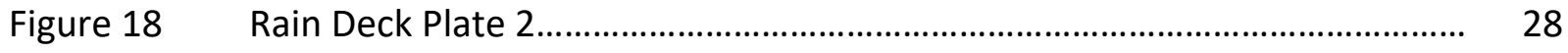

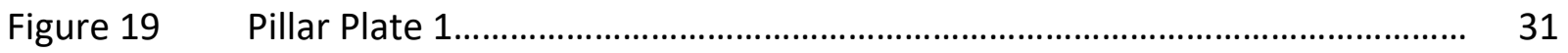

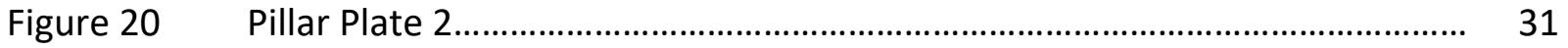

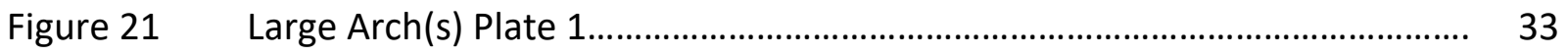

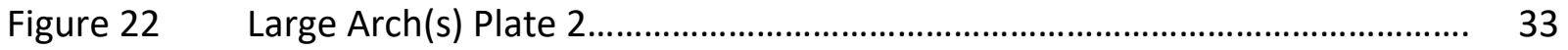

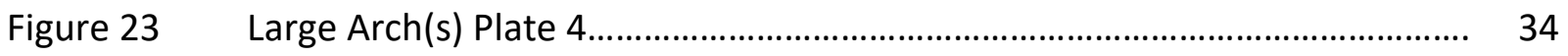

Figure $24 \quad$ Downstage Tolly \& Track................................................................................ 39

Figure $25 \quad$ Act 1 Scene 1 - Lear's Palace ....................................................................... 51

Figure $26 \quad$ Act 1 Scene 2 - Albany's Palace.................................................................. 52

Figure $27 \quad$ Act 2 Scenes 1-4 - Outside Gloucester's Castle............................................. 53

Figure $28 \quad$ Rain Machine and Deck Install......................................................................... 54 


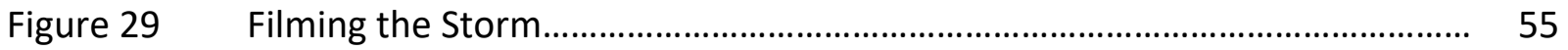

Figure $30 \quad$ Act 3 Scene 3 - Inside the Hovel the Fire Scene.......................................... 56

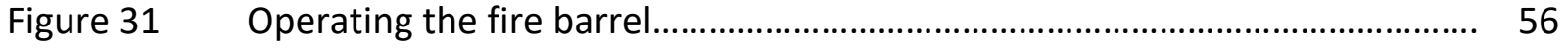

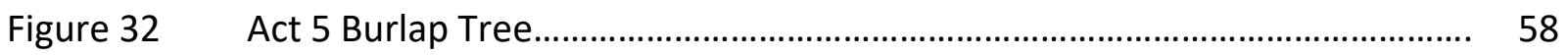

Figure $33 \quad$ Act 5 Final Look.......................................................................................... 58 


\section{INTRODUCTION}

West Virginia University's School of Theatre \& Dance production of King Lear was approached in a way that had never been done before at WVU, Filming a movie. The School of Theatre \& Dance teamed up with West Virginia Public Broadcasting to film King Lear. This was a unique experience and task for me as a Technical Director.

Our production was directed by Professor Gerald McGonigle. Video production was done by West Virginia Public Broadcasting with Larry Dowling as the Director of Photography. Lighting design was done by Professors Joshua Williamson \& Alan McEwen. Scenic design done by fellow graduate student Abigail Wagner, with sound by undergrad Alexis Allenbaugh in collaboration with West Virginia Public Broadcasting.

My role as the Technical Director was to take Ms. Wagner's designs and build them into reality as well as manage the day-to-day adjustments of the set during filming. This process began with discussions between Professor McGonigle, Ms. Wagner, and I about how they wanted the set to look and move to best suit filming. Most conversations throughout the process examined how these units would be used in scenes and from what angles they would be filmed from.

After these conversations I took the designs and set to work on bringing our world of King Lear to life through budgeting, scheduling, drafting, build, load in, and strike of the production. In the early stages of the process I did a lot of research and discussed with my advisor and colleagues on how best to build this world that fit within our budget and time. My main role was to deliver a film ready set that achieved the Designer's and Director's vision. 


\section{CHAPTER 1: THE DESIGN}

We started the design process with a global pandemic in mind. The design process is always a crazy and creative time because the director and designers are looking at the play for the first time and really deciding what they want the production to be. This show would go through many revisions before arriving at the final design that would become our version of King Lear.

A concept that got tossed around a lot during the design process by Professor McGonigle was that he wanted a "sand box" that he could play around in. Since there was no audience to be concerned with it was possible to film the set from $360^{\circ}$. He also stated that he did not want the design to be focused on any one particular historical period. Ms. Wagner played around with this idea until she landed on an abstract concrete overpass look that included a lot of very large objects with a cement like texture. Ms. Wagner's design included two tracking walls, two rotating and tracking walls, two pillars, two large rolling arches, and two small rolling arches. Each of these units would be pulling double, sometimes triple duty turning the space into many different locals. The units also helped to either shrink the space or expand it based on how they were configured. The images presented in this chapter represent the most used locations and demonstrate how the scenic units could transform the space, see Appendix E for complete designer renderings.

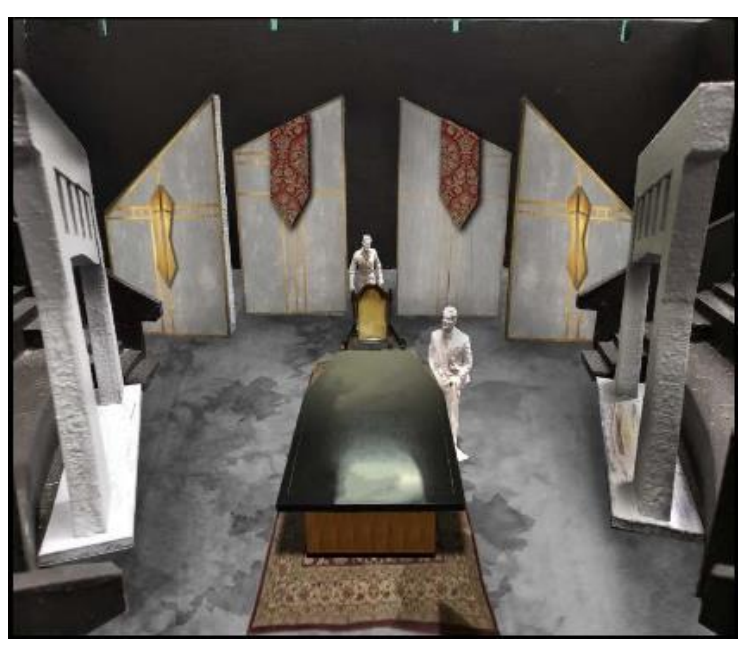

Figure 1: Act 1 Scene 1 - Lear's Palace The play begins in Lear's Castle ( Figure. 1) 
which contained all four wall units and the two large arches to create a "conference room" like feel.

From Lear's Palace the scene shifted to Gloucester's Castle (Fig. 2) which had the upstage wall units turned to make an interesting angle. The downstage walls would be tracked out to help frame the area with the pillars and one small arch being added downstage to fill out the playing space.

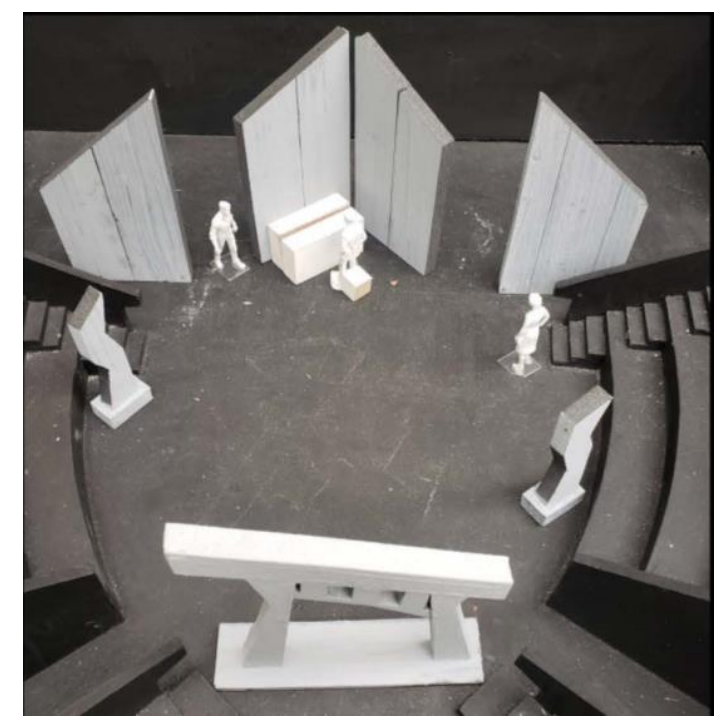

Figure 2: Act 1 Scene 2 - Gloucester's Castle

The last scene in the act would be at Albany's Palace which had the upstage wall completely flipped and moved to their most off-stage points and angled about $15^{\circ}$ towards the downstage walls. The two small arches would be pushed into the downstage voms to complete the look. 
Act 2 would then move the play to some of the outdoor locals. Outside Gloucester's

Castle. The upstage walls would turn $90^{\circ}$ and be in line with the onstage side of the downstage walls creating an almost hallway like look. All four of the arches would be used to round out and contain the space to create the courtyard.

From there the scenery would shift back to looks

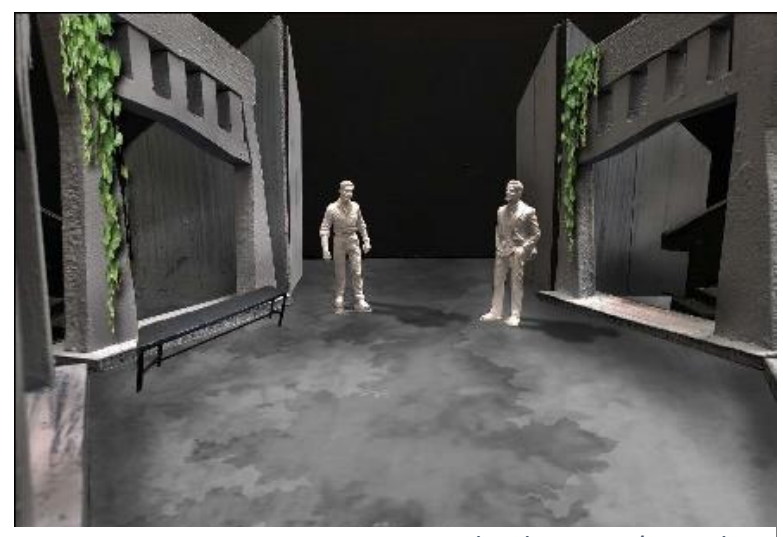

Figure 3: Act 2 Scenes 1-4 - Outside Gloucester's Castle from previous scenes throughout the act and end with the characters going into the heath.

Act 3 opened in the Heath which was just an empty stage with erosion cloth and burlap laid down to give the world some texture (Figure. 4). From the Heath we would go in and out of the hovel. The outside of the hovel consisted of all four arches just angled in to make a mazelike look of structures. Inside the hovel the upstage walls came together, and the large arches flanked it to box in the space (Figure. 5)

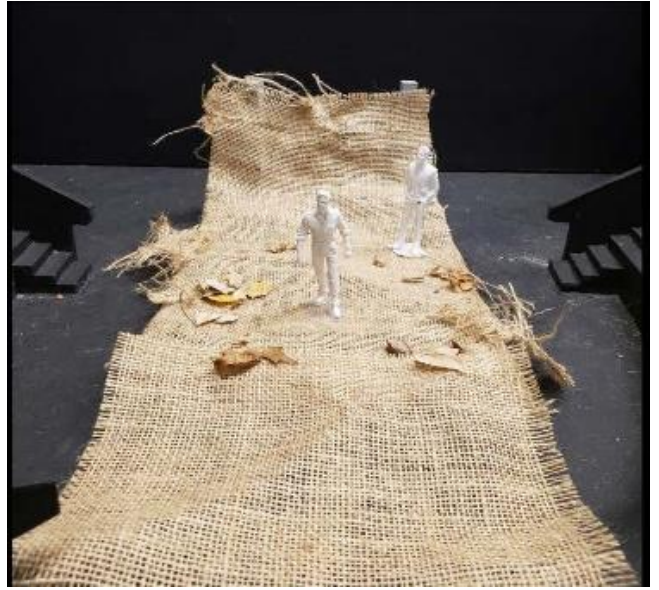

Figure 4: Act 3 Scenes 1 \& 2 - Heath \& Storm

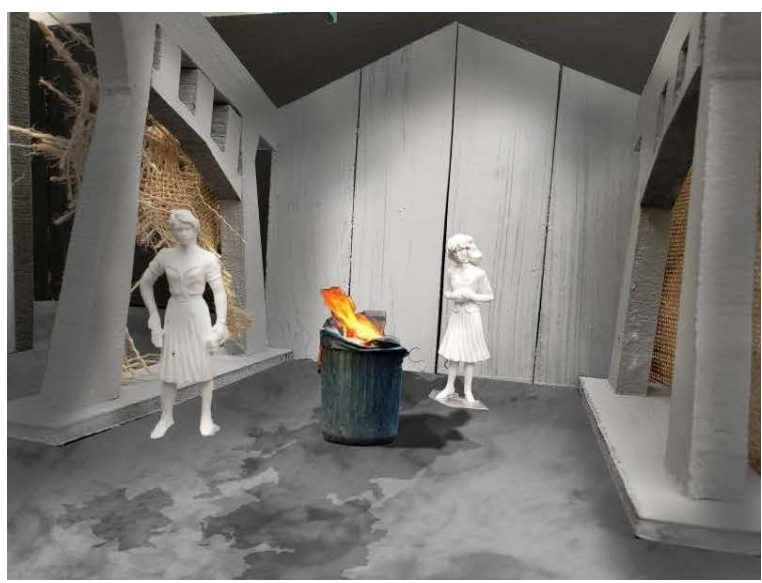

Figure 5: Act 3 Scene 3 Inside the Hovel 
Act 4 introduced us to a few new locations. Outside Albany's palace had the upstage walls flipped and close together with one pillar and both small arches downstage to create a wide angled space. Near the end of the act, we traveled to the fields of Dover and to the French camp. For the fields of Dover, the four arches come together to form an " $\mathrm{X}$ " that could be crossed through. In the French camp the large arches disappear and the small arches move upstage and downstage with slats added. When the tent is on stage it is rigged from the grid to drop down into center stage.

In the last act we travel from the French camp to the British camp crossing the field between the two camps. For the British camp, two small arches are pushed into the downstage voms and a large arch is upstage center with a pillar upstage right and the other pillar down center.

The field between the French and British camp was a variation on the French camp with the small arches switching sides and no shutters on the arches.

The renderings were a good starting point for the "sand box" but did not end up being the final product. Due to the flexible nature of the units, it allowed us the ability to adjust the design to better fit the filming needs and create a more dynamic looking King Lear. Looking at all the renderings and talking with the Scenic Designer and Director, it helped me get an idea of how they wanted the set to move and how the actors would be interacting with the world. To see all designer renderings, see Appendix E. 


\section{CHAPTER 2: BUDGETING \& PLANNING}

\section{$\underline{\text { BUDGET }}$}

The budget went through many revisions and changes before arriving at the final approved budget. I started my process by talking with my Designer, Director, Production Manager, and Advisor about how long filming would last, what was needed for the overall look, and how the set was to move and be interacted with. I needed to take all these issues into consideration to come up with the final budget that was in range with my assigned funds. Getting the answers to these questions would take four weeks, two passes, and about ten revisions before arriving at the final budget. The first pass of the budget came in at $\$ 7,176.32$ which included a $5 \%$ hardware budget and a $10 \%$ contingency. The second pass of the budget came in at $\$ 5,471.52$ also including contingencies. One revision was needed after second pass to get the budget down to $\$ 4,500$.

Due to COVID-19, the timeline for this show got shifted around quite a bit from starting in November moving to February and finally moving to March. This resulted in numerous budget adjustments preventing a quick turnaround of the final budget. After many weeks of back and forth on what the set was going to look like, we arrived at the final design which for me meant it was time to budget. We approached this budgeting process in a different way than what had been done in the past. I had previously used horizontal budgeting, where I would receive a set amount for scenery and then would work from there with the Scenic Designer on what they would like to cut or keep depending on available funding. This way of budgeting allows for money to move between shows to help with budgeting challenges. For this show it 
was decided that we would do vertical budgeting which meant that the entire production had a set budget of $\$ 12,000$. Professor Gerald McGonigle and Professor Aubrey Sirtautas our Production Manager had to determine how much each department would receive based on our budget proposals. We also had to film the production due to COVID-19 instead of performing before a live audience. This obviously created a lot of unknowns for everyone. This also meant thinking about my approach to the set and construction in a different way than I had done in the past. The camera now being the "audience" meant that my "audience" could be anywhere in the space or set. This meant I had to think about the set being fully covered from all directions. Load in was also something I needed to think through differently because of the covering making the units hard to handle.

After design presentations, I sat down with my two Assistant Technical Directors, Mr. Chris Sheriff and Ms. Pauline Johnson, my mentor and advisor Professor Steven Neuenschwander, and our Scenic Designer Ms. Abigail Wagner too look over all the scenic units. This meeting allowed us to ask Ms. Wagner about the units to fully understand her vision while at the same time dividing up who would budget what.

On the first budget pass of the show, we had a tent rig, a rain effect with rain deck, six walls ranging in sizes, four rolling platform units, and two pillars. I took the tent rig and rain effect. My first ATD, Mr. Chris Sheriff, took on the walls and my second ATD, Ms. Pauline Johnson, took on the rolling units and pillars. Trying best to utilize existing funds, I began my budgeting process by meeting with Ms. Wagner to see if we had anything in stock that could be used for the tent fabric. We found an old painted scrim that was the perfect size and already had all the ties still attached. This gave me the idea to approach the tent rig like a little girl's 
fairy bed netting or mosquito netting for camping. I initially thought about a circle but then also considered that nobody was going to see the rig from the grid so I wondered if a square work instead? After consulting with Ms. Wagner, it was decided that a square would work. The netting would be attached to the frame that was rigged, with pick points to a high trolley in the grid. This plan was estimated to cost $\$ 119$ and take 11 hours to build.

I then moved on to the rain effect. This unit presented a unique challenge for me because I had never attempted a rain effect. The rain effect needed to cover a $12^{\prime} \times 12^{\prime}$ square area. I had a basic idea of how this effect needed to work but was unsure on how to approach constructing it. I started my research by looking up "rain machines" and came up with results for film or how to do a cost effective one for photography. The photography presentation seemed like a good place to start, seeing if maybe I could take the concept of what they were doing and rework it to fit the show's needs. Most of their machines involved punching holes in a garden hose and tying it to a hexagonal wood structure or drilling holes in PVC. The further I explored this option, the more I did not think that the approach would work for our effect. To get the type of rain look that we wanted as well as the pressure that would be needed, simply punching holes in PVC or a hose would cause the rain to come out looking like streams of water not droplets. Another reason I went away from this approach was because of how large of an area I needed to cover. Wood construction for that size would be very large resulting in the structure being very heavy and hard to work with. Another concern was the wood warping and changing how the rain looked after testing and multiple uses. Therefore, I moved on to see what films do for rain effects. My research turned up many interesting articles describing massive rigs that they use on Hollywood blockbusters, which we could not afford. Other articles 
I came across were little ones that they use on student films that had to be placed on the ground and only covered a very small area. I did find one article that gave me step by step instructions on how to build it, but the draw back here was that it went up about $10^{\prime}-12^{\prime}$ and had to stay on the ground which would not work for how we were filming. I then started looking at how maybe I could combine the student film and photography versions. I came up with a plus symbol shape (Figure 6) where I could attach four hoses for the individual nozzles. The concept here being that one hose would run from the barrel of water to the pump which would then pump the water to a hose

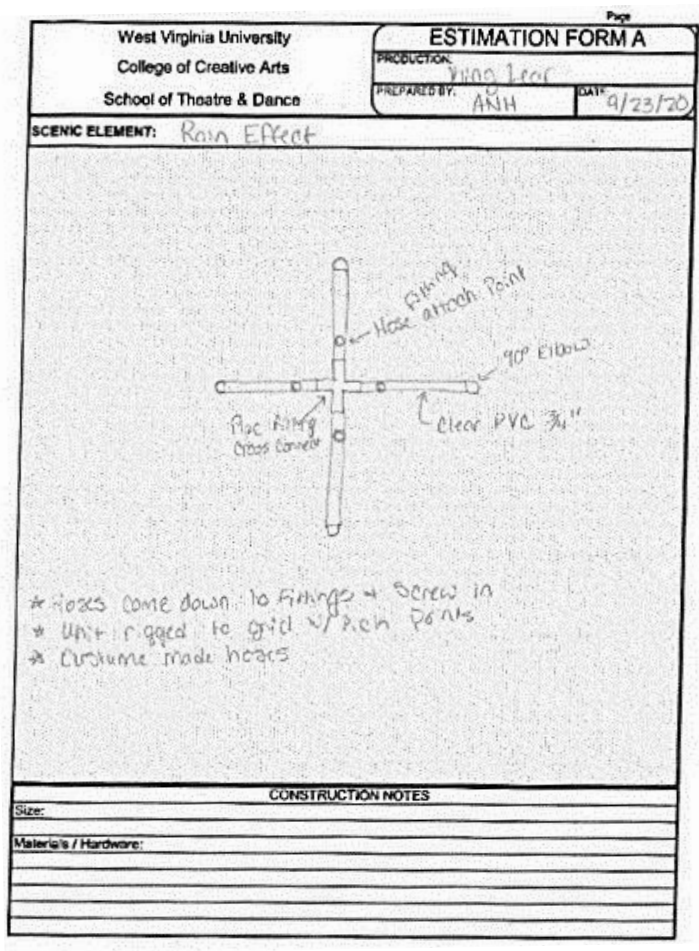

Figure 6: Budget Form A for Rain Machine junction box then out to the individual lines. After looking at all the individual pieces and then adding in a \$300 contingency for research and testing, this plan was estimated to cost $\$ 1,330.50$ and take 36 hours to build.

Initial thoughts for the rain deck were to make a large basin to catch the rain. I then could easily drain the water when the pool got full, and we would only need to dress the outer ring. Professor Neuenschwander brought to my attention that the actors needed to be on the same level as the outer ring. Therefore, I added an inner platform for the actors to stand on in combination with the outer ring that would hold the water and keep the spray from getting on the floor. To get an idea of what size deck would fit in the Davis Theatre, I tested in AutoCAD with a couple sizes until I found a general size that worked. I knew that I needed about 1' - 2' 
area around the inner platform for potential spill over. I found that I could fit a $14^{\prime} \times 14^{\prime}$ platform in the Davis. Knowing that the rain deck was going to get wet and most likely ruined in the process, I decided it best to just build both the inner and outer platforms so we would not ruin stock platforms. Another benefit to this approach was I could make sure that it was built tight to keep water from getting out underneath the deck. As a precaution if leaking did occur I added in some plastic sheeting for underneath the deck. This plan was estimated to cost $\$ 606.75$ and take 28 hours to build.

When I was satisfied with my budgeting and planning, I checked in on my ATD's to see how they were doing with budgeting their units. Mr. Sheriff was responsible for budgeting the three sets of wall units. The walls were similar in design, all being $1^{\prime}$ thick steel structures covered in $1 / 4$ " MDF. This made their overall construction easy to budget. The hard part of these units was where they had to rotate. Mr. Sheriff came up with a good idea for a grid square hanger, (see Figure 7), that involved skateboard wheels and unistrut. The idea was that we would be able to stand the walls up, lock them into a rotating flange on the floor that was lag screwed down and then move the unistrut into place above securing the pipe(s). This allowed the wall to be secured from above and below keeping the wall upright and straight. This plan made for a relatively easy load in and construction of the units. The walls themselves were built out of $1 \times 1$ and

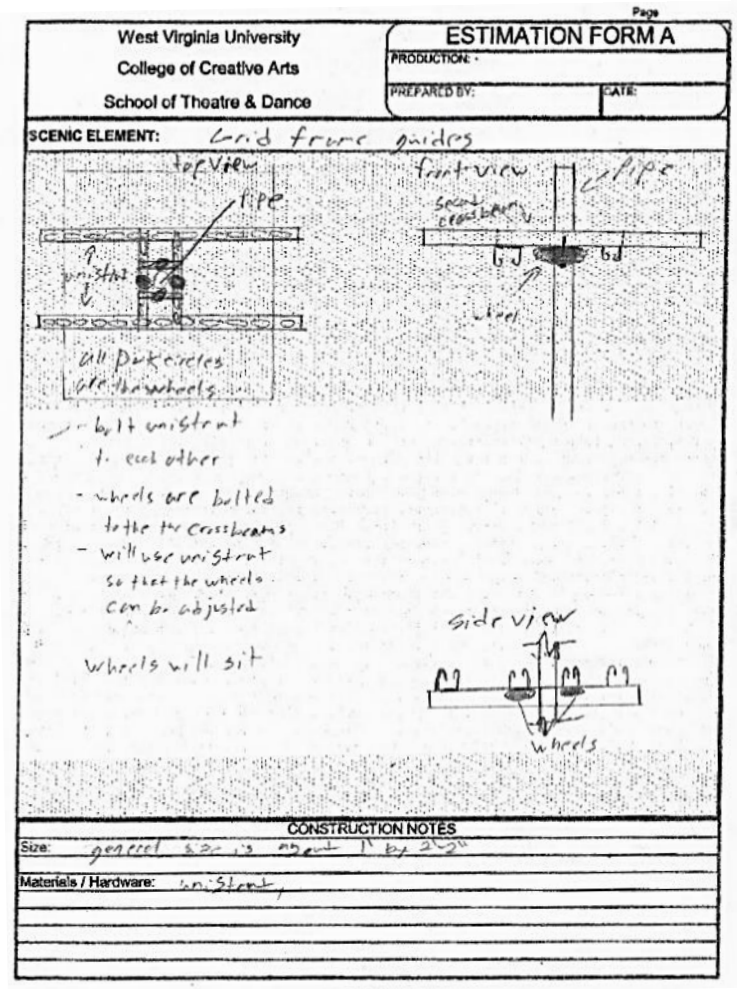

Figure 7: Mr. Sheriff's Form A for Rotating Walls 
$1 \times 2$ metal box tube and skinned with 1/4" MDF with a 1-1/2" schedule 40 metal pipe running through the center. We went with metal over wood for the walls because we needed material that could take the abuse of filming for a month without wearing away. Another reason I went with metal was that these were tall vertical units that had a lot of angles and straight lines and metal is manufactured to be straighter and not warp. Another reason to go with steel was because a large pipe needed to run down the center of the units. We were able to find all the unistrut that we needed in stock as well as all but two of the floor flanges that were required. The estimate for all three sets of walls came to $\$ 1,856$ and would take 128 hours to build.

Ms. Johnson had the pillars and the rolling platform units. Units where 1" thick organic shapes that presented a challenge for construction (Figure 8). Since the arches where on rolling platforms, I wanted these to be lighter than the wall units for easier handling and mobility. I advised her on some construction ideas that I thought would be the best way to achieve Ms. Wagner's design.

Next we moved on to the removable shutters Ms. Johnson came up with a good solution to

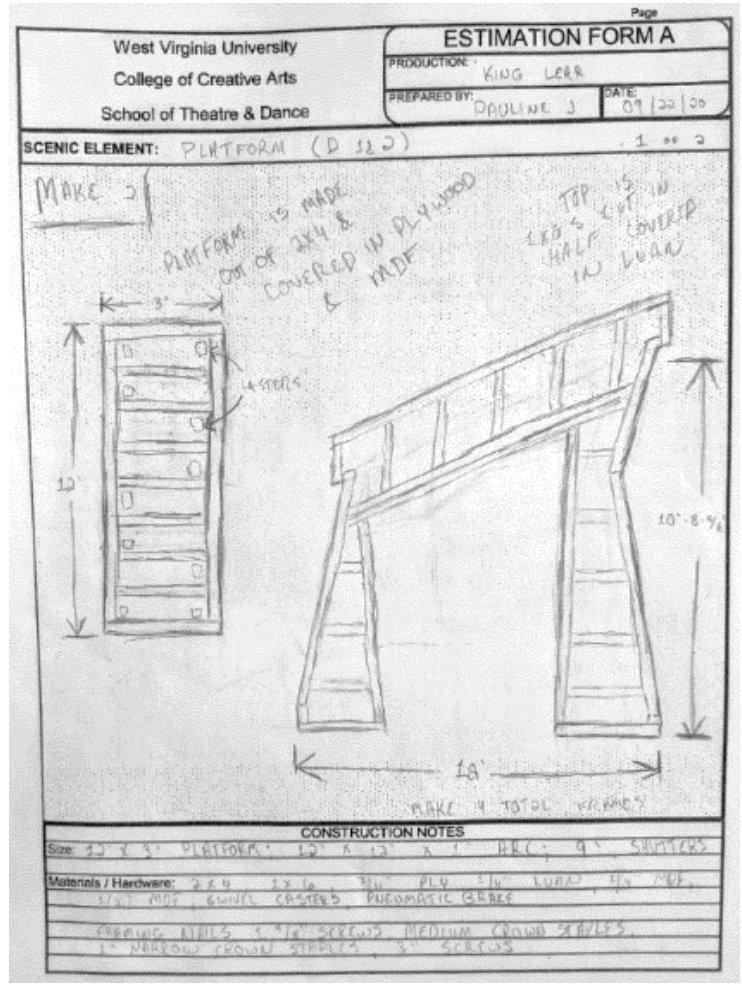

Figure 8: Ms. Johnson's Form A for Large Arches integrate them into the unit. The plan was to leave a gap in the underside of the arch so that we could insert the $1 / 2$ " MDF shutter piece into the gap and then through the top of the arch so we could bolt the piece into the unit giving us the positive connection that would keep the 
shutters secured. Since the arches rolled, we needed to come up with a way to keep the units from moving while actors where on them that would not be obvious, complicated, or seen. I talked with the Designer and Director about the movement of the units and where they would be filmed from. They told me that they would not be moved while on camera. With that information in hand, I decided instead of making the braking complex we could just chock the wheels on the platform with custom $2 \times 4$ 's wedges that were painted black to blend in. While looking at how I wanted to brake the platforms I realized that the pillars were small enough that we did not even need to put castors on them. Instead, we could just put them up on dollies to roll them where we needed to in space and then set them down. This eliminated the need for casters and brakes on these units which made it easier for construction and budget savings. The pillar construction was going to be similar to how the arches were to be constructed with some minor changes. Instead of using Hollywood flat construction we would do Broadway flat construction. Platform D 1 \& 2, aka the Large Arches have an estimated cost of $\$ 449$ and would take 43 hours to build. Platform E $1 \& 2$, aka the Small Arches have an estimated cost of $\$ 332$ and would take 43 hours to build. Pillars F $1 \& 2$ have an estimated cost of $\$ 116.50$ and would take 33 hours to build.

Paint was added to the budget at an estimated cost of $\$ 300$. Now that all costs were estimated, I compiled the budget sheets together, scanned and sent them in for review. The technical team then met so each department could propose their numbers and point out their high-ticket items. Professor Sirtautas and Professor McGonigle then reviewed the budgeted 
number to determine how much of the $\$ 12,000$ each department would receive. A few days later, we all got an email detailing out our new proposed budget targets. (Figure 9).

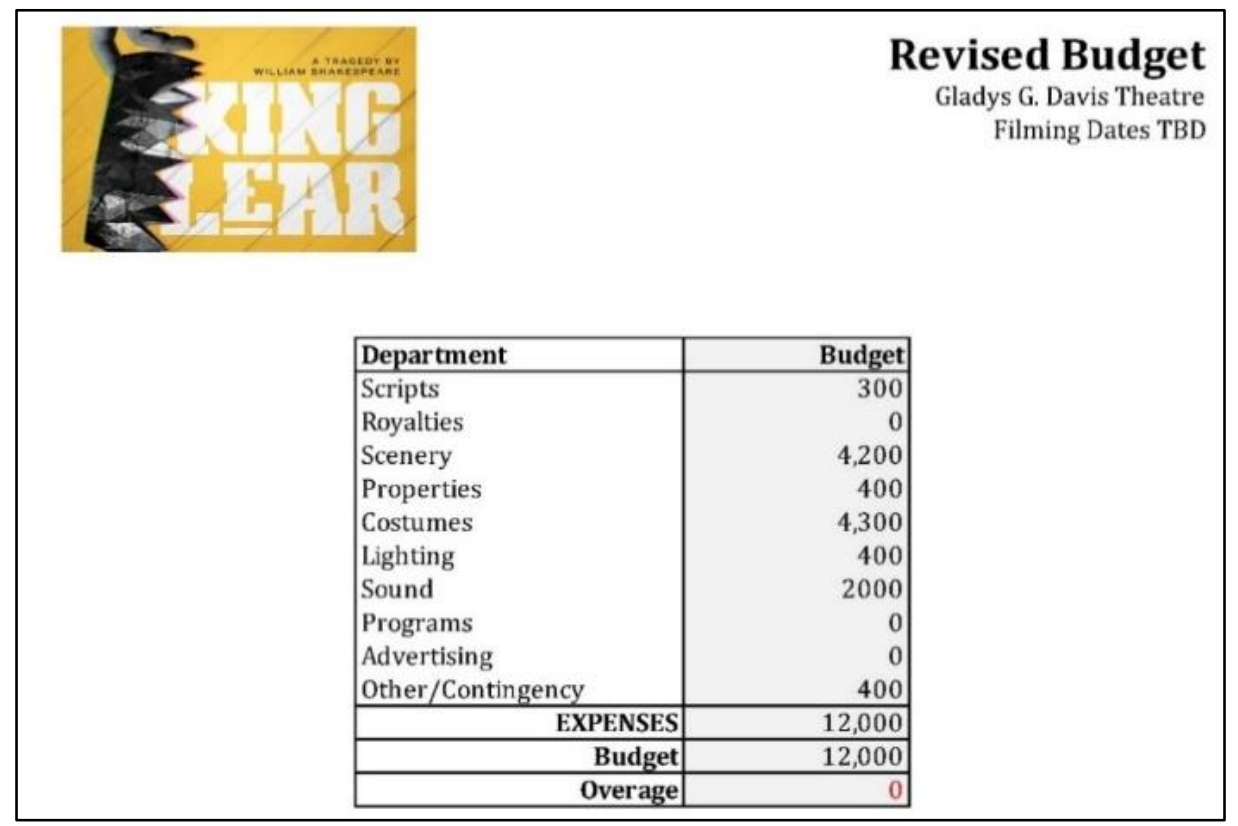

Figure 9: Department Budget Breakdown

As you can see, Scenery needed to get its budget down to $\$ 4,200$. The next step was to revise the budget and see if there were any more cost-effective alternatives for us to build some of the units. Ms. Wagner and Professor McGonigle also needed to look at what could possibly be cut from the design because there was no way we could afford to do all the units that were originally proposed. After waiting a few days, I got the new designs for the set with some cuts and additions.

The next pass of the budget went through five revisions before I got to the final version that I would turn in. The first item I looked at revising was the rain machine to see if there was a more cost effective way I could build it. I reached out to our shop manager, Mr. Byron Utley, to see if maybe he had ever tried to do something like this before. He said that he would look into 
it and reach out to his network. He later emailed me a YouTube link to a lawn watering rig. This intrigued me as I watched the video and thought this was a possibility. The rig consisted of some $3 / 4 "$ PVC and two sprinkler heads spread out along the length of the pipe and was in sort of a "T" shape (see Figure 10).

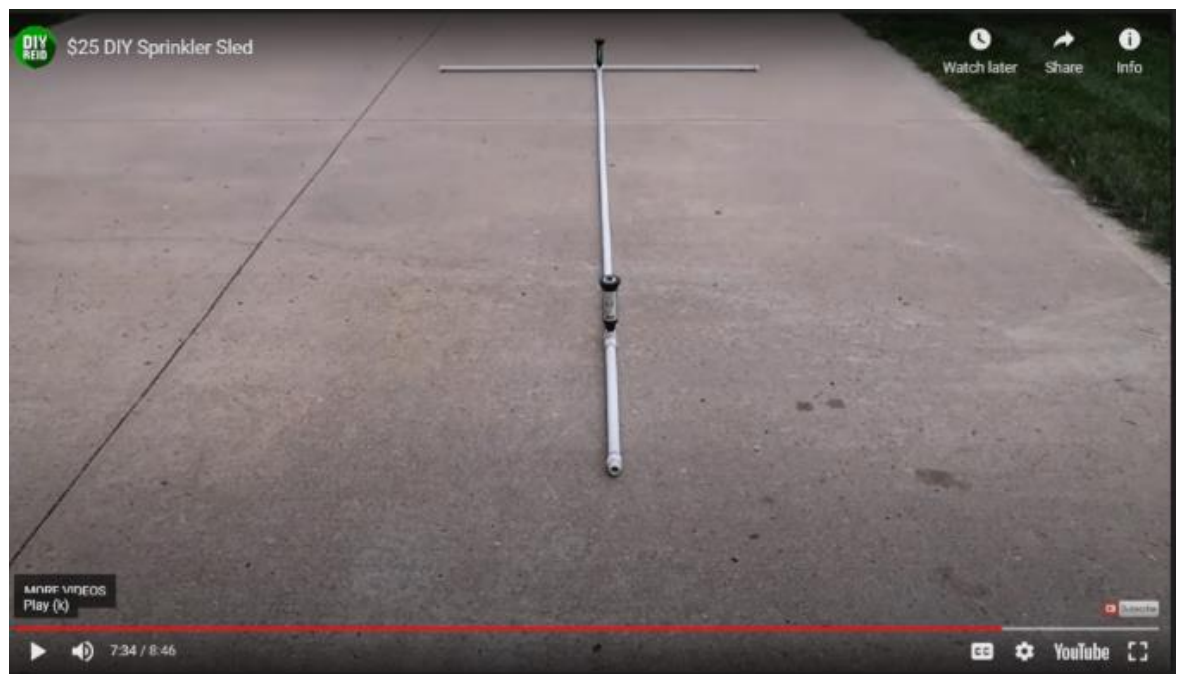

Figure 10: Screen capture of instructional video

I watched the video and thought with some modifications and some added hardware it could work. I was able to find some sprinklers with a cone radius that I thought would work with some nozzles I had found. I was able to to simplify the rain machine and get the cost down to $\$ 650.56$ and 43 hours to build. Cutting the cost down by $\$ 679.94$.

While looking at the rain effect, it was pointed out to me on the rain deck that I could build the whole outer ring out of stock platforms instead of building new because it

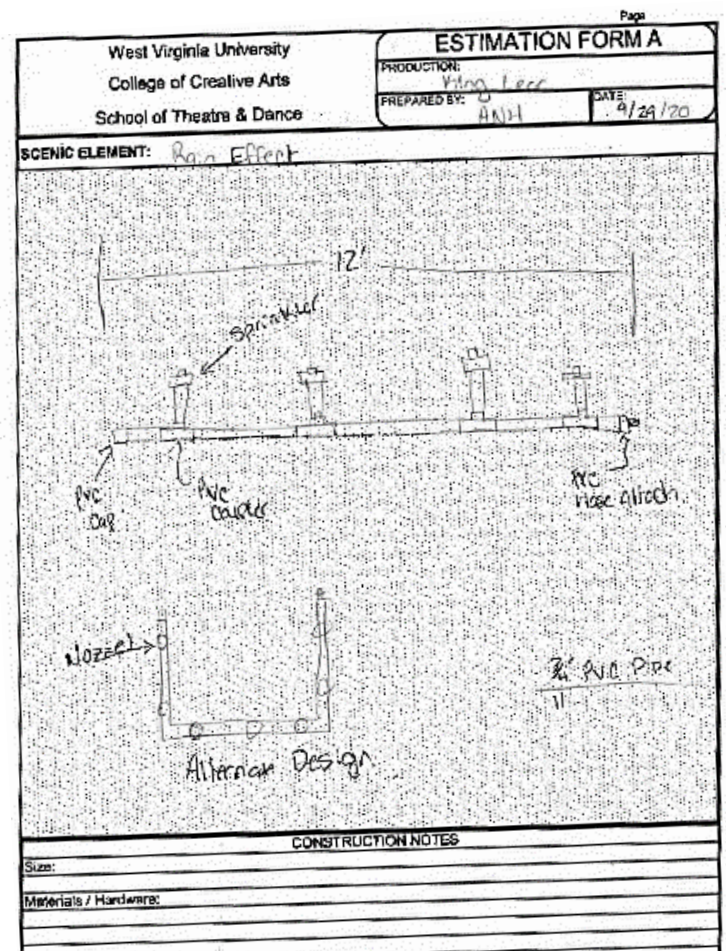

Figure 11: Revised Form A for Rain Machine 
would be covered by the pond liner and would not get ruined. This would end up saving money and time by switching the outer platform to $16^{\prime} \times 16^{\prime}$ instead of the $14^{\prime} \times 14^{\prime}$ based on our stock. Another thing that I revised on the rain deck was changing the inner platform from one large platform to three smaller ones that would be toe screwed together. With these revisions the rain deck cost went down to $\$ 460$ and 21 hours to build. This cut the cost down by $\$ 200.75$. While looking over the first pass of the tent rig budget, Professor Neuenschwander pointed out to me that I could simplify the tent rig down even more if I just built something that set and attached to grid square rather than something that rigged to a trolly. I went through a few different versions of how best to build this unit and still maintain the original look of the tent. The final look was a square shape with a cross in the center for stability that would set and bolt to the grid. This took the unit price down to $\$ 34.50$ and 11 hours to build. This cut the cost down by $\$ 84.50$.

One of the additions that Professor McGonigle wanted was to add a live fire effect and Ms. Wagner was on board if the budget permitted. I got together with Professor Neuenschwander to see what he would recommend. After talking with him, I came up with a workable plan that would require a lot more planning during the build process. With the addition of a live fire effect, we needed to get permission from the Fire Marshal which meant more revisions to the plan and build. The effect was something that Professor McGonigle really wanted to do so I put it in the budget while Professor Neuenschwander started conversations with the Fire Marshal. The plan for the big fire effect was estimated to cost $\$ 930$ and take 50 hours to build. Along with the big live fire effect, Professor McGonigle also wanted smaller "camp" fires in coffee cans set throughout the scene. I came up with a plan for these in a very 
funny way. While talking with Mr. Utley and Mr. Sheriff about some thoughts I had for this effect, Mr. Utley mentioned just getting little camping stoves and setting them into paint cans that we already had. We could put sand in the cans to contain the fire and we would not have to deal with propane lines. I think I literally yelled "that is brilliant!" and began to budget it out. The plan for the campfires estimated cost was $\$ 63$ and 3 hours to build.

With all these adjustments, we were still approximately $\$ 2,000$ over, which meant that more adjustments needed to be made. Ms. Wagner ended up cutting Walls B $1 \& 2$ and keeping walls A\&C. Instead of using rotating walls, it was suggested that we go with tracking walls instead. However, Professor McGonigle wanted Walls C (the upstage walls) to still be able to rotate. The downstage wall (A) was relatively easy for Mr. Sheriff and I to take another look at because we had worked with tracking flats before on other productions and we just needed to come up with a way to attach the pipe to the tracks themselves. Mr. Sheriff came up with a trolly that would span two tracks and we could bolt the pipe to the trolly while welding the pipe into the wall frame making for a relatively easy load in and load out. The hard part was taking the same principle we were using on the downstage walls and translate it to the upstage walls so they could track and rotate. Mr. Sheriff, Professor Neuenschwander and I had a lot of backand-forth conversations about how to achieve this effect. We arrived at taking the same trolly design with the addition of a rotating flange bearing to it that would allow the walls to rotate as well as track in and out. A piece of flat iron was added on top of the pipe to keep the pipe from slipping through the flange and help maintain the upright position of the wall. In addition, there had to be some modifications made to the upstage walls to allow us to get inside of the wall to bolt the pipe and adjust the wheels and brakes. We came up with the idea of a "push to 
release" door. Mr. Sheriff took this idea and ran with it. The only other big change that I made on the walls was changing out the swivel casters on the downstage walls for straight casters and triple swivel casters on the upstage walls. Overall, the revisions would end up costing us approximately $\$ 406$ and 55 hours to build for Wall A and approximately $\$ 544.60$ and 70 hours for Wall C. This cut the cost down $\$ 905.34$.

The other big budget challenge was Ms. Wagner and I realizing that we did not have enough erosion cloth and burlap in house to pull from to do the all the designs she wanted. We went onto RoseBrand and found what she was looking for. These were an estimated cost of $\$ 220$ for erosion cloth and \$247 for the burlap.

Even with all these changes and budget adjustments, we were still coming in over budget at $\$ 5,471.52$. Professor Neuenschwander said that he would take on the cost of the Fire Effect, and Professor Sirtautas and Professor McGonigle raised our budget $\$ 300$ getting us to $\$ 4,500$ and on budget. With the budget resolved, I could move on to the next stages of the process; detail planning, drafting, and ordering of materials.

The budgeting process overall was a bit of a roller coaster for me due to COVID. We went through so many changes it often felt like I had no idea what was going on and that I would not be able to meet my deadlines due to what felt like constant changes. This came from what I felt was a lack of communication and collaboration between the Director, Scenic Designer, and myself. I would go home and revise the budget and then come in the next day and find out what I had done was either no longer needed or something had been added to it that made my plan moot. I felt like I was wasting a lot of valuable time. This also made it hard for me to get accurate numbers and clarity of expectations on some days. Lastly, this caused 
added stress and a lack of accurate communication within my own team. I encountered issues with one of my ATD's as she did not complete assignments on time or within instructions causing me to have to take over her work so we could get the budget approved in a timely fashion. See Appendix A for final approved budget.

\section{SCHEDULING}

Now that the budget had been approved, I was able to work up a build calendar, generate purchase orders, and build a load in schedule. Overall, the initial planning seemed to go well. My team and I were all very excited to get started on drafting and building. As I have come to learn and expect, even the best laid plans can go awry very quickly.

I called a meeting of my ATD's so we could go through the budget line by line. This was done to compile a list of materials that needed to be ordered and to ensure that we had the correct number of items. I like to meet with my team when scheduling because this is something that I struggle with as a Technical Director and more heads are better than one. Scheduling is a weird balancing act of knowing how long it should take to build something on paper and combining it with knowing that the building process rarely goes as planned. Finding that balance comes with experience and building in some cushion time to help alleviate these issues. I am the type of Technical Director that likes to keep my ATD's and carpenters in the loop about what is going on throughout the entire process. I do this to try and cut down on confusion and mistakes which helps avoid errors as well as creates a learning experience for the team and build team morale by letting everyone know they are an integral part of the 
production. By including everyone, this assures that if something happens where I am unable to be in the room or not available for whatever reason, my ATD's can take over for me.

Doing this line by line run down of the budget while scheduling allows me to refine my build times and see if anything was missed as well as confirm times for build, load in and strike. When the numbers were confirmed, I then moved on to doing the build calendar. This process was interrupted by the news that that filming for King Lear had been moved to the spring semester instead of its original time in November. This decision influenced how I wanted to break down the build calendar as well as shifted around when things would need to be done. I adjusted the build calendar by breaking it down by semester and only giving people expectations for the current semester. I believed giving them the complete schedule would overwhelm the crew and cause un-needed anxiety. For the calendar itself I used one that I had created in an earlier class and had been using for shows that proved to be effective. I broke the calendar down by week, carpenter, and unit. See Figures $12 \& 13$ on pages $20 \& 21$.

A part of doing the build calendar is deciding who will build what and how long will it take that person to build it. Whoever budgeted the unit gets to build it or at the very least supervise its build. I like to do this because the person who budgeted the item has an idea of how they want it built and are most familiar with the unit helping to eliminate confusion. Putting the schedule together with my team allows them to know where things line up so they can start planning accordingly.

Now, with the first build calendar completed, my team and I were ready to move on to ordering materials so things where on their way while we drafted and prepped for build. 


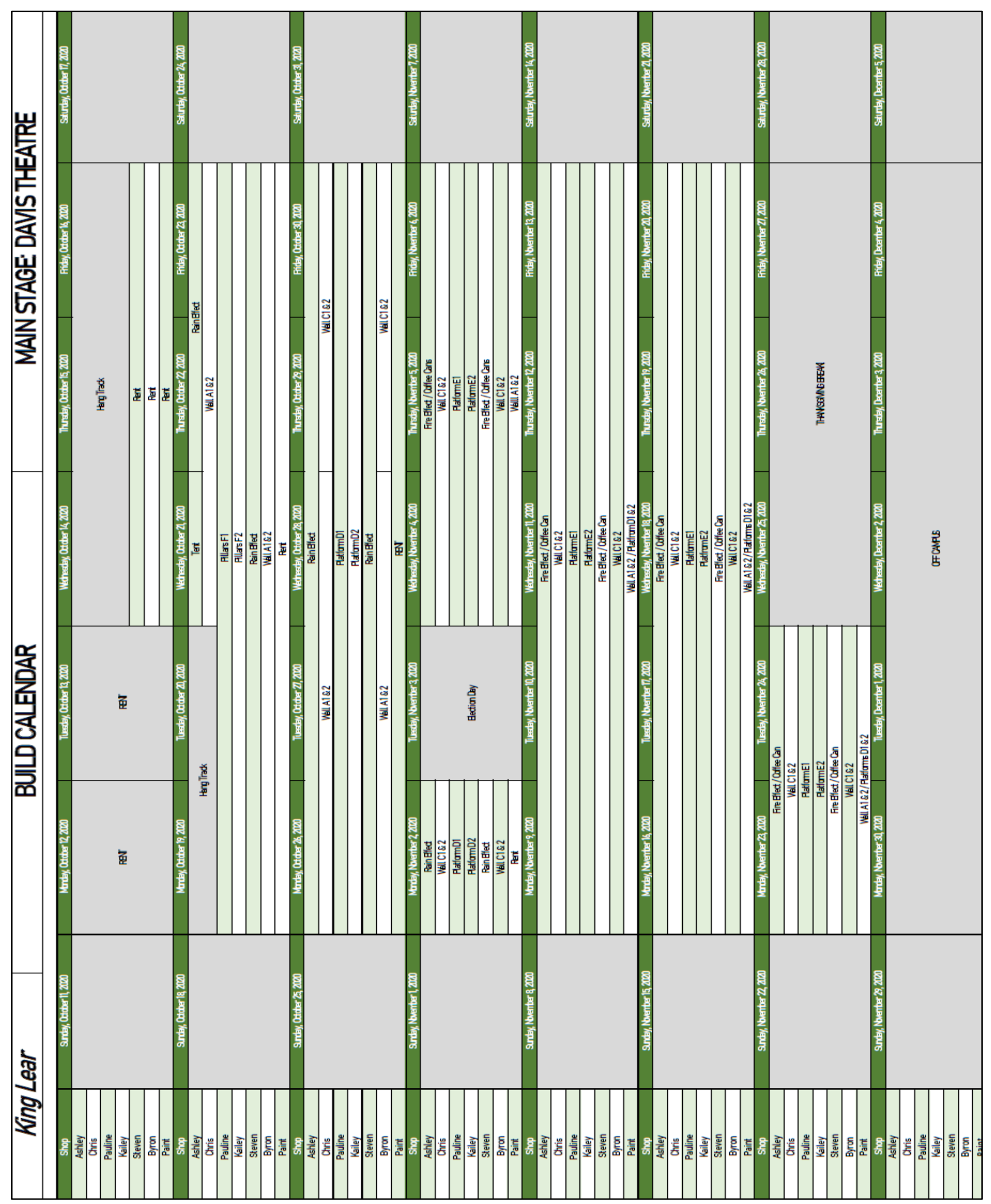

Figure 12: Build Calendar for Fall Semester 


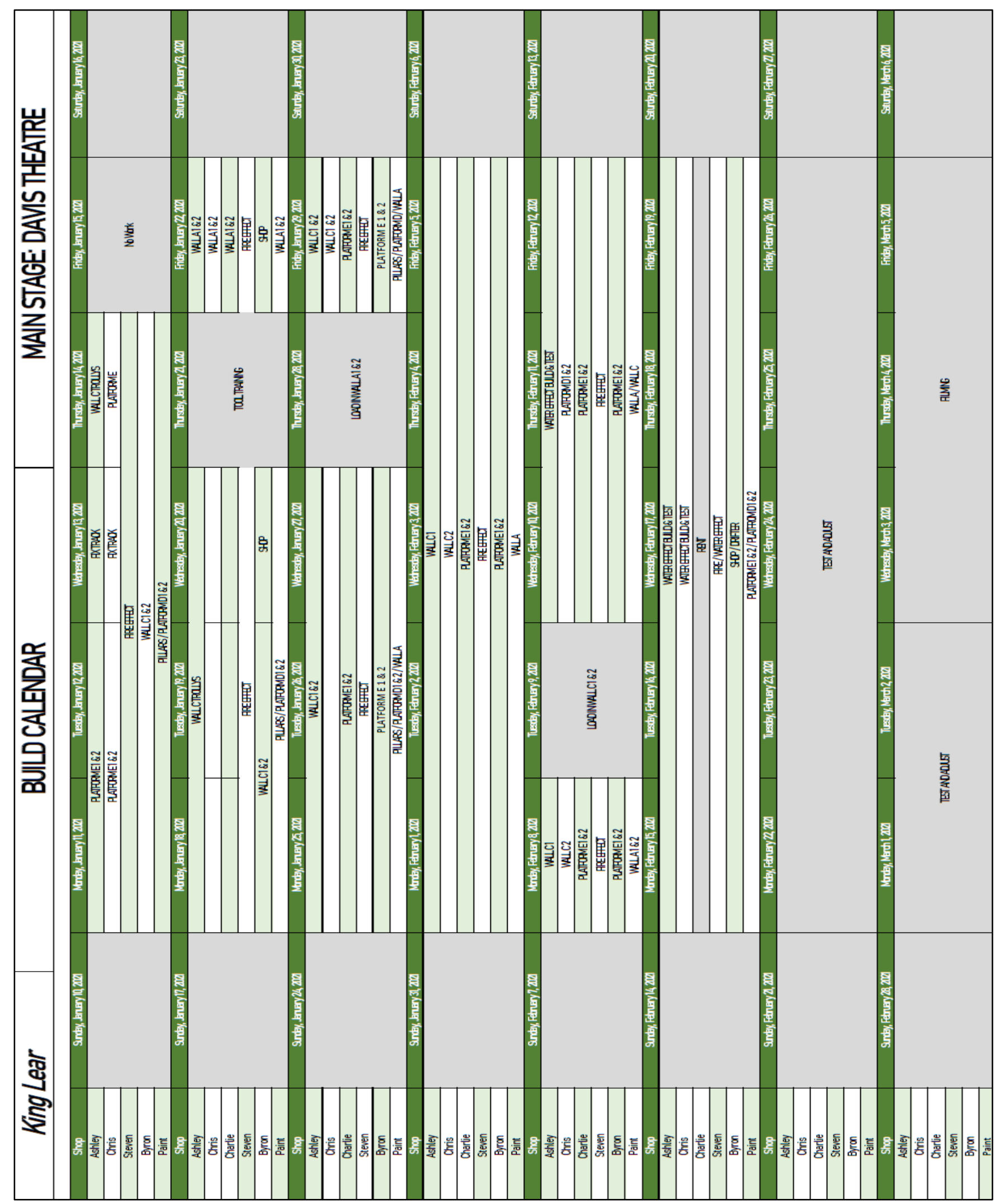




\section{ORDERING MATERIALS}

This step takes place right after the budget and the schedule are done. I mainly do this after scheduling because I use this step as a double check that I have all the materials needed for each unit and that I did not miss anything.

Ordering materials goes both through the shop manager and myself. I was responsible for compiling a list of needed materials and submitting the list to the shop manager for purchasing. I have seen and used a few different forms for ordering materials and have created a form that works best to help me keep track of what was purchased, the amount purchased, and what unit it was purchased for. I personally am a very visual person and color coding helps me keep everything straight and organized. Items in green are items that I need to purchase while items in yellow are items that the shop manager needs to purchase. The chart has 4 columns, Item, Units, Material, and Amount. Another column has been added to track the purchase and determine if returns are required. Off to the side, I put a box that sums all the materials that I need to buy so I do not have to go through and count something every time. I also added color keys just in case I am not around, and someone else needed to navigate the document (See Figure 14). 


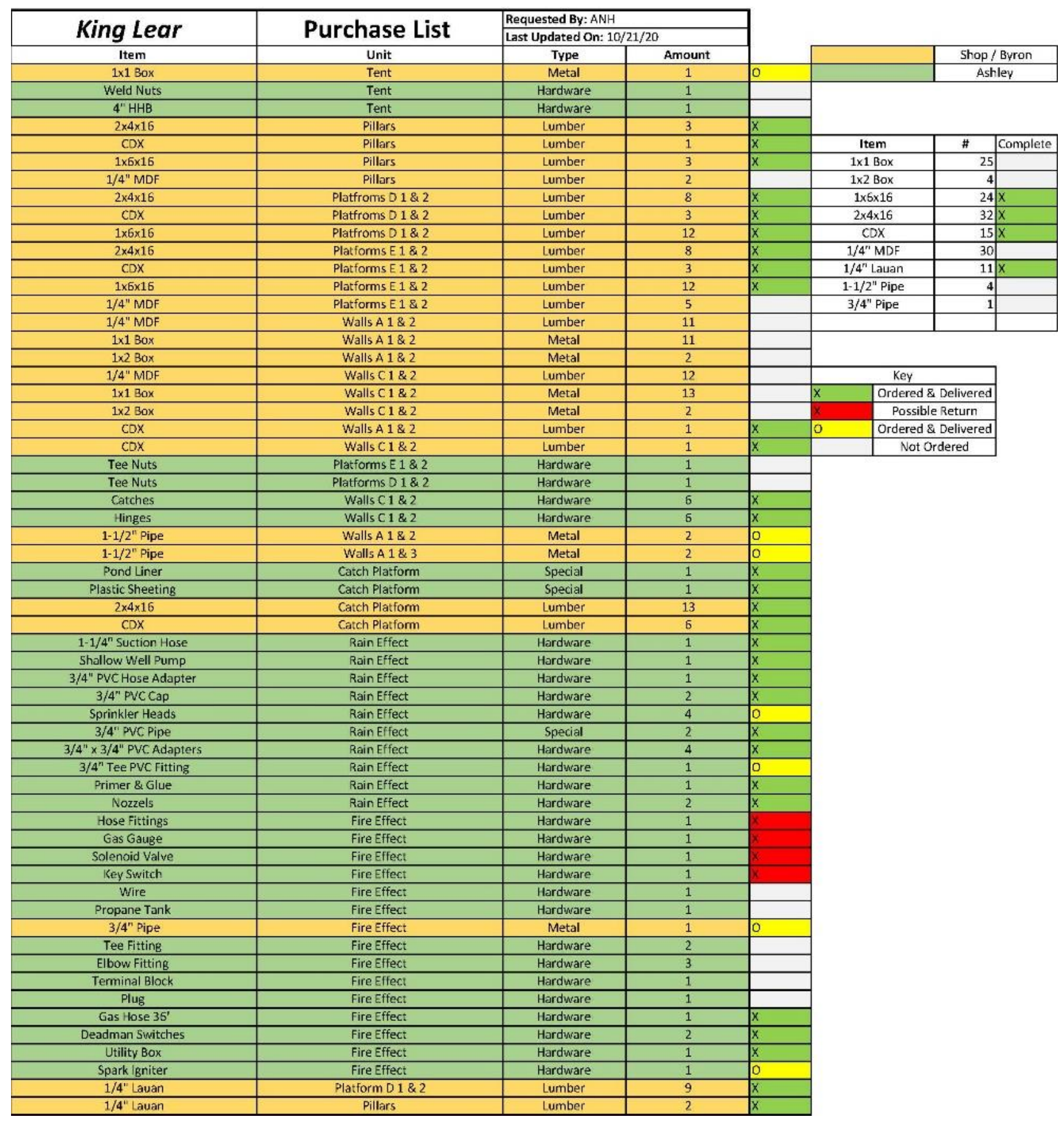

Figure 14: Purchase Order Form

This document worked well in the ordering process, and would have helped with budget

tracking, but we ran into an issue with unit prices escalating. Due to COVID-19 causing cost of 
construction materials to go up in a way that I was not aware of I went over budget by about $\$ 250$.

I learned a lot from this about better checking on what things cost, keeping up with receipts, and that I need to be more proactive by updating unit costs on items. In conclusion I am going to change my purchase order / budget tracking form by adding a budgeted price for the Item column as well as an actual cost column so I can verify unit costs to budget and stay within the budget parameters. I will also be checking on prices and receipts more often to assure that I will not go over budget again. 


\section{CHAPTER 3: BUILDING}

\section{DRAFTING}

In the next stage of the process, it was time to put our ideas, theories and plans into AutoCAD and start drafting. Mr. Sheriff drafted the four wall units, Ms. Johnson was to draft the four rolling platforms, and pillars, and I drafted the rain machine, rain deck, and the tent rig. I started the drafting process by looking at what needed to be in the shop first by using the build calendar (See Appendix B).

For the tent rig, I started by taking some measurements of a grid square to see what could fit in the opening. After taking some measurements, I went back to my budget sheets for the tent and looked at what I had drawn on the budgeting sheet to give me a jumping off point. Once I had the box drawn, I started putting in the details, the 2 " flat bar, 1 "x1"x 1/8" angle iron, and the bolts adding as much detail as I could to clearly describe what I was trying build. It was while I was adding detail to the drawing that I realized that it was kind of hard to really understand what I wanted the final product to look like. I decided to draft the unit in 3D to better demonstrate and model the outcome. This way I only needed to draw the unit once and I could show the overview as a southwest isometric view to better inform the welder what was needed. This also allowed me to be able to point to certain parts of the unit to better explain the design. After the 3D version of the rig was complete, I started plating so it could go to the shop (Fig. 15) 


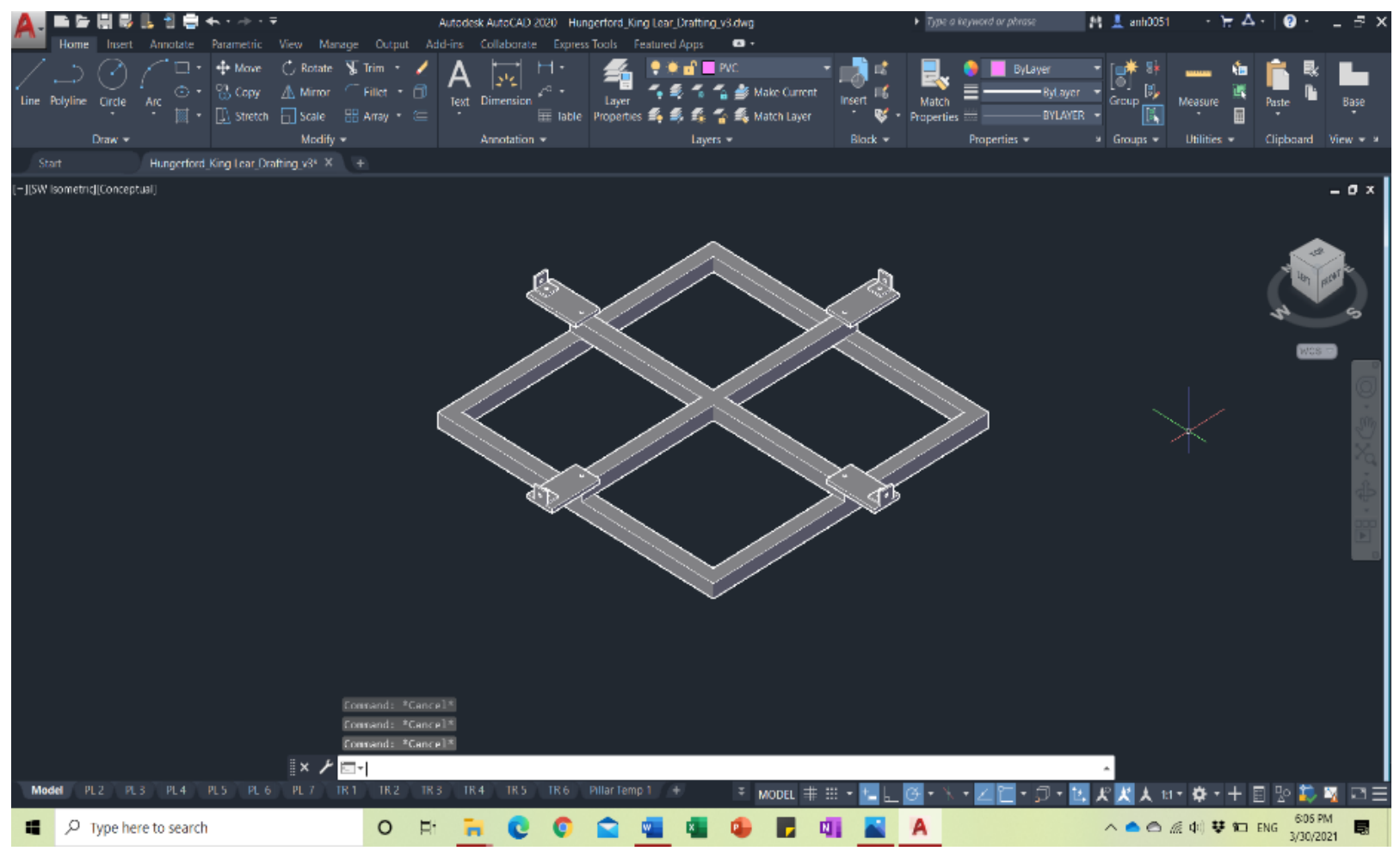

Figure 15: 3D Model of Tent Rig shown in AutoCAD

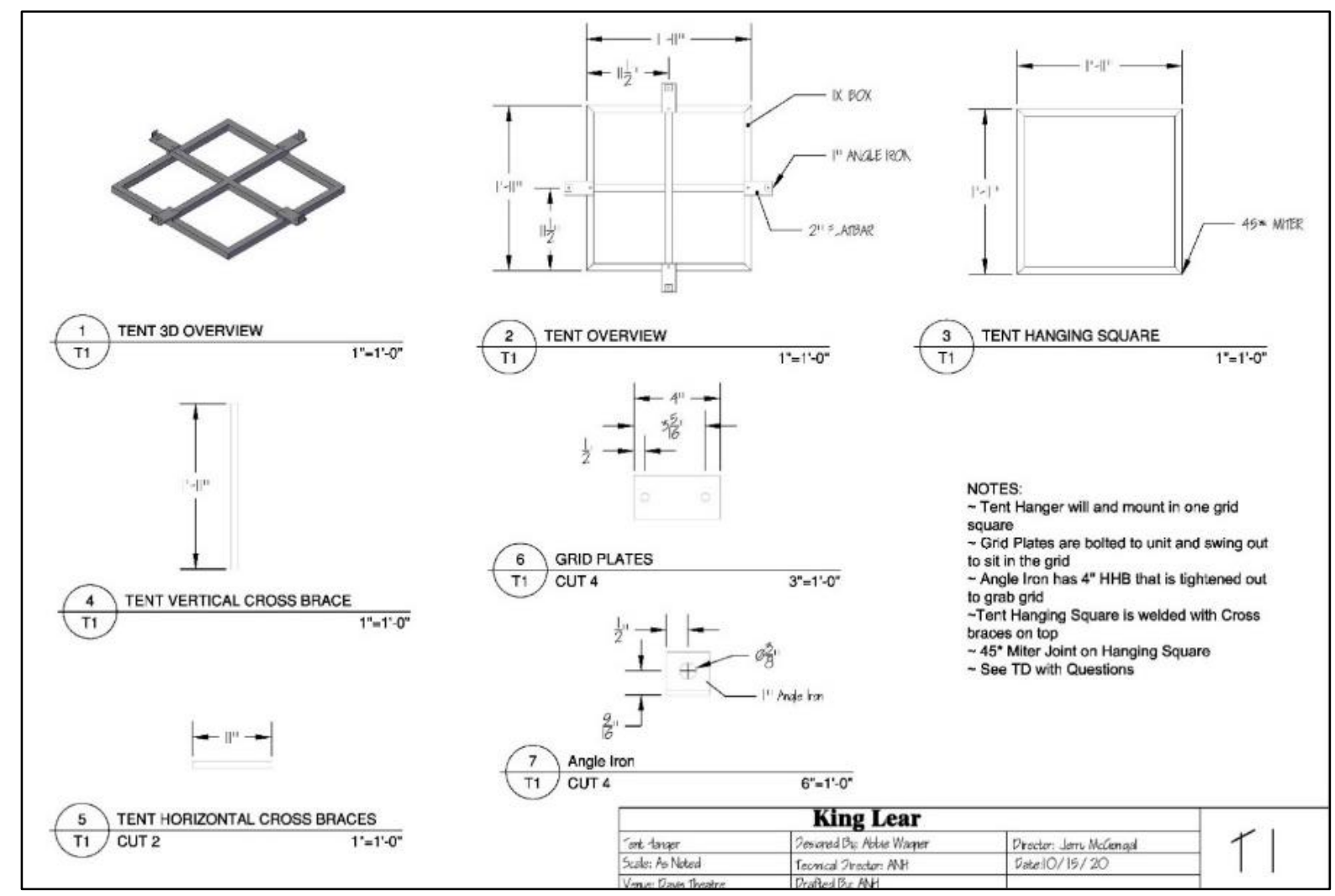

Figure 16: Tent Rig Plate 1 
After the tent rig was done, I moved onto drafting the rain effect. I started with the rain deck because I already had some roughed-out squares that I had used for budgeting. The outer ring of the deck had six $2 \times 8$ stock platforms and two $2 \times 4$ stock platforms. When assembled, this would make up a $16^{\prime} \times 16^{\prime}$ outer ring of the deck that would help to contain the rain. Next I added in the $3 / 4 "$ plywood skirt that would go on the inside of the ring. This was added to give us something solid to form the pond liner to as well as help contain the pool of water. Looking at the top view of the deck I realized that it was hard to see what I was wanting the deck to look like. To better help explain I drew a section view of the platform with all the components so the builder could see where everything needed to land. After I had the outer ring complete, I started working on the inner platforms of the deck. Since these platforms were going to get rained on, they needed to be built with the knowledge that we would be throwing them out at the end of filming due to water damage. I took in the inner platform 2" making it a 11'-10"x11'10 " square to allow for easier load in and better drainage (Figures 17 \& 18). 


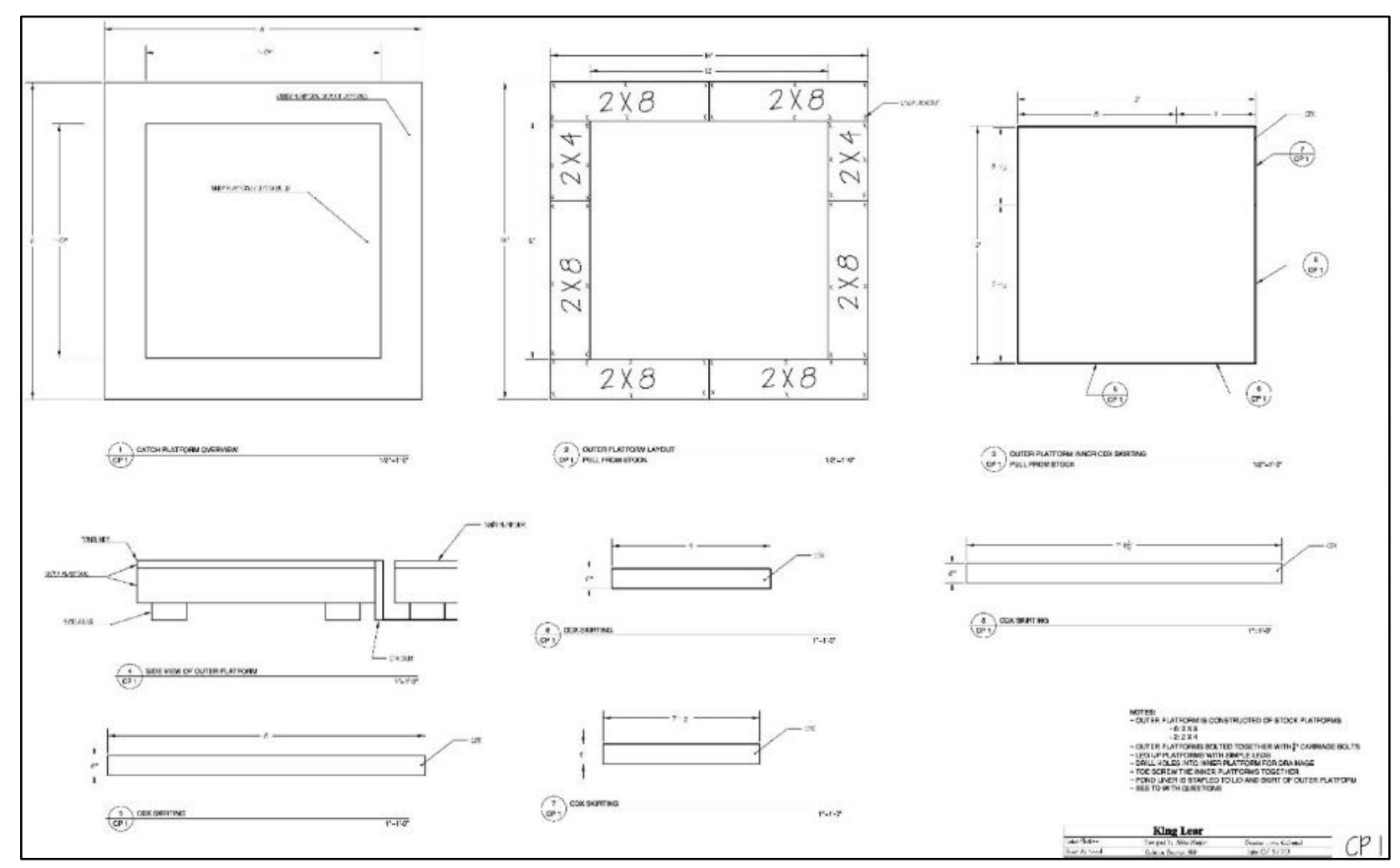

Figure 17: Rain Deck Plate 1
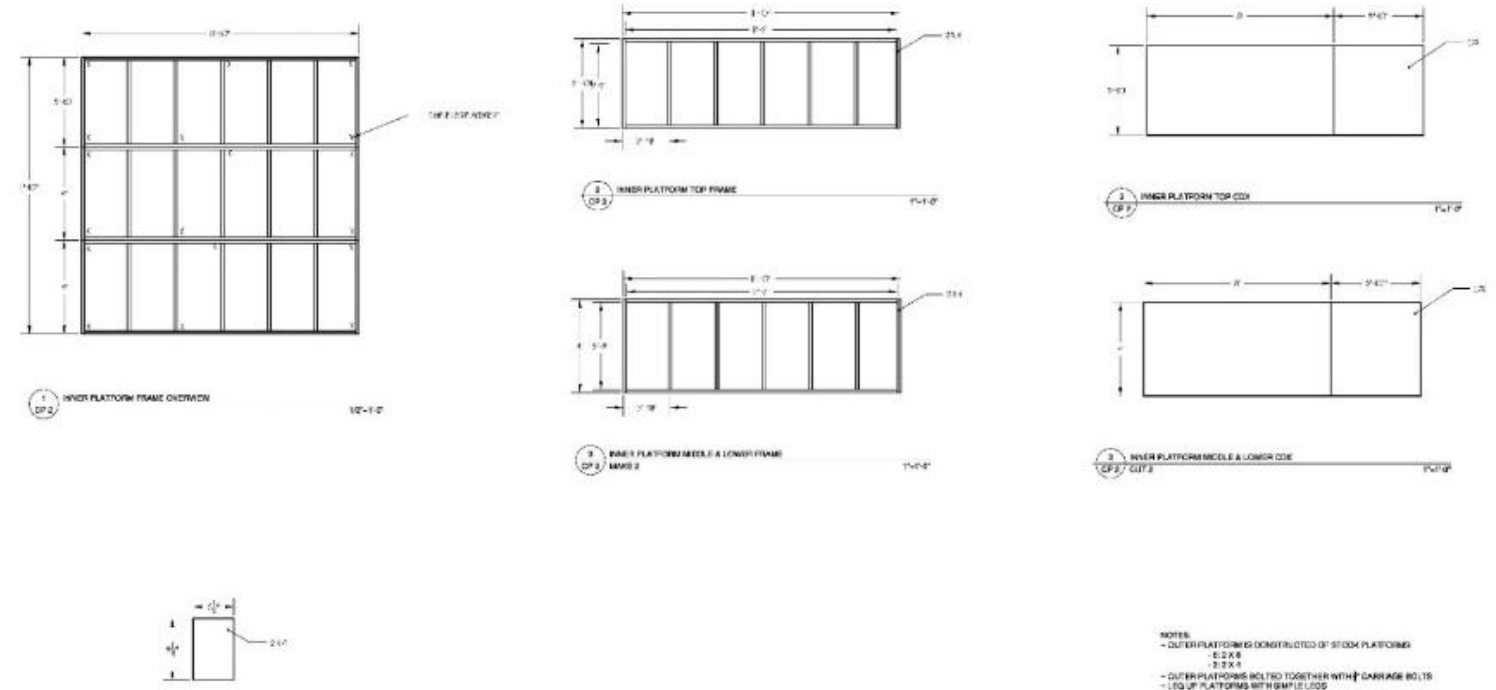

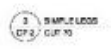

$x \rightarrow c$

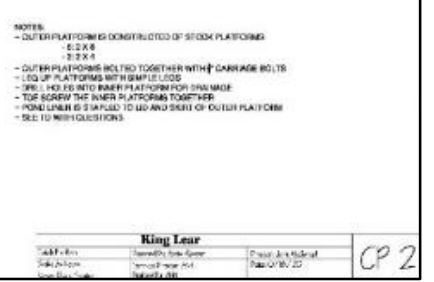

Figure18: Rain Deck Plate 2 
I drafted the rain machine next. I knew how I wanted it to work, but I had several different shapes in mind to try and get the type of rain we wanted. I ultimately decided to draft three different versions of the machine, but by the end of build drafted the machine five times. The first version of the machine that I drafted was the one from my budgeting [Appendix A]. It was a straight piece of PVC at 6' long with five tee fittings, two spray nozzles, and three sprinkler heads screwed into the fittings. The second version of the machine was much larger than the first one as I made it into a $6^{\prime} \times 6^{\prime}$ box and increased the number of sprinkler heads from three to four. This was to get better coverage of the space and hopefully add more variety to the spread of the cones. The third version was one I was not $100 \%$ sold on but thought it best to draft an option. I added more nozzles as opposed to adding more sprinklers and I made it look like a double T. I plated the rain machine very simply because I was the one that would be building it and I just wanted rough sizes of PVC.

Near the end of build and after many test runs, I finally arrived at the final version of the machine. The final version was a variation of version two with no sprinklers and a different type of nozzle. It retained the U-shape box and stayed at a $6^{\prime} \times 6^{\prime}$ size. This was done because I could control the cone shape from each nozzle to make the spread smaller or larger depending on what was needed. After testing the $6^{\prime} \times 6^{\prime}$ machine it was determined that it was too big. We cut the machine down by $1^{\prime}$ and added a center joint for the center nozzle to cover the space.

As the TD it was my job to check over the ATD's drafting to make sure that it would work with the rest of the set and that the drafting was clear and correct. Mr. Sheriff was usually very good with getting me drafting to look at and taking my feedback as well as having the drafting ready for the shop. Mr. Sheriff was always very articulate in how he wanted to build something 
and explained his reasons as to why he wanted to build it a certain way. This was his first time drafting for the shop so there were little things that needed to be changed. Unfortunately, I had issues with Ms. Johnson at this point in the process. She stopped communicating with me and the crew completely. I had difficulty getting drafting from her and when I did get drafting to look over and gave feedback, it would take days to correct. Unfortunately, it did reach a point where I could not keep the shop moving without her drafting and the corrections were becoming harder and harder to understand. I made the decision to take the units away from her and draft them myself. This was not a decision that I made lightly as I wanted her to succeed and do well, but I also could not complete the build on time with her lack of communication and responsiveness. Ms. Johnson was drafting the four arches and the two pillars, and I took over drafting the two larger arches and pillars and give Mr. Sheriff the two smaller arches.

Fortunately, I had a copy of Ms. Johnson's drafting so I was not starting from scratch and could see what needed to be fixed. Since her pillars were already started in the shop, I immediately jumped in to evaluate what was done. As I started looking at her drafting in model space, I realized the reason why we were having so many issues was because there had been an obvious miss communication about the best way to build the unit. I wanted it built like a cut to fit Hollywood flat that got spreader boards stapled to the inside of the frames to achieve its $1^{\prime}$ thick façade, but this was not the case. The best course of action would be a complete redraft. While redrafting I discovered that we could cut the whole shape out of one sheet and we only needed four sheets of lauan. The shop layout of the lauan pillar could be achieved with a fullscale template (Figures 19 and 20). 


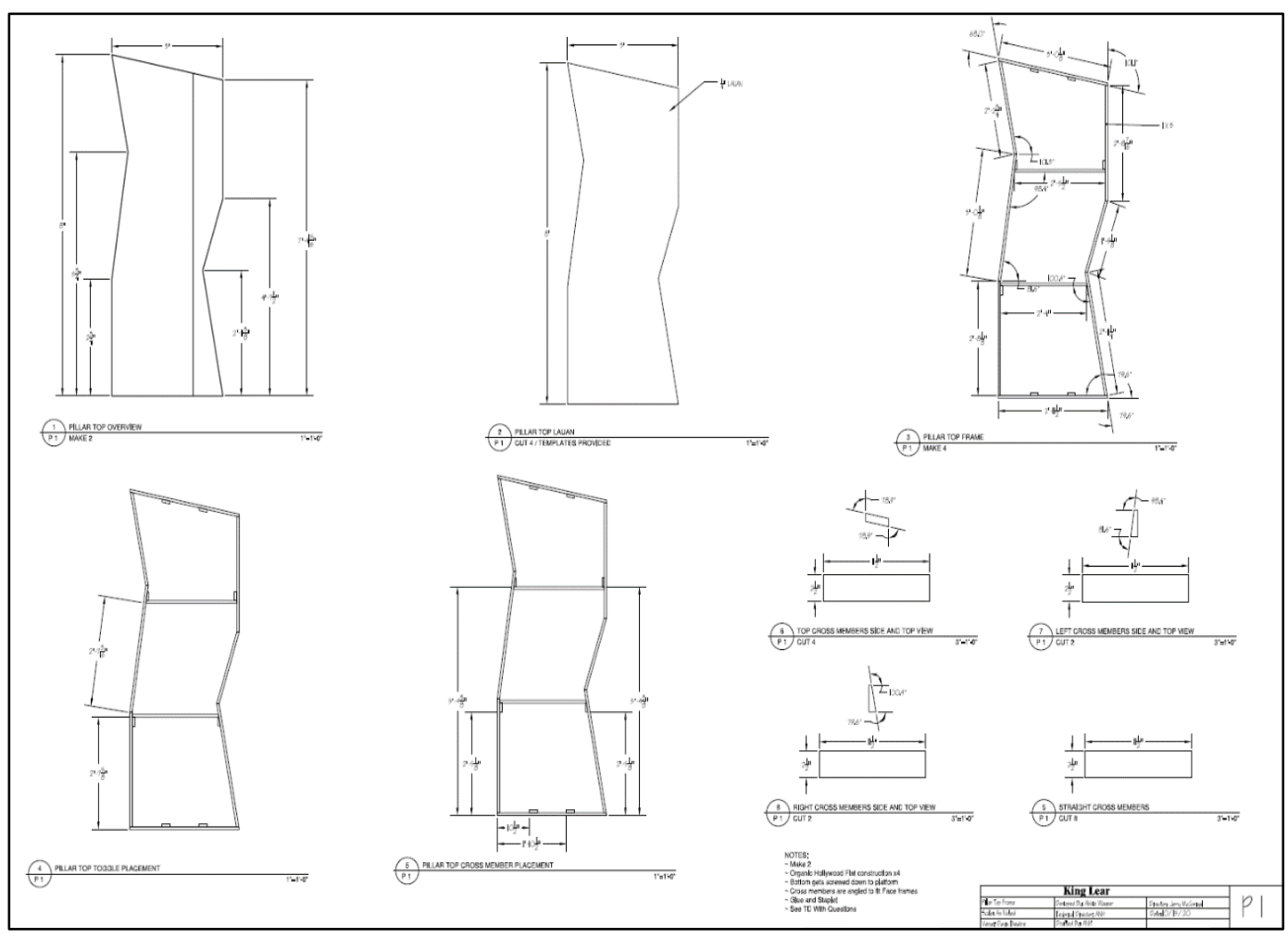

Figure 19: Pillar Plate 1

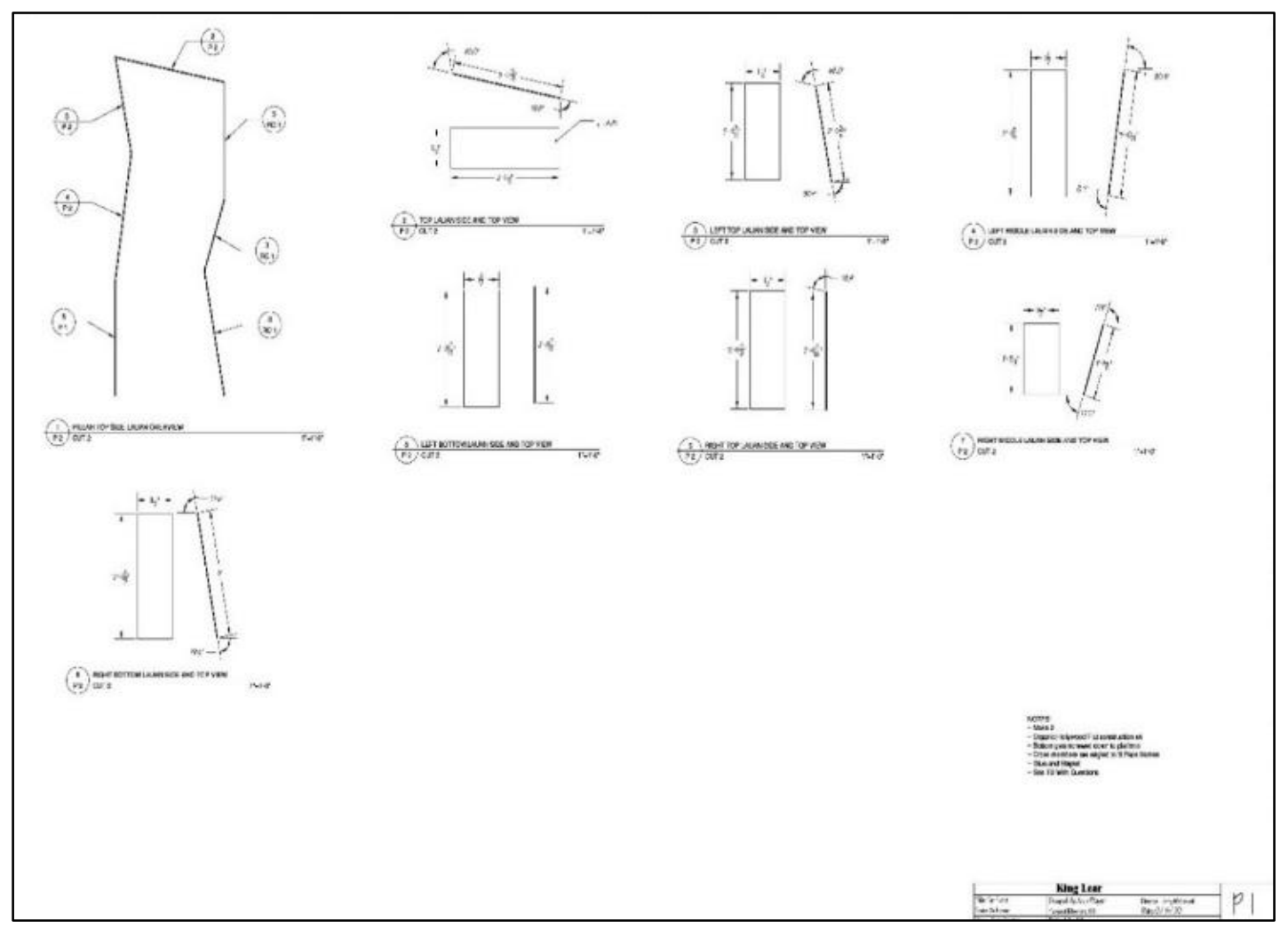

Figure 20: Pillar Plate 2 
After I got the pillar drafting back into the shop and the unit moving forward, I started work on drafting the large arches. The arches were a cut to fit frame that broke into a header and two legs. I started drafting the arches the same way that I did the pillars by drawing out the lauan sheets and laying in the arch parts that I wanted. The header was the hardest part because it spread out across three sheets of lauan and was on an angle. I then moved on to the legs of the arches and repeated the process. The rolling platforms that the arches would be riding on were standard theatrical platform construction (Figure $21-23$ ). While drafting the arches I noticed that Ms. Wagner had never stated that the shutters needed to go into the unit and that she wanted them to attach to the back. Once I realized that I went and talked to her about the shape she had drawn the shutters and asked if there was a reason that the shutters needed to be one whole piece. Ms. Wagner said no there was no design reason that the shutters were done this way. I proposed that to save on some build time, we make them lighter and easier to store by making them straight rectangles. 


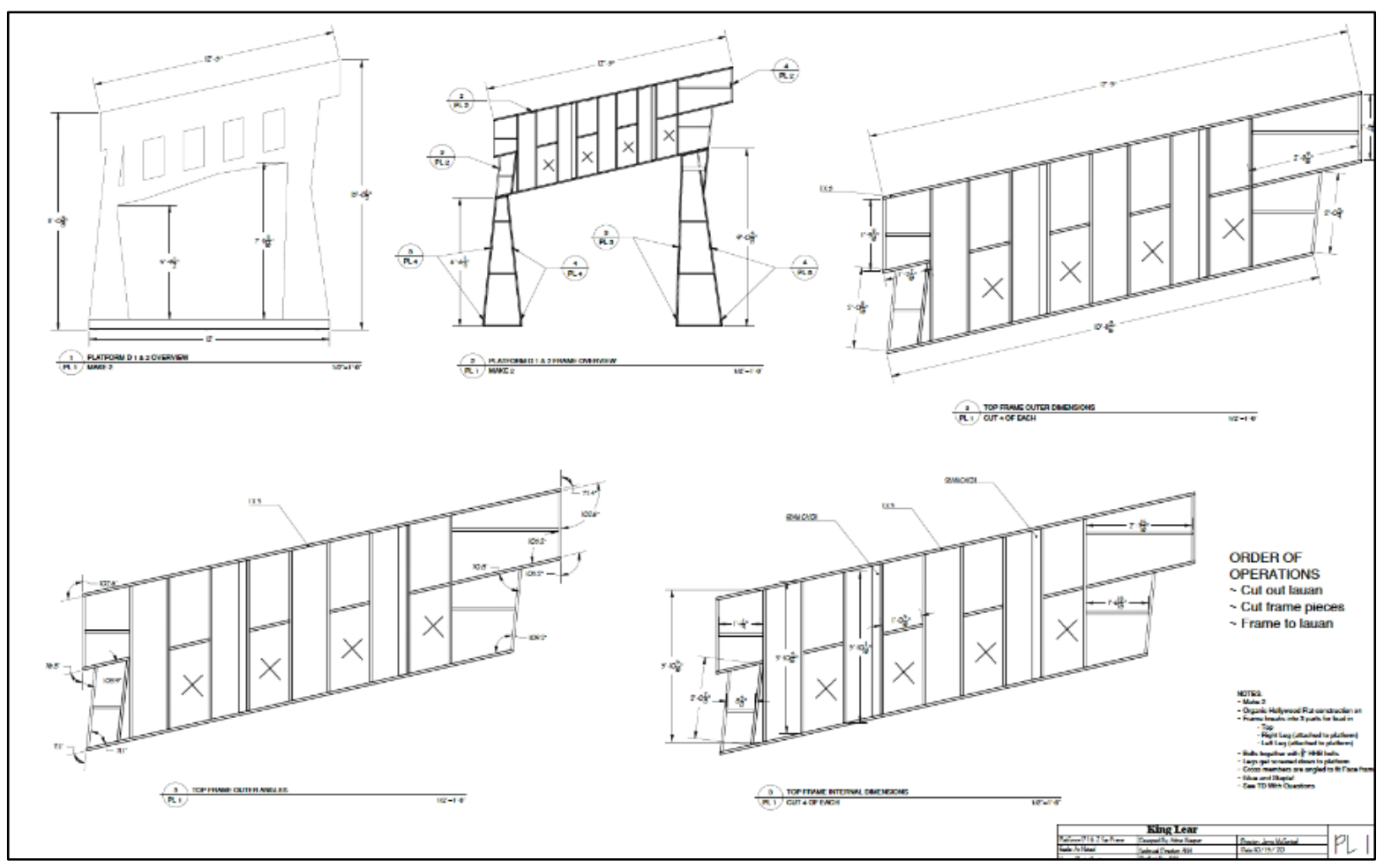

Figure 21: Large Arches Plate 1

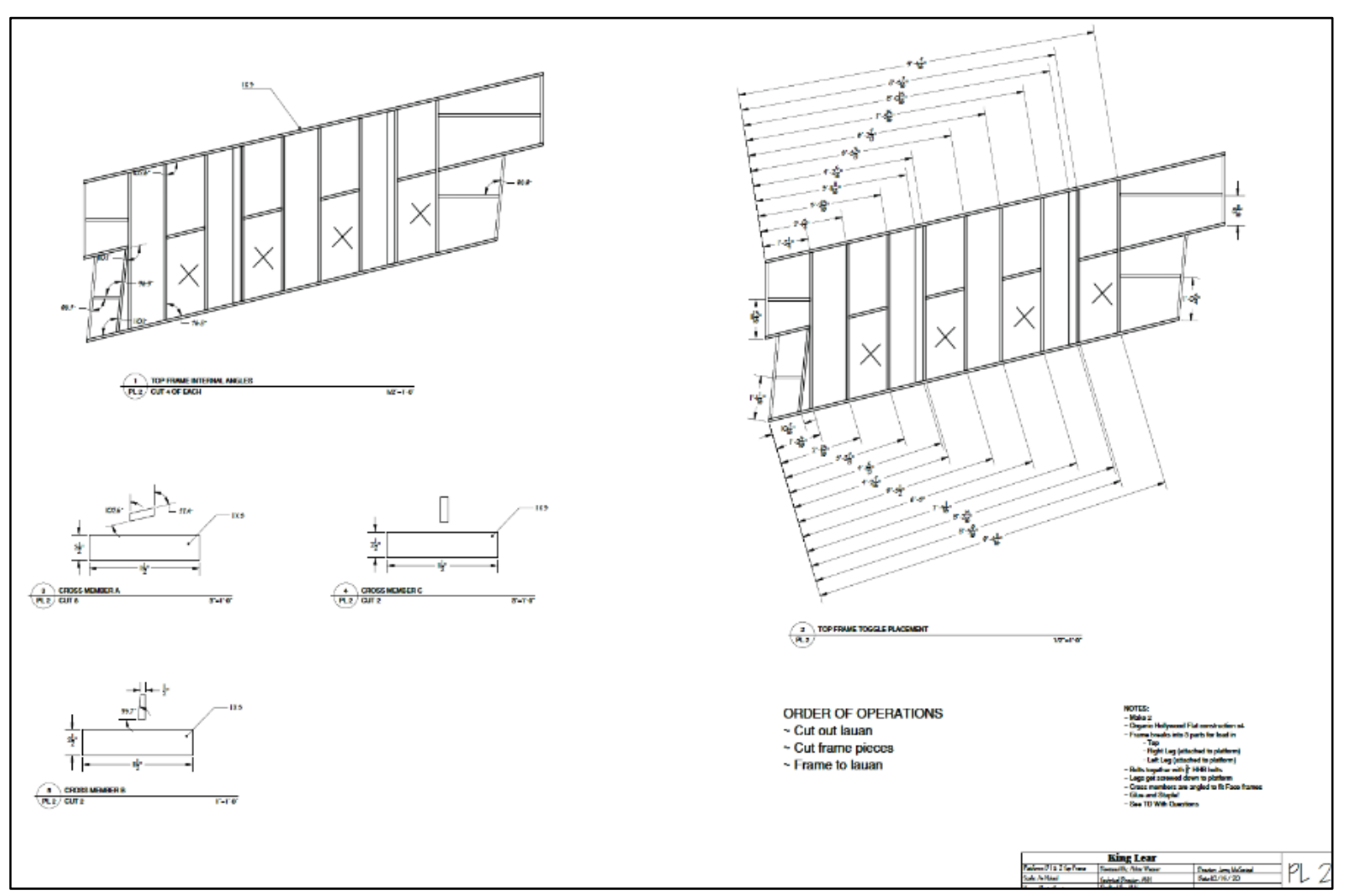

Figure 22: Large Arches Plate 2 


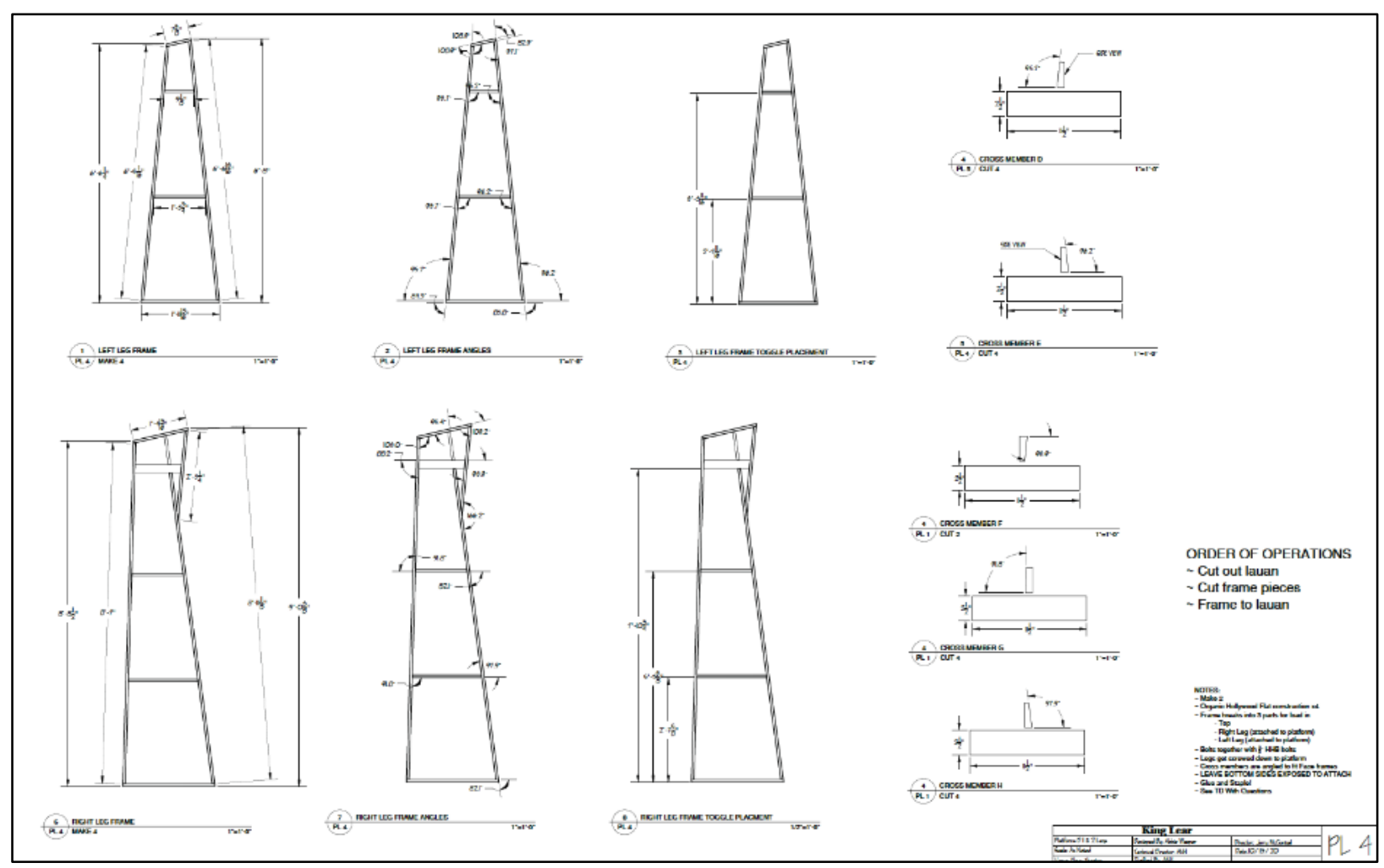

Figure 23: Large Arches Plate 4

The drafting process for King Lear was unlike any show I had drafted from previously. I usually had the designer drawings to rely on for shapes and examples. For King Lear, I had to draft with minimal information, and I really had to think through how I wanted something built and how it would function in the space before I could even start the drafting. Also, being the main person in charge of the build meant that I had to make some hard decisions when I started to see that things were not working. The drafting phase of the process is all about planning and building on what you had already thought about back in the budgeting phase. It is at this stage where everything comes out of the theoretical world and moves into reality. 
$\underline{\text { BUILD }}$

Build for King Lear was hard, fun, and challenging at the same time. COVID-19 really changed how everything operates both in the classroom and in the shop. Wearing masks in the shop made wearing our normal PPE harder and more uncomfortable. We also had to wear face shields on top of our masks when we could not be six feet apart. COVID-19 protocols also restricted the number of people we could have in the shop at one time which reduced the number of hands we had at any given time. We also had to work in zones to try and keep us separated as possible in the event that someone did test positive. The separate building zones did lead to some morale depletion. We had to work in our own little bubble, and we really could not interact with one another. We did find ways to make it better over the course of build, but the first few weeks of build were rough. Schedules had to be moved around all the time, meaning it felt like we had a lot of time to build but simultaneously not enough time to build. The illusion of more time also lent itself to allow for things to be added to scenery that was not originally budgeted. Build challenged both my confidence and skills over the course of this process. I did a lot of growing and learning more in this phase of the show than I did anywhere else in the production.

Contributing to the rocky build start was the delays with budgeting. I had less time to draft before build started and often, we were drafting and building at the same time. This also meant that while we were drafting, the shop was in a holding pattern until we could get them the finished drawings. Once my ATD's and I finished the drafting, build went a lot smoother.

The rain deck was relatively easy to build because it was just pulling platforms from outdoor storage and legging them up to height. We did run into a small hiccup of not having 
enough $2 \times 4$ stock platforms to finish the outer ring. I decided to change out one side from a $2 \times 4$ and $2 \times 8$ to two little $2 \times 2$ platforms with a $2 \times 8$ platform. I chose to have these platforms legged up with simple $2 \times 4$ legs because the deck was only getting raised 6 " off the ground and it would save us on buying more material as well as build time. While some of the students started work on legging up the platforms, Mr. Sheriff took a few students and began work on building the inner deck. The inner deck was a typical theatrical platform construction $2 \times 4$ frame with 2' center internals, a 3/4" plywood top all glued and screwed together. This process took about two and half days to fully complete.

While the rain deck was getting worked on Ms. Johnson was working on the pillars. Her team started out by building the base which was a small platform legged up to $1^{\prime}-7^{\prime \prime}$ tall, with a 1/4" MDF skirt. The base of the pillar was a relatively simple build consisting of a $3^{\prime} \times 4^{\prime}$ platform with compression legs. The compression legs were used to give a place to staple the MDF facing. After the bases were completed, I noticed that the bottom of the platform was very flimsy. I decided to put in a front and back $2 \times 4$ skirt on the bottom of the legs to give me a place to put the furniture dollies. It was not long after the bases were completed that the pillars started to stall out in build due to incomplete drafting and Ms. Johnson leaving the production. I eventually had Mr. Sheriff take over the build of the pillars because I needed to keep the units moving forward. The tops of the units had been laid out in a very confusing manner and did not seem to match the drafting. I felt that it was too complex and needed to be simplified. While helping Mr. Sheriff get his bearings on the project, we realized that the pillars where not correct. I decided to go back to the drafting and check to see if I could make heads or tail of what had happened in CAD. After weighing all my options and seeing the condition of the pillars, I decided it best to 
keep the bases and completely restart the tops of the pillars. This was a tough decision to make because it meant that I had lost almost two and half weeks of build and I had also lost materials due to incorrect sizes and change in how the unit would be constructed. I changed the build from a 1x3 Broadway flat construction to a $1 \times 3$ Hollywood flat construction. Ultimately the change was good because it paved the way for a better understanding in the shop of how the arches would be constructed next. Before the side wrapping of the pillars was complete, I asked Mr. Sheriff to add in some $3 / 4$ " plywood "plates" to the inside of the units to reinforce the general area where some wall sconces were anticipated to be attached. With the change in construction and a new project lead, Mr. Sheriff had the units completed in about two weeks. This was longer than I anticipated but the end result was a unit that did not need a lot of touch ups and was one that I felt more comfortable putting on stage and in front of a camera. The pillars were also a learning curve for the shop about how to frame organic flats. Once we worked out all the bugs on the smaller units, we knew what to expect going into the arches which were a lot bigger and more complex.

Mr. Sheriff got Mr. Utley started on building the downstage walls. All four of the wall units were going to be constructed the same way with a $1 \times 1$ and $1 \times 2$ metal frame under a $1 / 4$ " MDF skin with a 1-1/2" schedule 40 pipe down the center. The only things that really changed between the upstage and downstage walls were the angles at the top and how the pipe got added to the center and attached to the trolleys. Building of the frame went well and Mr. Utley got them done very quickly. It was when we got to skinning the units that there was some confusion and slowdown. We initially talked with Ms. Wagner about cutting a chamfer into the facing while testing the door mechanism for the upstage walls and we worried that if we chamfered one edge 
it would look weird and break the illusion of them being large concrete slabs. I recommended that we chamfer all the edges to make it look more cohesive and give more of the illusion of concrete. Ms. Wagner liked the idea, and we went with that as our plan for all the walls. About a week later in a production meeting, I noticed that there was a new element that had been added to the renderings that Ms. Wagner was showing Professor McGonigle. She had added 2" gold bands of trim to the walls and most of the other units. I asked what those were and if that was something that needed to be added to the units? If so, I had not budgeted for them. Ms. Wagner assured me that the bands were going to be painted on the walls/units and I was good to continue build as I had planned. It was during a camera test for lighting when we were checking how paint would look on camera that it was determined that the 2 " gold bands would be changed from painted on the wall to $1 / 4^{\prime \prime}$ and $1 / 2$ " pieces of MDF trim. I knew we had enough $1 / 2$ " MDF in house to do it but I was unsure if we would have enough $1 / 4$. Due to this change she wanted the seams to lay flat. I explained that we would still need to put the one chamfer in the door so it could open properly but if we were putting trim over it, it would be covered. While all these discussions were underway I had to put a pause on the skinning of the walls until we had a better idea of what was happening. Once we got clarification, I resumed build of the walls and asked that the chamfer be left off the rest of the units. Mr. Utley completed the frames of all four wall units at a very good pace and was able to hand the skinning of the units back over to Mr. Sheriff. Then he worked on the details of where and how the pipes would be attached before completely sealing them up. In the downstage walls, I decided that the pipe would be welded onto the frame for more stability and in the upstage walls the pipe would be bolted in to allow for greater flexibility. When we came back from winter break, I had the shop put a high priority on the wall units. Mr. 
Sheriff drilled the pipe holes in the tops of the downstage walls and attached the straight casters so we could then weld in the pipe and seal up the backs of the units. This took us about a day to complete. Skinning the upstage walls took us a little longer to complete because we had to deal with the door opening and the installation of the door itself. While Mr. Sheriff worked on finishing up the walls, I worked on welding the trollies that the walls would ride on. These trollies would be attached to the tracks that would shift the walls onstage and off. The trollies were a relatively

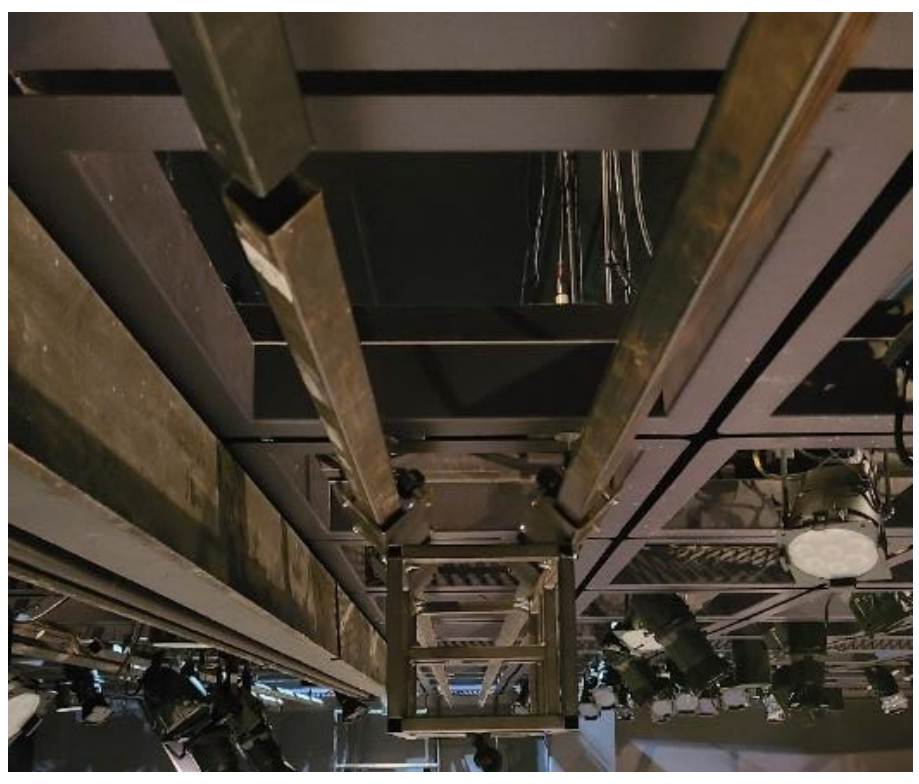

Figure 24: Downstage Trolly and Tracks simple box construction that had some supports in place to trap and bolt the pipes in place (Figure 24).

The next scenic units to move into the shop were the large arches. Much like the pillars, the arches were a $1 \times 3$ organic Hollywood flat construction that would be attached to a rolling platform. The units ended up being built in three parts and assembled in the shop and moved into the space as one whole unit. These units presented a challenge due to steep angles making difficult attachment points. The hardest part of these units was the side wrap which had a lot of steep angles and changes in direction. The inside wrap of the window openings was also difficult due to the units being $1^{\prime}$ thick. It was hard to get a good position to physically staple the lauan to the frame. Once we found a good system for cutting and stapling these units took about a month to complete start to finish. 
The last of the units to go into the shop were the small arches. By the time these units made it into the shop, we knew what worked and what did not due to mistakes made on the other units. They took about a week to complete.

I started work on the rain machine back in October 2020 and finished working on it in March 2021. My initial plan was to have a 50-gallon barrel sitting behind a closed door that led up to the grid. From the barrel would run a hose to a pump that would then lead to a garden hose that ran across the grid to the PVC construction delivery system. Once all my parts arrived, I started testing with the pump. I wanted to confirm that the pump I ordered would deliver the amount of pressure I needed to get the rain to come out like a storm. In short, the pump did not work. I could get it to work in short bursts but nothing consistent. I tried different fittings, a different hose but nothing really got it to work how I wanted. Eventually I ended up replacing it with a sump pump. During one of my pump tests, Professor Neuenschwander asked where I had been getting the water for testing. I told him I was using the paint sink for testing. We both looked at the water in the barrel and determined that the water from the sink was clean enough to use on the actors, so I changed tactics from using a barrel and pump to get the water on stage to hooking the garden hose straight up to the paint sink. This allowed me to control the pressure better as well as the temperature. Now that I was able to get the pressure that I wanted, I retested the nozzles and sprinklers, and it still was not the effect I wanted. I quickly scrapped that idea of combining the two. Luckily, Professor Neuenschwander had a garden nozzle that he had used previously for a different effect that worked perfectly and gave me better control of the cone spread. After that test I put the machine on hold while other units got prioritized in build. Later in March I picked the rain machine project back up. I used 3/4" PVC to build a $6^{\prime} \times 6^{\prime}$ " $\mathrm{U}$ - 
shaped" box mechanism. The nozzles screwed into threaded fittings at set points in the rig that were placed to get the best spread of the water. Once I had the machine built, it was time to test. I laid down the rain deck in the shop so I could see how much water the machine generated and how long we could run the effect. I ran into a few issues when we laid the inner deck. It was way too tight which unfortunately caused holes in the pond liner. Luckily, I ordered a liner that was bigger than what we needed and the holes were in a place where I could just move the liner to where it was not in the basin patching the one hole that did remain in the basin. We increased the size of the outer ring by 3 " and then cut into one corner of the inner deck so we could monitor the water levels. Once the deck was set and good to go, I set up two vertical pipes and clamped a pipe across horizontally at the height I wanted the machine at. The test went off well and the rain stayed in the $12^{\prime} \times 12^{\prime}$ area. We did find a bare spot and decided to add one more nozzle and shrink the machine down by a foot. I made the adjustments and we tested it again and it worked perfectly. 


\section{CHAPTER 4: LOAD IN}

\section{SCHEDULING}

With the show getting moved from the fall to the spring semester it meant that I had to reevaluate loading in the set. I had started to load in a part of the set back in the fall so that lighting had an idea of where four of the units would be traveling. Loading in a set usually takes about two to three days to get all the units in the door and maybe a day or two to put on the finishing touches. Install of the set was done phases due to how build went and how paint needed to work. I put load in into the build calendar rather than making it its own schedule.

How I determined when units would be loaded in was mostly based off when units were completed and the needs of paints and rehearsals. The paint technique that they were using would require the units to be upright. With them being on wheels, there was no good way to paint them in the shop safely without them falling over. I consulted with Professor Neuenschwander to see if they could be painted in space if no sanding took place, he said that was fine. I then determined that we could get both sets of walls loaded into the space before rehearsal started. I determined that once the walls were loaded in the other scenic units would follow as they were completed.

\section{$\underline{\text { Load In }}$}

Load in for King Lear started all the way back in October 2020 with hanging the tracks for the walls. This was one of the most challenging things that I loaded in for many reasons. I 
underestimated how long it would take me to hang the tracks. I had initially scheduled this to take five days to get both sets of tracks up but ended up taking me about two weeks to fully get the tracks in the air. The delay was mostly attributed to me having to find the correct lengths of track and the necessary hardware. Once all the tracks were installed, they needed to be leveled and spaced correctly. To hang the tracks, we used a series of grid hangers that had been built specifically for the Davis grid that consisted of an eye bolt that hung down so I could run a bolt through a tab on the track and attach all of it together. The plan to hang the track was to tie rope to the tracks and hoist it up to the gird, so I could secure it from the Genie lift. Overall, the plan worked, but we did have to move the upstage tracks back a row due to a miscalculation on where the tracks needed to be.

During the spring 2021 semester, the downstage walls were completed and ready to load in. The plan for loading in these walls was to get them into the space, attach the trolly and then stand the wall up and roll it onto the track. I would have one person in the lift to help balance it and guide it onto the track while ten people on the ground helped to stand it up and move it into place. However, when we tried to stand it up, we ran into some issues. With the lights already hung it limited where it was safe to raise the wall and raising the wall in a jack knife manner made it too difficult to handle. Professor Neuenschwander advised that it would be easier if he went up to the grid and helped pull the wall up with a rope. With two people helping from above, we were able to turn and adjust the wall once it was standing. We got the walls up and on the tracks with minimal issues after that. After installation we discovered that the walls did not have enough internal framing to support the type of paint treatment being done and the general humidity of the theatre causing the MDF to start bubbling. We had to 
remove the backs of the downstage walls to put in more framing, which took up about two extra days of work. Thankfully, we caught this before the upstage walls were in and fully skinned so we added the extra framing in the shop.

A week later we loaded in the upstage walls. The plan was to do these walls the same way that we did the downstage walls. Once we got the first wall up, we found that we had trouble with the track itself. The bolts holding the track were too long and prevented the trolley from moving correctly. We had to remove some bolts to allow the wall to slide down the track so the other wall could get on. We were then able to address all the bad bolts holding the track. Another speed bump encountered while loading in the upstage walls was not having the correct hardware for the second trolley. After the upstage walls were loaded in and secured, Professor McGonigle started playing with them in rehearsal and determined that he wanted the upstage walls to be used as doors for a couple of the scenes. The upstage walls were designed to rotate, but with how they were hung on the track and the swivel casters underneath they were gliding a little too well. After talking with Professor Neuenschwander about what needed to happen with the walls, he recommended a cane bolt to pin the walls in and allow them to turn on a central pivot point. It was while we were trouble shooting the cane bolt, we discovered that we needed to add some weight to the units to make them more level. This also had the advantage of improving how the walls moved on the track.

The next units to be loaded in were the large arches. The original plan was to walk them in as 3 separate pieces and then assemble them in space. It was here that Ms. Wagner and I had a communication problem with how the units were supposed to look and with how I wanted to load them in. Due to where I placed the breaks in the units it would be rather noticeable where 
the seams were. Looking at the load doors that we needed to get the units through, I determined if we turned them the right way, we could do it as one piece. We did get the arches stuck a few times in the process of dealing with the legs but eventually we did get them through the doors. Once the units were in the space, we attached them to their platforms. We used rope and pully's tied to the grid to lift the arches off the ground enough to slide the platforms underneath and then we screwed the legs down. I noticed that the units were very top heavy and the $1 \times 3$ of the frames themselves was splitting when we drilled into them which was not safe. Professor Neuenschwander recommended putting in two $3 / 4$ " plywood boards on top of the framing so we could lag screw the legs to the platforms. Doing this made the units feel a lot sturdier and safer to operate. About a week later we loaded in the small arches repeating the process. The last units to enter the space were the pillars that just rolled in. Load in continued at the beginning of filming week. Trim was put on to units and Ms. Wagner, The AD Team, and I were in discussions on what needed to be ready first. My crew and I were already done with the finishing details on the two large arches and the upstage wall units. The downstage wall units were getting the back trim put on as well as the pillars getting fully trimmed. On Monday March $1^{\text {st }}$, I saw a note on the rehearsal report that the Director would like to add the shutters to the arches for Wednesday's filming. I quickly reprioritized the shop because the shutters were not originally needed until Act 2. I pulled my ATD, Mr. Sheriff, off the back trim for the downstage walls and shifted one of my carpenters onto finishing the walls. Mr. Utley took over fixing the cane bolts on the upstage wall units so I could go and get the shutters cut and up to paint. Once we had all the shutters cut and painted for both arches, we got ready to install them onto the units. Since I was unsure which arches they wanted 
shuttered I went to confirm with the Scenic Designer and Director which were being used in the scene. Professor McGonigle confirmed that the two large arches were correct and in the correct placement. He was, however, unsure by what I meant about the shutters getting attached to the back of the unit. I showed him where I intended to attach the shutters on the back between the openings near the top of the unit. Professor McGonigle informed me that that would not work as they would be filming from that direction and would show up on camera. He thought they would be inserted into the unit on the underside of the arches. Discussions I had with Ms. Wagner said that she wanted the shutters attached to the outsides of the units. I explained to Professor McGonigle that the way the arches had been constructed would not allow me to insert the shutter panels into the unit without having to completely redo the underside of the units resulting in them not being ready for filming on Wednesday. Nevertheless, I said I would investigate possible solutions and talk with Professor Neuenschwander and see what I could do. Ms. Wagner and I sat down and had a discussion on possible solutions but all solutions we thought of either involved adding more to the unit that would ruin the look of the design or be caught on camera. Professor Neuenschwander confirmed that whatever we did it would not be ready in time for filming on Wednesday. Professor Neuenschwander recommended that Ms. Wagner and Professor McGonigle discuss the misunderstanding and see what they could come up with and let me know what was decided. While waiting for confirmation of what I would do with the shutters, the crew and I went back to finishing the other units. Later Ms. Wagner came back with Professor McGonigle and told me that they had reached the conclusion that the shutters would go on the back of the unit and the shutter panels would need to be cut down to match the angle of the openings so that it blended in better. Also, the back of the shutters 
would need to be painted. Professor Neuenschwander also recommended that we add some trim over the shutters on both sides, so it looked cleaner and more cohesive with the design. I pulled Mr. Sheriff again and we got straight to work on getting the extra trim and shutters attached. By the end of the day on Monday, we had the trim finished on the downstage walls, the shutters and trim on the large arches, and the cane bolt fixed and working on the upstage walls. I also had a plan to finish the small arches, reattach trim, and keep working on pillars for my Wednesday deadline.

Tuesday was a non-instructional day for the University, so I spent the whole day in the shop getting ready for filming. By the end of Tuesday, we had finished getting all of the trim on the walls and arches.

Load in for this show was very hard for me. I had a lot of trouble commanding the room and I got completely overwhelmed by so many people trying to tell me how to do things. Unfortunately, I did let this get to me a little bit and this undoubtedly made this part of the process harder for me because instead of listening to my own instincts and taking my time to clearly articulate what I wanted to happen, I came across like I did not know what I was doing and flustered which I believe shook the crew's confidence in me. On the flip side I did learn many things. Once I take a deep breath and before anything happens, I need to make sure to speak with conviction on what I want to happen and let the crew know that if things go awry, to just give me a second to gather my thoughts and I will come up with a solution. Next, I do not necessarily need to listen to every voice screaming at me to do it their way. I am the one with the larger picture in mind and I am the one that knows how and where the units can break or move to accommodate certain requirements. I can listen and acknowledge that I have heard 
the input and will take it into consideration, but ultimately it is my decision on what needs to happen with each unit. Lastly, I need to stay calm as things are not always going to go according to plan and that is okay. It is more important that I get the unit safely in the space rather than trying to force the unit to do something it cannot do, which could result in damage or even worse, someone gets hurt. 


\section{CHAPTER 5: FILMING}

\section{$\underline{\text { THE FILMING PROCESS }}$}

Before filming could begin, we needed to take some extra precautions due to COVID-19 to ensure the safety of the cast and crew over the next month. The precautions that were taken where as follows; before we could enter the space, we had a mandatory temperature check and a daily questionnaire to ensure that nobody entered the space that was not supposed to be there as well as checking that everyone was not symptomatic. Next, depending on our proximity to the actors, we were required to be tested once, twice, or three times a week to ensure that nobody was COVID-19 positive. Lastly, the cast and crew were also required to wear an appropriately fitting mask, double mask when in the space. Another thing was the requirement of certain individuals to use additional PPE. For example, mic techs and dressers needed to wear a gown, gloves, mask, and face shield when interacting with the cast. Grips, deck, and boom operators only needed to wear masks and hand sanitize frequently.

In the rest of this section, I will break down how the filming process went from week to week as well as how my job as the Technical Director integrated into the filming process. Filming King Lear took place over three and a half weeks with one week off in between week one and week two. We started filming on March $3^{\text {rd }}, 2021$ and ended on April $1^{\text {st }}, 2021$. 
WEEK ONE: March $3^{\text {rd }}-$ March $6^{\text {th }}$

Wednesday was also another non-instructional day so we filmed during the day. I was excited to see how the set would look and come to life on camera. I arrived early to do a final walk through of the space and make sure there was nothing I had missed before my call time. This is something that I like to do as a TD because it gives me peace of mind that I have done all that I can do and that the set looks exactly how it is supposed to. Once the crew was checked in and settled, the faculty and film crew had a talk with all of us about how filming would go as well as the guidelines and restrictions that had been set in place due to COVID-19. As Mr. Dowling the director of photography and the faculty concluding their directions, the crews were released to the department heads for training.

As the Technical Director, part of my job is to train the crew on how to properly sweep and mop the stage every day before filming. The Technical Director also trains them how the set moves and makes sure they are comfortable with operating the scenic units. For King Lear I had two crew members that I was responsible for directing and training called the deck crew. Along with moving the set the deck crew was also responsible for doing a fire walk. Since we were using a lot of haze this show, the fire alarm system needed to be turned off, so we did not accidently trip it. A fire walk is when someone must physically walk throughout the building every hour to make sure there are no fires in the building. This was only required when the system was turned off for more than four hours. We also trained the deck crew on fire extinguishers so that we were ready for when we did the live fire effect. We also wanted to ensure the deck crew knew they could attempt to put out a small fire on fire watch if one was discovered. WVU's Environmental Health and Safety (EH\&S) department came down to train 
the deck crew as well as Mr. Sheriff and myself on how to properly use fire extinguishers. We were able to try a computerized extinguisher so we got a feel for the weight, how long the extinguisher would last, as well as how we needed to move with it.

I was asked by the Director to stay in the venue in case I was needed. One big take away from the first day of filming was that I was going to be doing a bunch of hurry up and wait. My job for the most part was complete once the scene was shot. I spent most of the first day of filming walking quietly around the space observing what was happening and seeing what the cameras were capturing on the monitors that had been set up around the Davis Theatre as well as one installed in the shop. We wrapped filming on Wednesday and the department heads had a short meeting to talk about notes that would need to be addressed before filming the next day. There were a couple of minor touch ups that needed to happen but nothing substantial.

Thursday's filming was

a little bit different because instead of filming for the whole day the University resumed classes. This meant we would start filming at $5 \mathrm{pm}$ and go to $11 \mathrm{pm}$. Filming itself on Thursday was a lot like how it went on Wednesday since

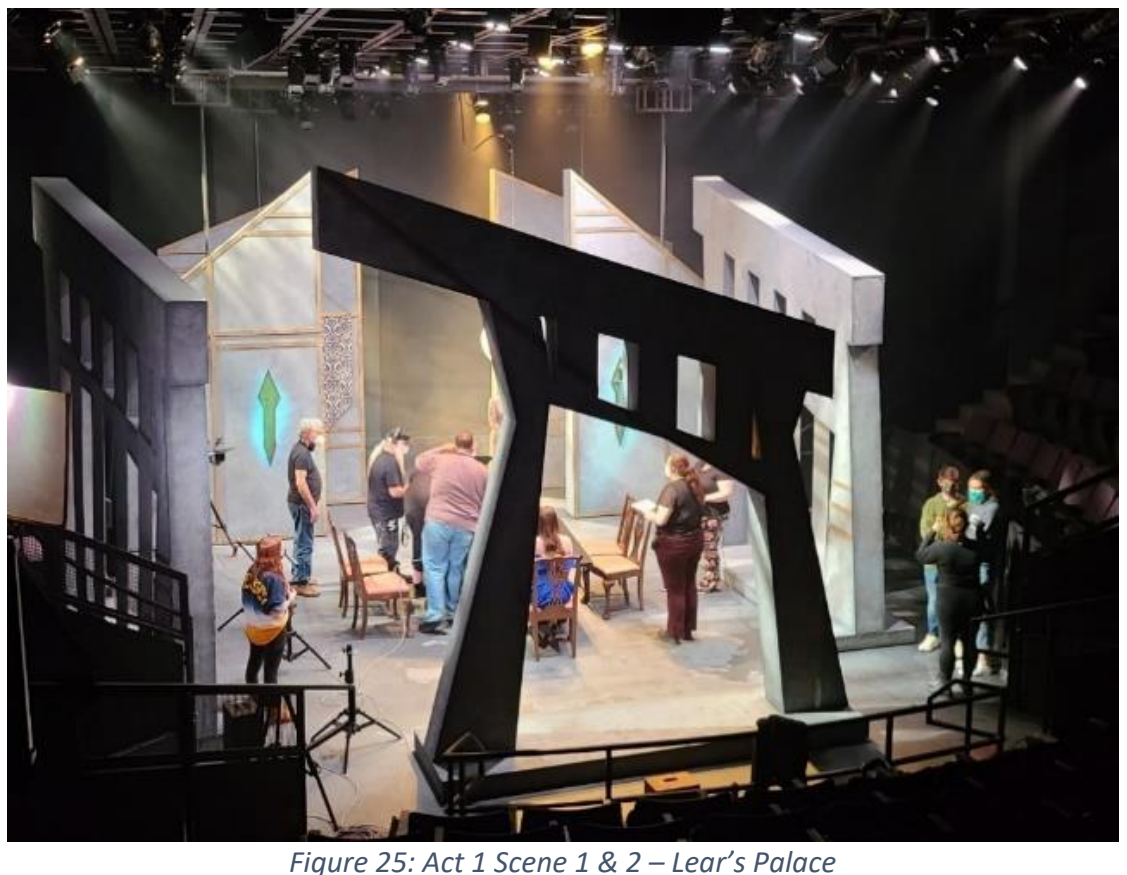
we were still in Act 1 Scene 1 /

2 (Figure 25) which did not require a scene shift. 
Friday's filming came and we

wrapped up the first couple of scenes and then did our first big scene shift. The two upstage walls got clamped together with the downstage right wall moved more on stage. The last small arch got added with its shutters and the large arches adjusted slightly more downstage. This configuration of the set was where we stayed for the rest of filming that day (Figure 26).

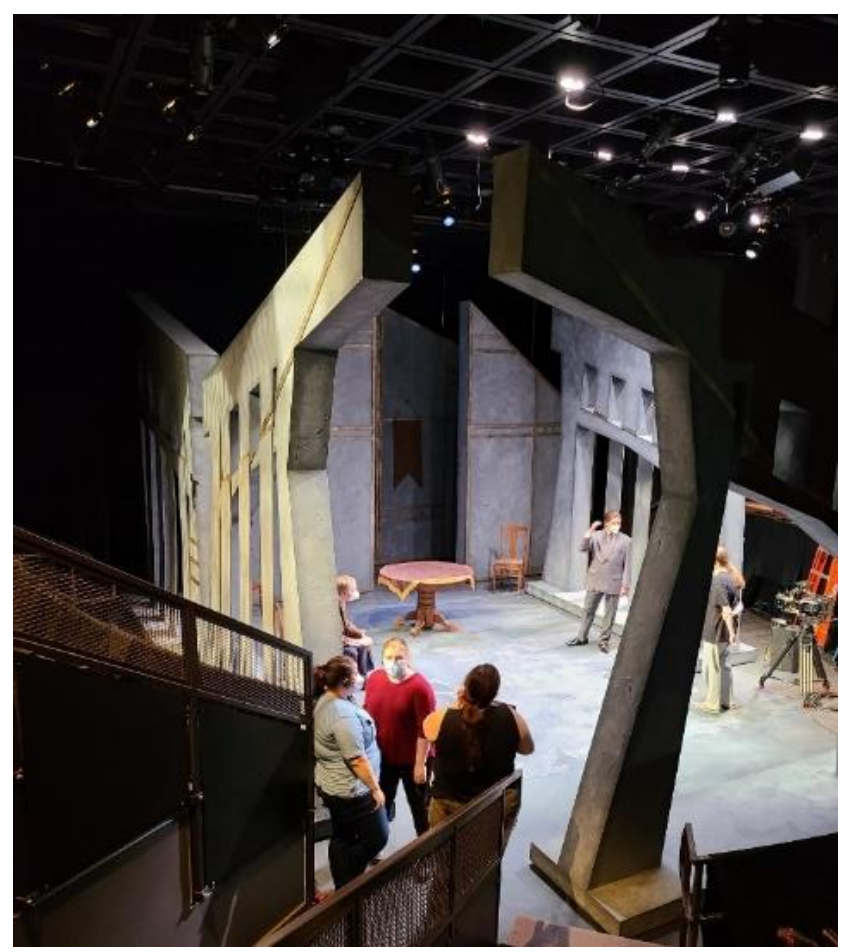

Figure 26: Act 1 Scene 3 - Albany's Palace

Saturday concluded the first week of

filming, completing most of Act 1 and tracking 2 days ahead of schedule. Some things that I had learned throughout the first week of filming is that there is a quick burst of activity and then a long lull before I was needed again. I also learned about how much planning and thought must go into making a shot look just right. Unlike live theatre where the audience will only ever see it from one angle, filming can capture so many more angles and you may end up filming the same thing repeatedly just to get different angles. I took to watching what the camera operators were doing and how they were adjusting ever so slightly to make a shot look good. I also just sat and listened to what they were saying to each other, so I understood what was shifting. I also used this opportunity to learn what certain items or movements were called. 
WEEK TWO: March $15^{\text {th }}-$ March $20^{\text {th }}$

Filming resumed on Monday, March $15^{\text {th }}$ after a week off for rehearsals. We started by resetting the set back to Albany's Palace. After finishing up filming in Albany's Palace, we shifted part of the set to an outdoor look to film a couple of smaller scenes. When those were done, we took a small pause to do a large shift of the scenery to outside of Gloucester's castle (Figure 27). Ms. Wagner and Ms. Cole worked on stapling greenery to the arches while the crew, Professor Neuenschwander and I got to work on opening the upstage walls to put the cane bolts down.

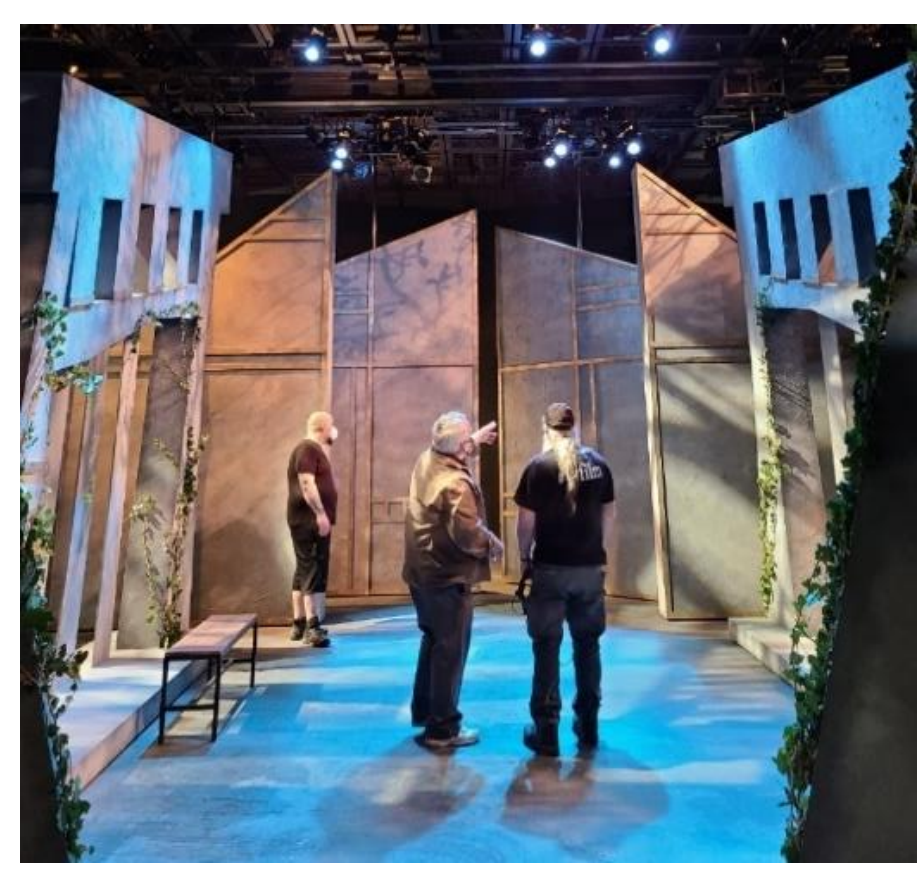

Figure 27: Act 2 Scene 2 Outside Gloucester's Castle

We stayed in this look for the next three days. Filming went well and I did not have too much to do during filming except make some occasional adjustments.

On Thursday' we made the shift from outside the castle to inside the castle for the eye gouging scene. This was one of the most fun nights we had filming. I had done special effect makeup before on stage but doing it for film is a whole other beast to tackle. I liked getting to see the different camera angles used to catch the gruesomeness of the scene. The other cool thing was getting to see what our costume department could do to make this look realistic. They made prosthetics for the actress to put on that made it look like her eyes had been ripped out along with realistic eyeballs for the actor to smash. 
Friday was a dark day for filming so we could load in the rain deck. We started load in at $8 \mathrm{am}$ and ended at $5 \mathrm{pm}$. Load in for the rain deck was a bit of a whirlwind because most of the shop staff was out getting COVID-19 vaccines. We loaded in the effect in phases. In the first phase, we laid out the floor's protective plastic and the bottom and sides of the outer ring. We then brought in and raised the machine to the grid. While I was at my vaccine appointment, Professor Neuenschwander, Mr. Utley, Mr. Sheriff, and the other shop staff worked to finish bringing in the top of the outer ring, the pond liner, and run the hose back to the

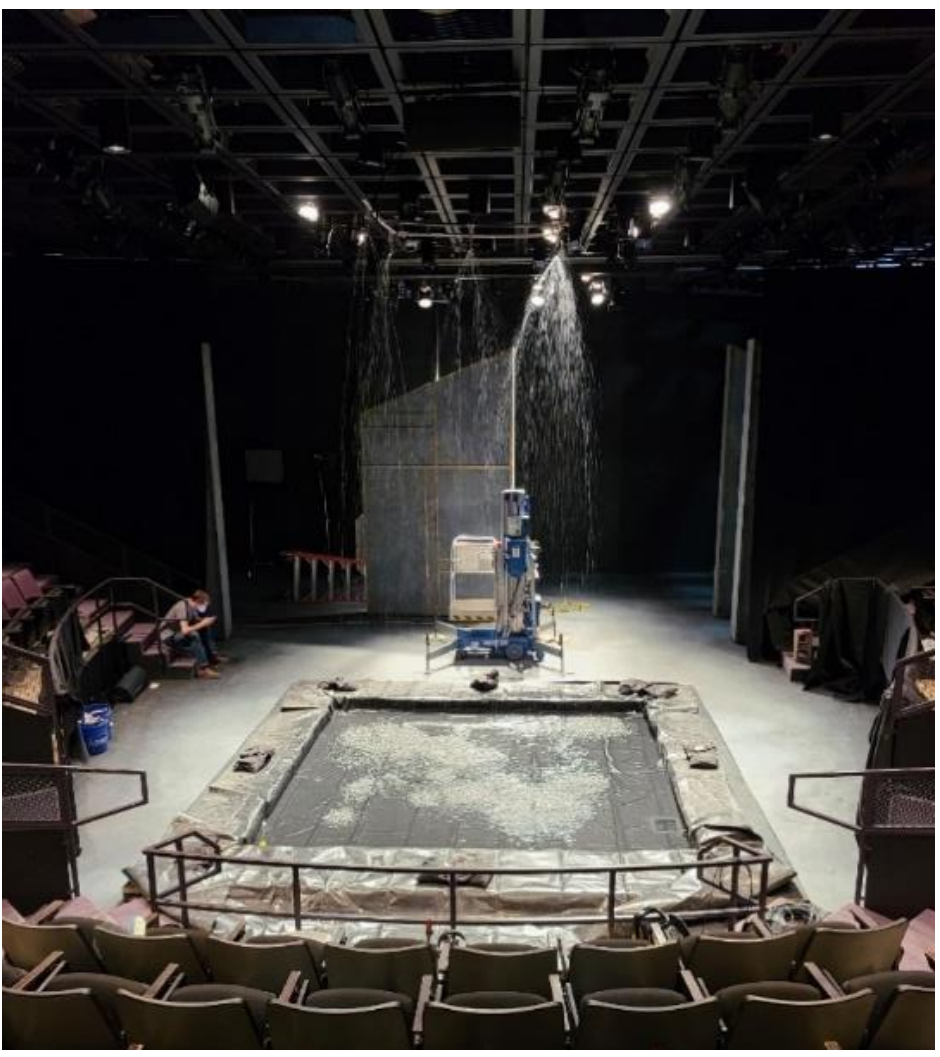

Figure 28: Rain Machine and Deck install paint room sink. When I came back, we finished stapling the protective plastic to the deck. We did a test of the machine to make sure that the nozzles were set how we needed giving people a chance to see and hear the effect before install was complete (Figure 28). Once I was satisfied that everything was working how it was supposed to, we drained the pool and then installed the inner deck. While the inner deck was getting installed, we also brought up and installed a raised camera deck. The last hour was spent raising the erosion cloth back drop and dressing the rain deck for filming. 
Saturday's filming was one of the most active days for me. I wore many hats that day from checking in people at the COVID station to being on standby to run to the grid to adjust the rain if needed. Thankfully, all that testing and adjusting from the previous day held and I did not have to run to the grid and the rain turned on and looked amazing (Figure 29). Due to the large size of the pool, we did not need to drain the basin during the filming day, but we did push

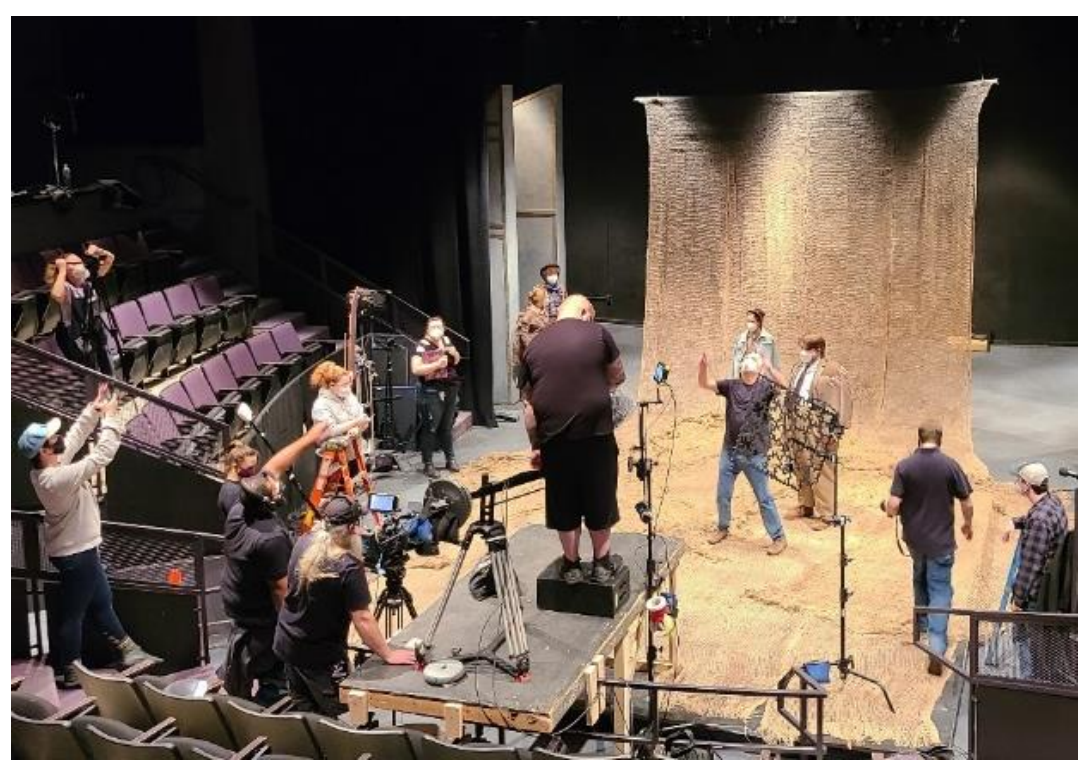

Figure 29: Filming the storm.

its limits to its highest point. We did a preliminary strike that evening taking out the inner deck, camera deck, and we hung the erosion cloth to dry so we could fully remove the whole deck Monday and prepare for the live fire scene. This wrapped up a successful week two of filming. 


\section{WEEK THREE: March $22^{\text {nd }}-$ March $27^{\text {th }}$}

We resumed filming in a maze of scenic units

that created the outside of the hovel that would

lead us into the fire scene. Near the end of the

day on Monday, we shifted the scenery offstage

and brought in the upstage walls and turned

them $90^{\circ}$ along with adding the fire barrel to

create the inside of the hovel (Figure 30). We

did run out of time on Monday to film the fire,

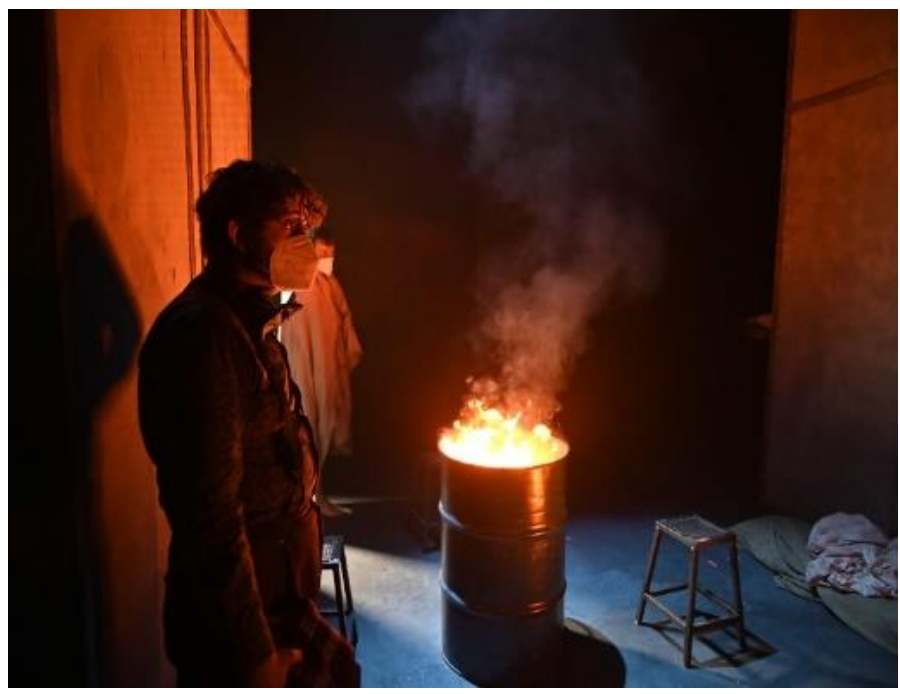

Figure 30: Act 3 Scene 3 - Inside the Hovel Fire Scene but we started our evening on Tuesday with the live fire. The fire scene took up most of the

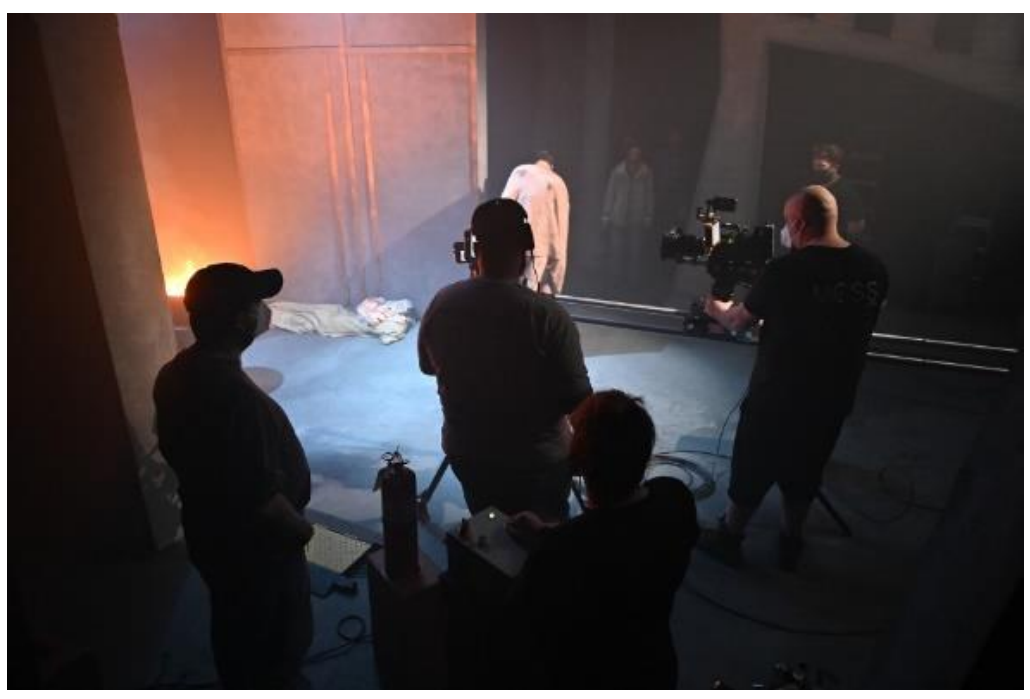

Figure 31: Operating the fire barrel. filming day Tuesday. While I

operated the fire effect, Professor

Neuenschwander and Mr. Sheriff

kept watch with fire extinguishers

in the event of something going

wrong (Figure 31). It was a lot of

fun to do a bigger fire effect than I

have done in the past. I also

learned a lot from Professor Neuenschwander about how to put the fire control box together what kind of parts go into making a fire effect work as well as the types of precautions that need to be considered when doing a live fire scene on this kind of scale. The rest of Tuesday was doing re-shoots from earlier scenes that had been missed. This meant doing two big scene 
shifts to get us back to where we were in the previous shots. We did run into a bit of bump when it came to putting a wall sconce on one of the downstage walls. I had cut into the trim so the sconce could fit at a certain height. Due to camera angles and positions of actors in order for the sconce to be caught on camera it needed to move down. This led to an issue with the trim because we had no more trim and no more paint for the trim. We did resolve to cut more trim and get more paint and made the adjustment.

Wednesday ended up being another dark day for rehearsal and on Thursday we went back to Albany's palace and spent most of the day filming there. We had one scene shift on Thursday back to the inside of Gloucester's castle where we had live candles. A fire watch was conducted for these scenes. During the day on Friday, I hung two tabs and moved all the scenery behind the curtains to make the space essentially into a black box. This was done so we could use the erosion cloth to create a very textured outdoor look for the next several scenes. The outdoor scenes were mostly just shifting around the erosion cloth to make it look different in various areas. On Saturday, we took away the erosion cloth and hung the tent which would be our setting for the next three scenes that would lead us into our last week of filming. 
WEEK FOUR: March $29^{\text {th }}-$ April 1st

Once we were done filming in the tent, I was busy with three scene shifts. I had to drop one of the tabs and rig up a small erosion cloth batten to give the illusion of a tree (Figure 30). We then removed the tree to do a massive shift of every single scenery unit into the final look for the conclusion. The final look for the show was my favorite configurations because it used all the units, but it was done in a very dark and encroaching way that gave an excellent grounding to the final scenes of the play (Figure 31). After wrapping filming on

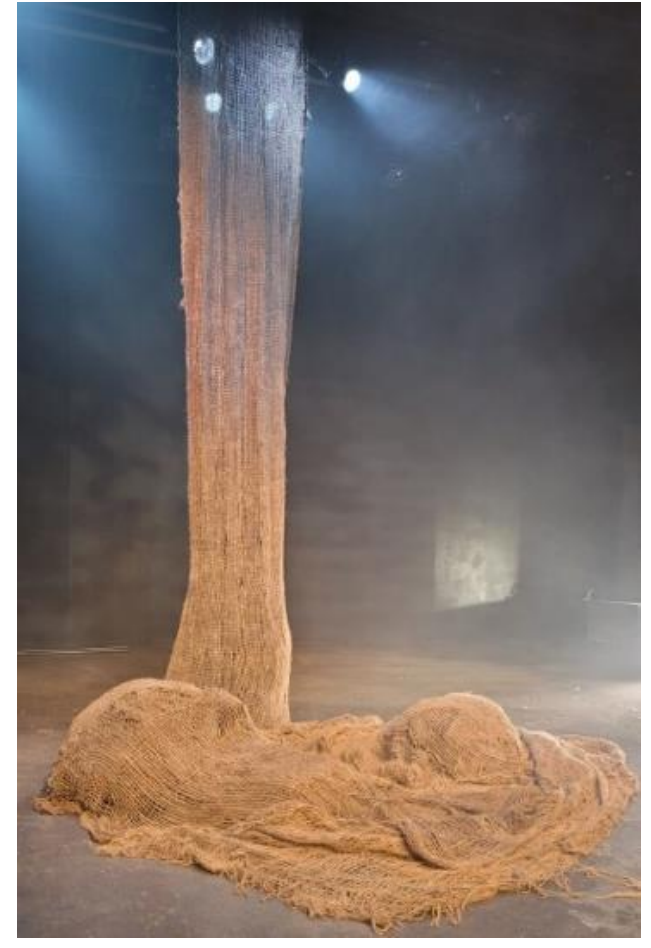

Figure 30: Act 5 Burlap Tree Thursday, I had a bittersweet sense of relief and sadness to being done with my final show.

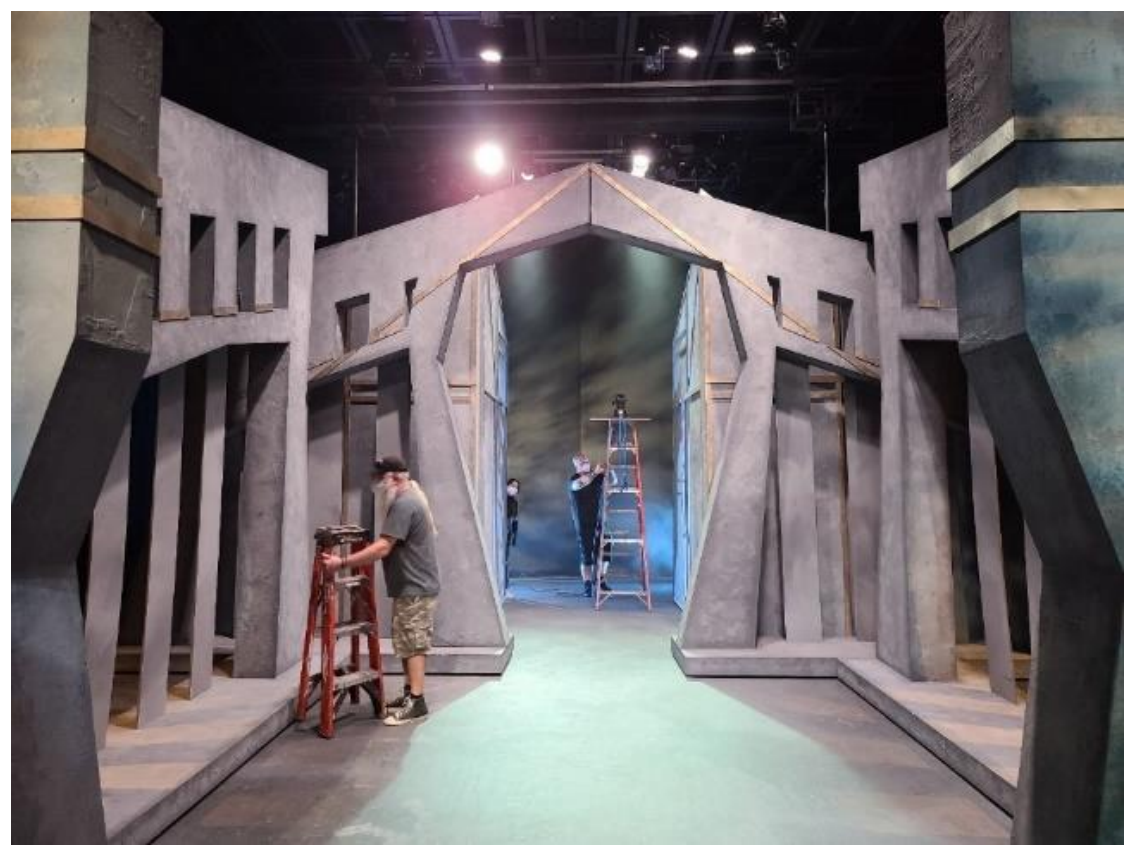

Figure 31: Act 5 Final Look 


\section{CHAPTER 6: STRIKE \& CLEAN UP}

$\underline{\text { Strike }}$

Strike was scheduled for Monday April $5^{\text {th }}$ during lab hours. I set about scheduling strike by looking at what we needed to strike and estimating about how much time and people it will take to do it. I did two versions of the strike schedule.

After talking with Professor Neuenschwander and Mr. Utley about what they would like to keep for the shop it was determined that most of the set would be trash. I set a goal for the shop to have at least all of the arches and pillars down and thrown away by end of day. I also wanted to have the walls stripped down to their frames by the end of day on Monday. My strike list was laid out in excel and has a column for who oversees the project, how many crew are needed, the process, and a time estimate. The document also includes a small section for what I wanted saved. Ultimately the goal is to get the set down as quickly and safely as possible. When planning strike, I tended to overestimate how much we could get done overall while underestimating how much time it will take to do individual projects. After talking with Professor Neuenschwander and taking another hard look at it I realized this was over ambitious and revised it to what I had wanted to achieve goal wise. See Appendix F for full strike plan.

Taking away what I learned from load in and some guidance from Professor Neuenschwander, I think strike went a lot better than load in. I felt a lot more confident in giving instruction and feeling a lot more in control of the room. My strike plan did not go completely according to plan, and I was way off in my time estimates, but I took that as a learning opportunity to really look and pay attention to how long it takes to do something. 
Overall, I was happy that I at least hit my goal for Monday and did not have too much left to complete on Tuesday. 


\section{CHAPTER 7: SELF EVALUATION}

\section{WHAT I WOULD KEEP AND WHAT WOULD I CHANGE}

With this being my first time out of the gate on my own as a TD there are some decisions that worked well and some that I would go back and change if I were to do this again.

A decision that worked out well for me was deciding to build the arches out of lumber rather than steel. Due to the organic nature of these units, steel would have made it twice as heavy and harder to operate smoothly. I will admit to way over complicating the build, but once we figured out how to simplify it down, it went rather smoothly. There are a couple things I would change on the units. I would put pneumatic brakes on the units instead of wedging them. This would have made it easier for operation and offer more discrete braking. Another thing I would have changed is how the slats got put on the units. I may have tried discrete hooks on the underside of the arch so they were more inset, or I would have had the bolts that stuck out slightly on the back that could have just hooked onto.

I am super proud of how the rain machine turned out and looked on camera. There is not much that I would change about it. The only thing that I would consider changing is how I rigged it to the underside of the grid. Instead of using rope to level it I would build arms into the machine itself that rigged to the underside of the grid. This way the machine would be more rigid and would be set at a certain angle that would guarantee consistency in the look and pressure of the rain.

For the wall units I would keep the construction itself the same, but I would investigate a different way for attaching the pipe to the trollies and the units. While the plan we used 
worked there was no flexibility in it which ended up hurting us more than helping due to the unevenness of the stage floor and miscalculations of pipe lengths. I think that if I had run the pipe the whole way to the bottom of the wall frames it would have made it easier for us to raise and lower the pipe. Also, I would have added in braking on the rotating walls.

\section{WHAT I LEARNED}

I am a firm believer in trying to learn something new every day and that everybody has something to teach us, and this show and production did not disappoint. Every step of the process brought new challenges, mistakes, and growth throughout.

Budgeting is something I am still working on getting right. I am a very tactile and visual person and numbers are just not my thing. This makes budgeting hard for me. I have found ways to try and double and triple check myself to make sure there is nothing that I have missed or that I have not written something down incorrectly. The big thing I learned here is to triple check your prices on items because prices do change. I thought I had accurate numbers and did not think that prices had drastically changed due to the pandemic which created my budget over-run. On all my future shows and endeavors, I will be calling all vendors and get their most up to date pricing before submitting a budget and keeping a closer eye on receipts to make sure the numbers are matching up.

Scheduling is a numbers game as much as it is a psychological game. What I mean by this is knowing in theory how long it should take someone to build something is not the same as reality. We are human and we have good days and bad days. Taking all that into account 
when scheduling can be a challenge. Several times there were places where I either overestimated our time or underestimated it and this resulted in us feeling rushed and stressed near the end of the build. I have learned more about how much time it takes to do something and about getting better estimates on how long it will take to do.

I need be confident in the room even if I do not feel it. This was something I struggle with professionally and personally. I know that I am still very green at being a TD and that there is still much to learn, but I need to have confidence and not second guess myself. I did find throughout the process, people walked and talked over me because I would easily get flustered and second guess myself when asked building questions. This ended up causing me more frustration and shook my confidence more than it should have. I still have a long way to go but I do feel that near the end of the process I was starting to be a lot more vocal and authoritative in the room.

I learned you do not have to take the advice of everybody in the room with you. This became more apparent with build and load in and ties back into my confidence issue. I learned as a TD you are going to have a lot of people yelling at you to deliver on things, build things a certain way, and do things a certain way and it can get overwhelming. As the TD you are the main person for a lot of communication which means keeping the bigger picture in mind when talking with everybody and you decide what is best. This means sometimes justifying your decisions and standing by them or acknowledging when someone has a good idea and take that into account.

I need to take my time. People can and will rush you, but you are responsible for the health and safety of everybody under you and if you need a minute to make sure everything is 
okay, you take it. There will always need to be a sense of urgency when building a show, but it does not need to be a stressful hurry. Do it right the first time even if it is not as fast as people want it to be.

Filming is not for me. I found throughout the filming process that I missed the excitement and energy of doing a live performance. One of the main reasons I decided to go into theatre was because I liked that you can never see or do the same show twice. The repetition and stop and go of the film world is just not for me.

\section{CONCLUSIONS}

From Budgeting to Strike this show has been a rollercoaster. Like with any creative endeavor there is always room to improve and grow and I have learned and grown a lot from this experience. I learned how to research, test, and build a working water effect. I learned many ways not to build an organic flat. I learned the proper procedure for fire effects along with how to build one. I learned the importance of double-checking numbers even if you feel confident with them. I am happy and proud of all the work that my team did, and I feel like we delivered on a good "sand box" set with two live effects. I will carry this experience and its lessons with me into the future and keep on growing. 


\section{WORK CITED}

DIY Reid, director. \$25 DIY Sprinkler Sled. YouTube, YouTube, 19 Aug. 2018, www.youtube.com/watch?v=axS3eIfTpoA.

Renée, V, director. Learn How to Build a Good DIY Rain Machine for $\$ 15$ (\& a Great One for $\$ 60)$. No Film School, No Film School, 9 Jan. 2015, nofilmschool.com/2015/01/how-buildgood-diy-rain-machine-15-great-one-60.

\section{PHOTO CREDIT}

Abigail Wagner for Figures 1-5 and Appendix E

Brian Presinger for Figures 30 \& 31

All photos not credited are property of the author. 
APPENDIX A: PRODUCTION ESTIMATE

\begin{tabular}{|c|c|c|c|c|}
\hline \multirow{3}{*}{$\begin{array}{c}\text { West Virginia University } \\
\text { College of Creative Arts } \\
\text { School of Theatre \& Dance }\end{array}$} & & \multicolumn{3}{|c|}{ PRODUCTION ESTIMATE } \\
\hline & & \multirow{2}{*}{\begin{tabular}{|l} 
PRODUCTION \\
PREPARED BY:
\end{tabular}} & \multicolumn{2}{|c|}{ King Lear } \\
\hline & & & $\overline{\mathrm{ANH}}$ & $23-\mathrm{Sep}$ \\
\hline \multicolumn{5}{|l|}{ DEPARTMENT: Scenic } \\
\hline \multirow[b]{2}{*}{ ELEMENT } & \multirow{2}{*}{\multicolumn{2}{|c|}{ COST ESTIMATE }} & \multicolumn{2}{|c|}{ TIME ESTIMATE } \\
\hline & & & CONSTRUCTION & LOAD-IN \\
\hline Tent & $\$$ & 34.50 & 11 & $\overline{2}$ \\
\hline Catch Platform & $\$$ & 460.50 & 28 & 4 \\
\hline Rain Effect & $\$$ & 650.65 & 36 & 4 \\
\hline Platforms D 1 \& 2 & $\$$ & 449.00 & 51 & 1 \\
\hline Platforms E $1 \& 2$ & $\$$ & 360.00 & 51 & 1 \\
\hline Pillars F 1\&2 & $\$$ & 172.00 & 37 & 1 \\
\hline$\overline{\text { Tracking Walls A } 1 \& 2}$ & $\$$ & 406.00 & 55 & 5 \\
\hline Tracking - Rotating Walls C $1 \& 2$ & $\$$ & 544.60 & 71 & 5 \\
\hline Paint & $\$$ & 200.00 & $\frac{1}{1}$ & $\frac{1}{1}$ \\
\hline Burlap & $\$$ & 247.00 & 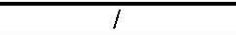 & $\frac{T}{1}$ \\
\hline Erosion Cloth & $\$$ & 220.00 & $\frac{1}{1}$ & 7 \\
\hline "Coffee" Can Fires & $\$$ & 63.00 & I & 1 \\
\hline & & & & \\
\hline & & & & \\
\hline & & & & \\
\hline & & & & \\
\hline & & & & \\
\hline & & & & \\
\hline & & & & \\
\hline & & & & \\
\hline & & & & \\
\hline & & & & \\
\hline & & & & \\
\hline & & & & \\
\hline & & & & \\
\hline & & & & \\
\hline & & & & \\
\hline & & & & \\
\hline & & & & \\
\hline & & & & \\
\hline & & & & \\
\hline & & & & \\
\hline & & & & \\
\hline & & & & \\
\hline & & & & \\
\hline & & & & \\
\hline & & & & \\
\hline & & & & \\
\hline SUB TOTAL & $\$$ & 3807.25 & 340 & 23 \\
\hline $5 \%$ Hardware & $\frac{\phi}{\$}$ & 190.36 & $\frac{340}{---}$ & \\
\hline SUB TOTAL & $\$$ & $3,997.61$ & -- & \\
\hline $10 \%$ Contingency & $\$$ & 399.76 & 34 & 2.3 \\
\hline TOTAL & $\$$ & $4,397.37$ & 374 & 25.3 \\
\hline
\end{tabular}




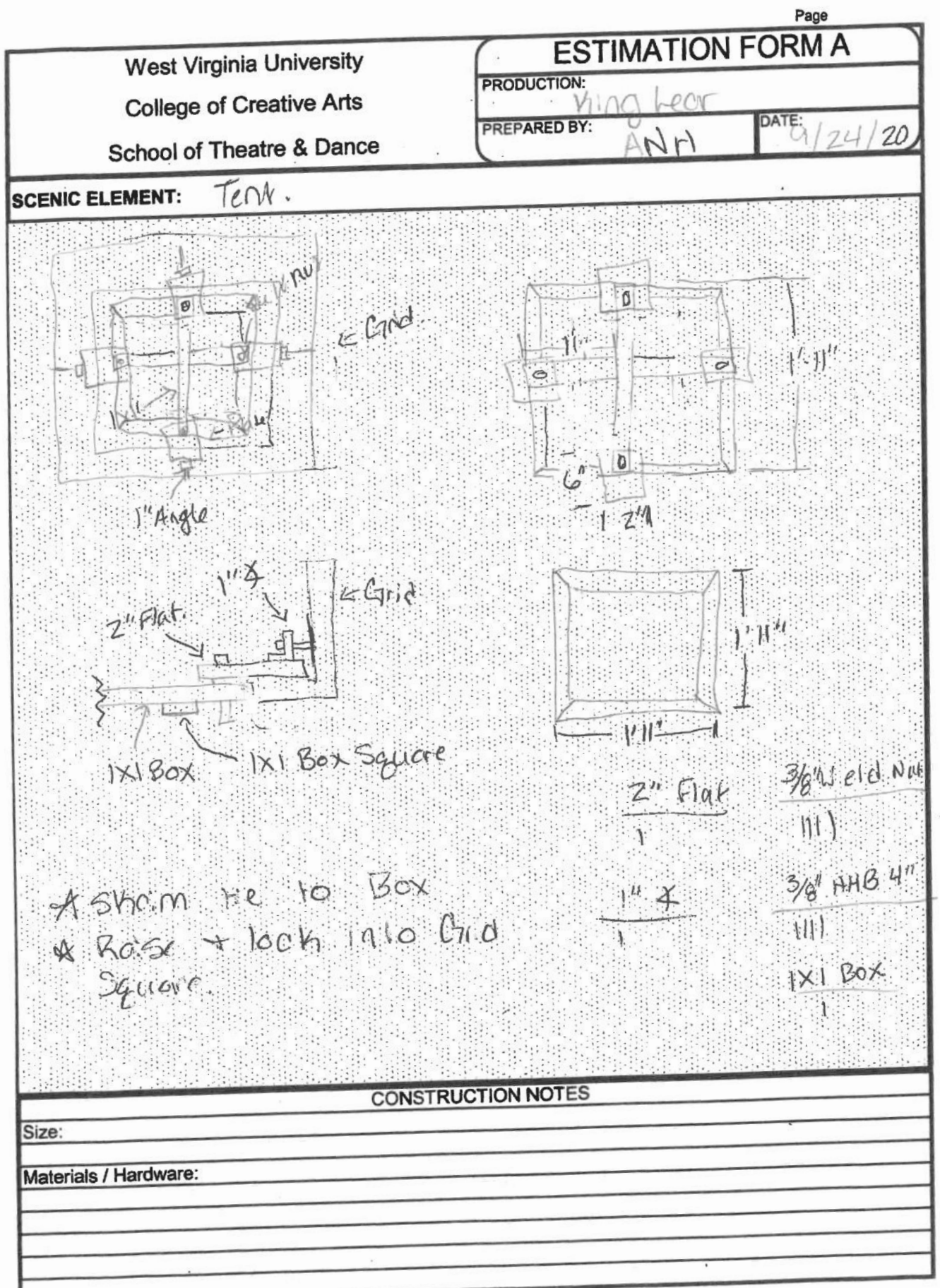




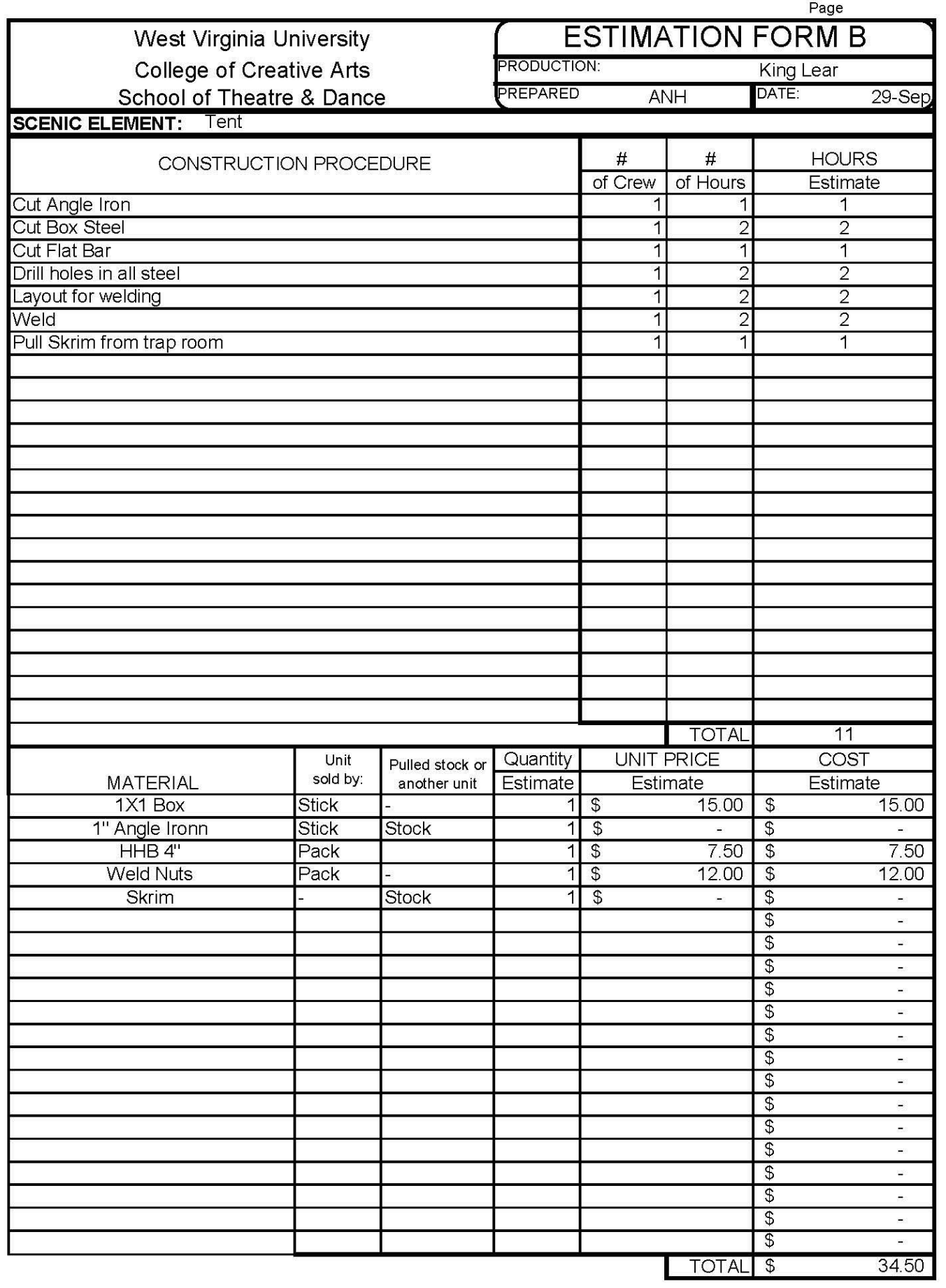




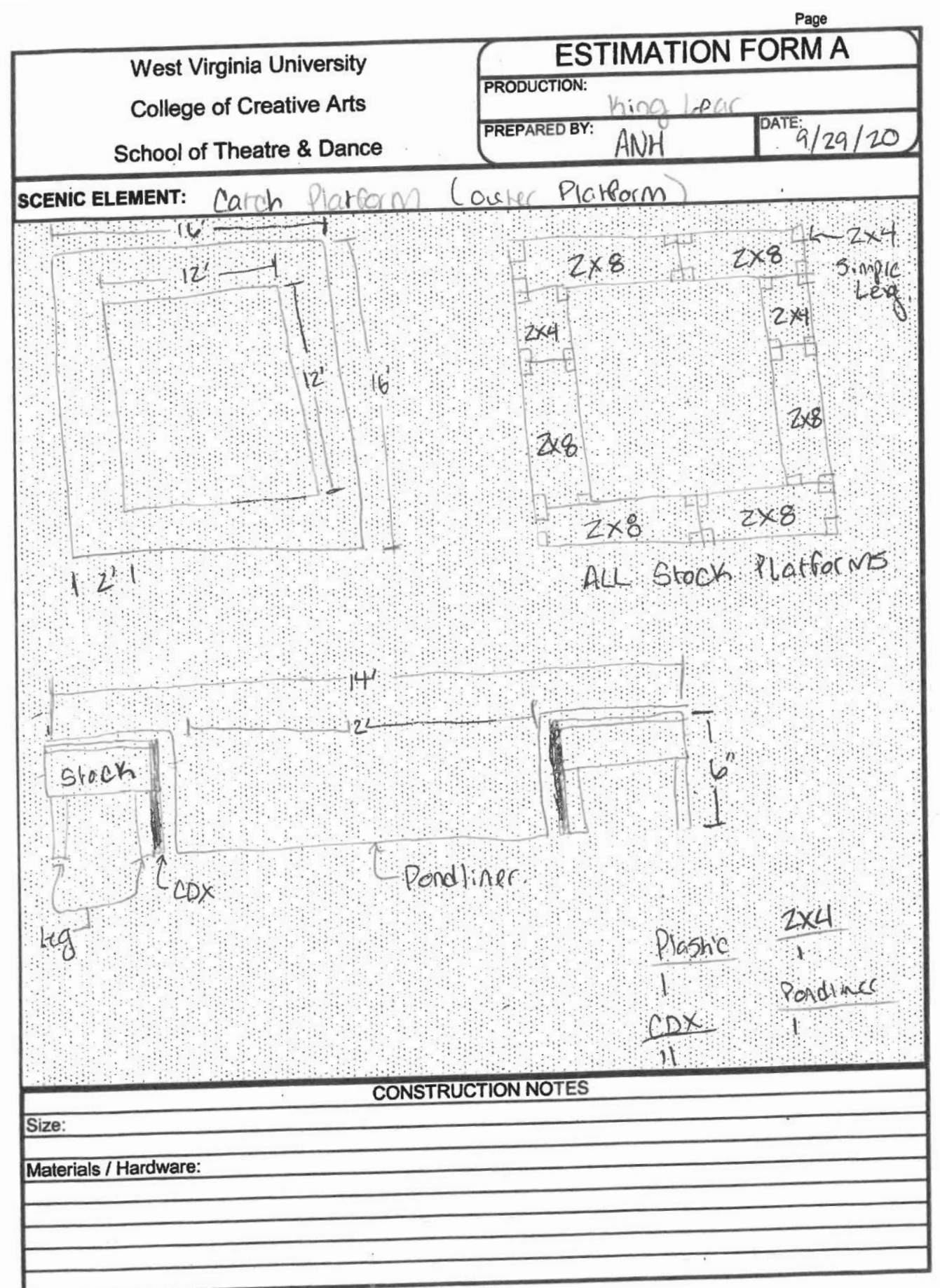




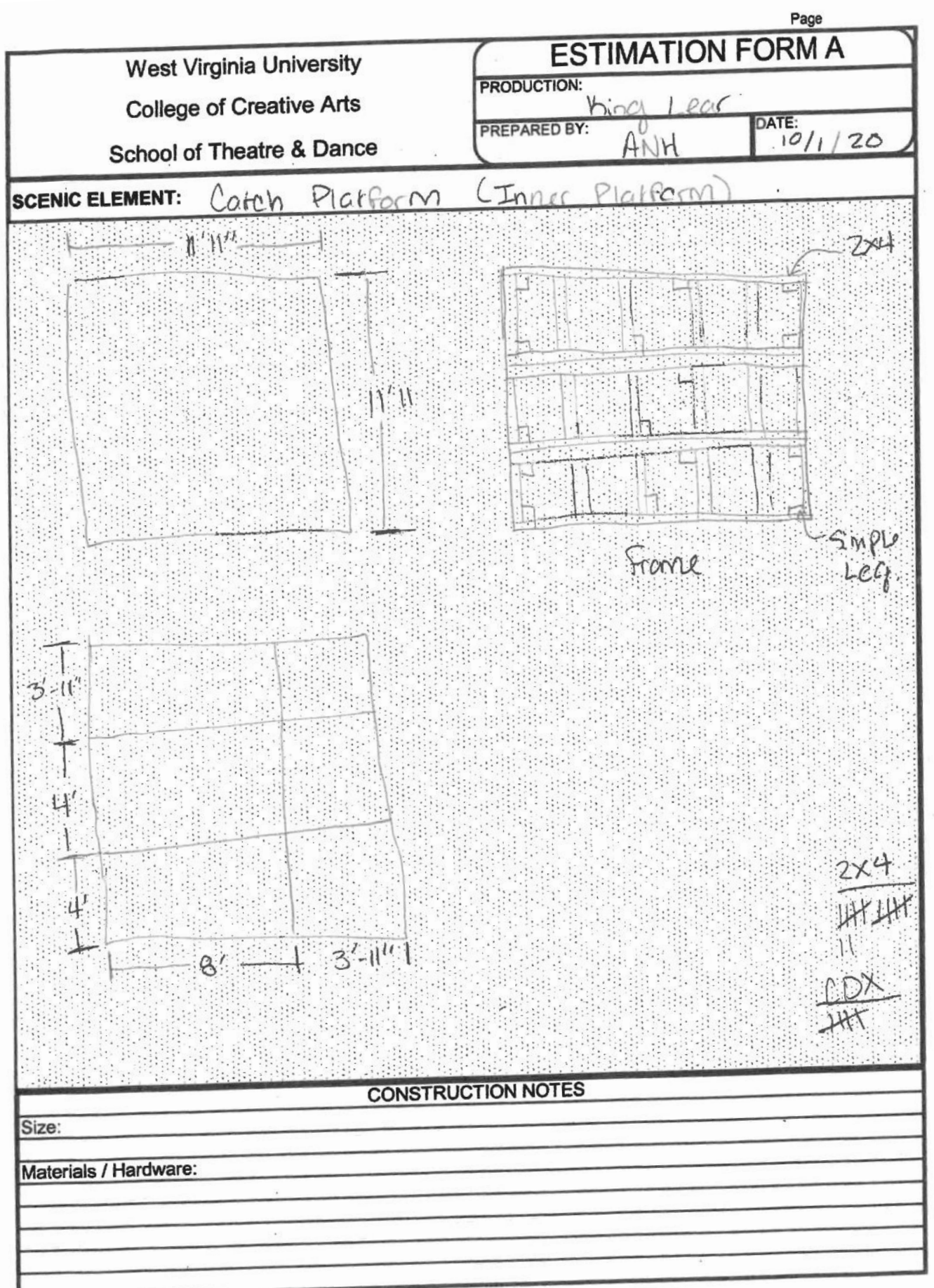




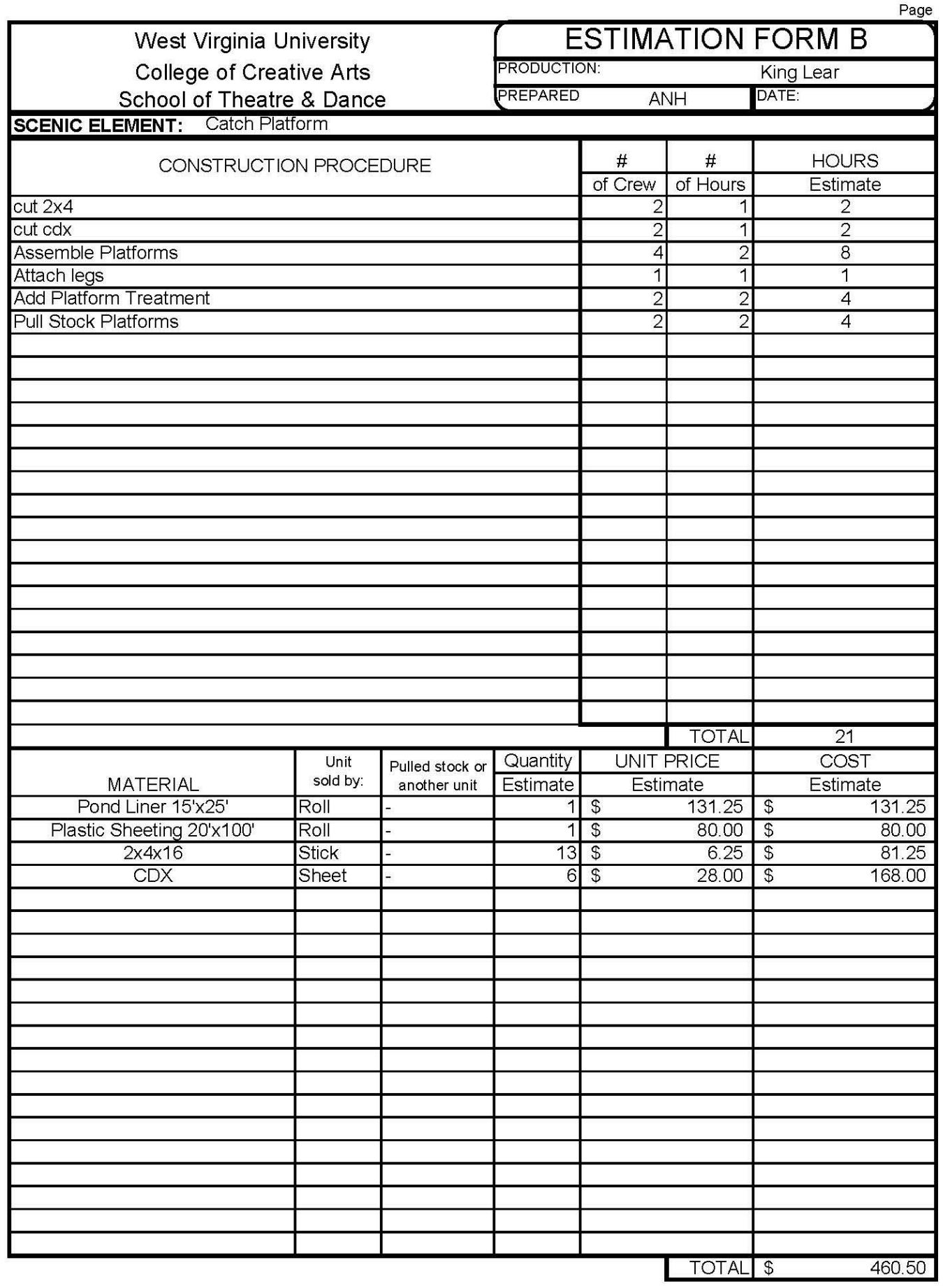




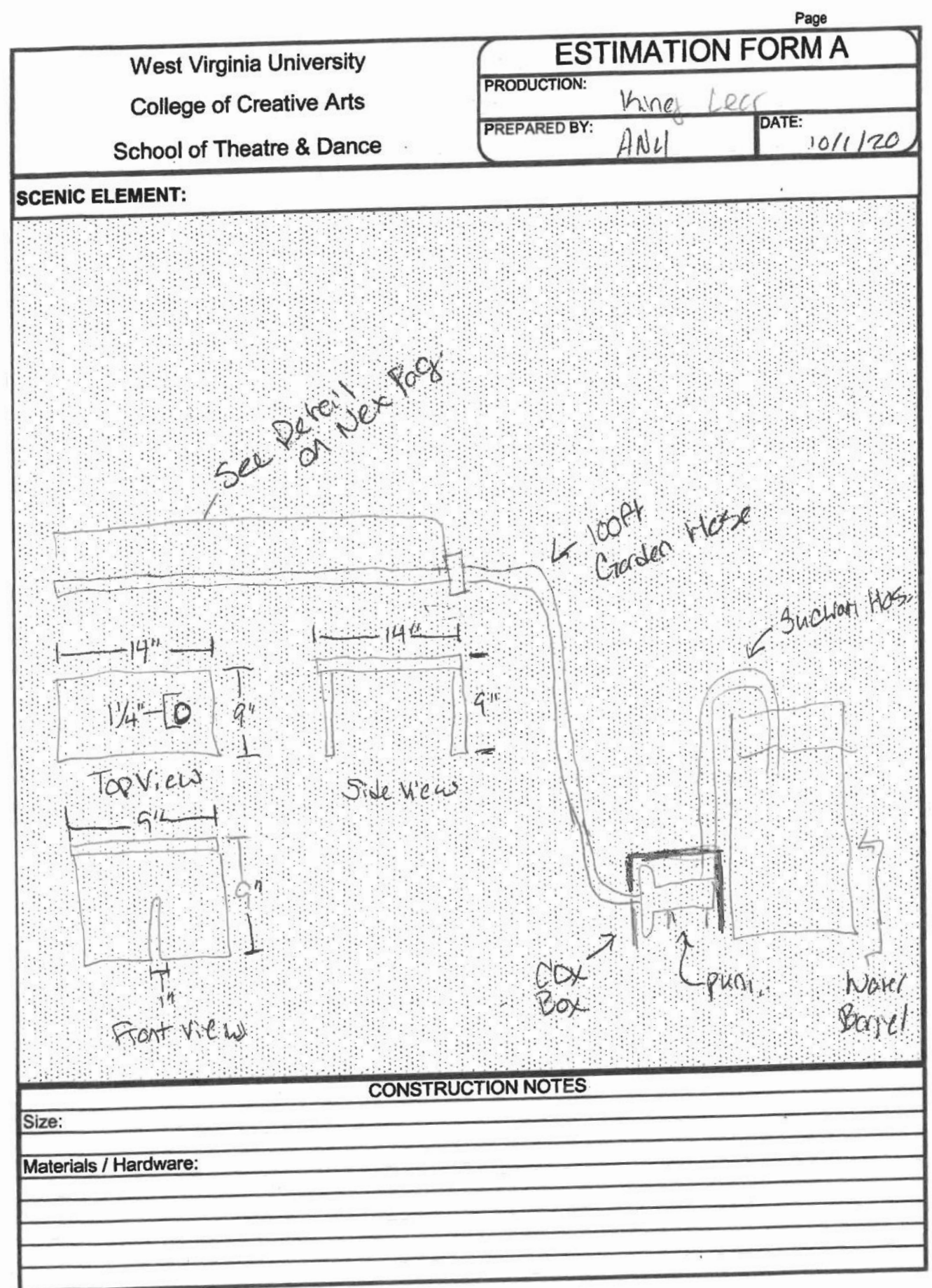




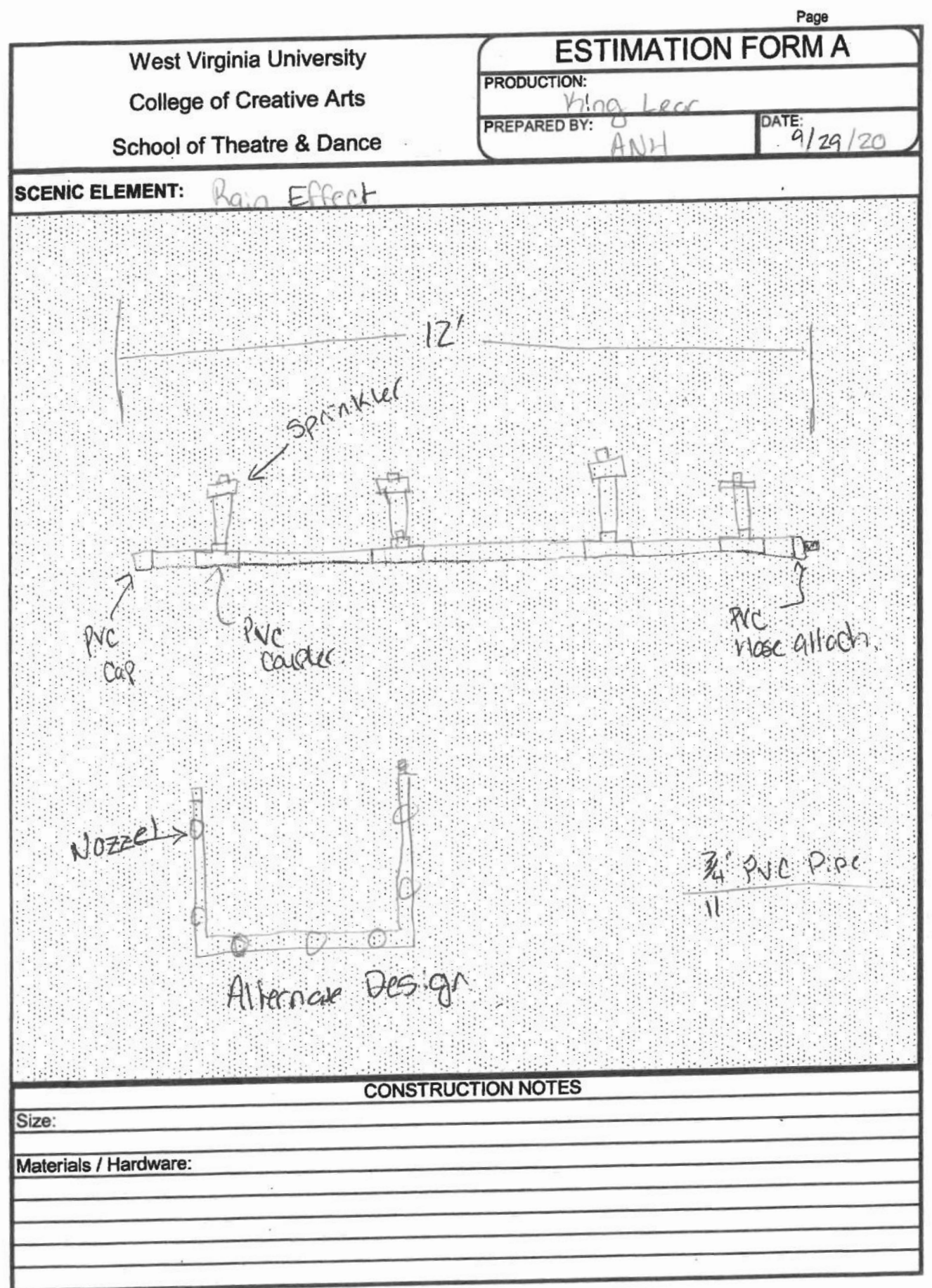




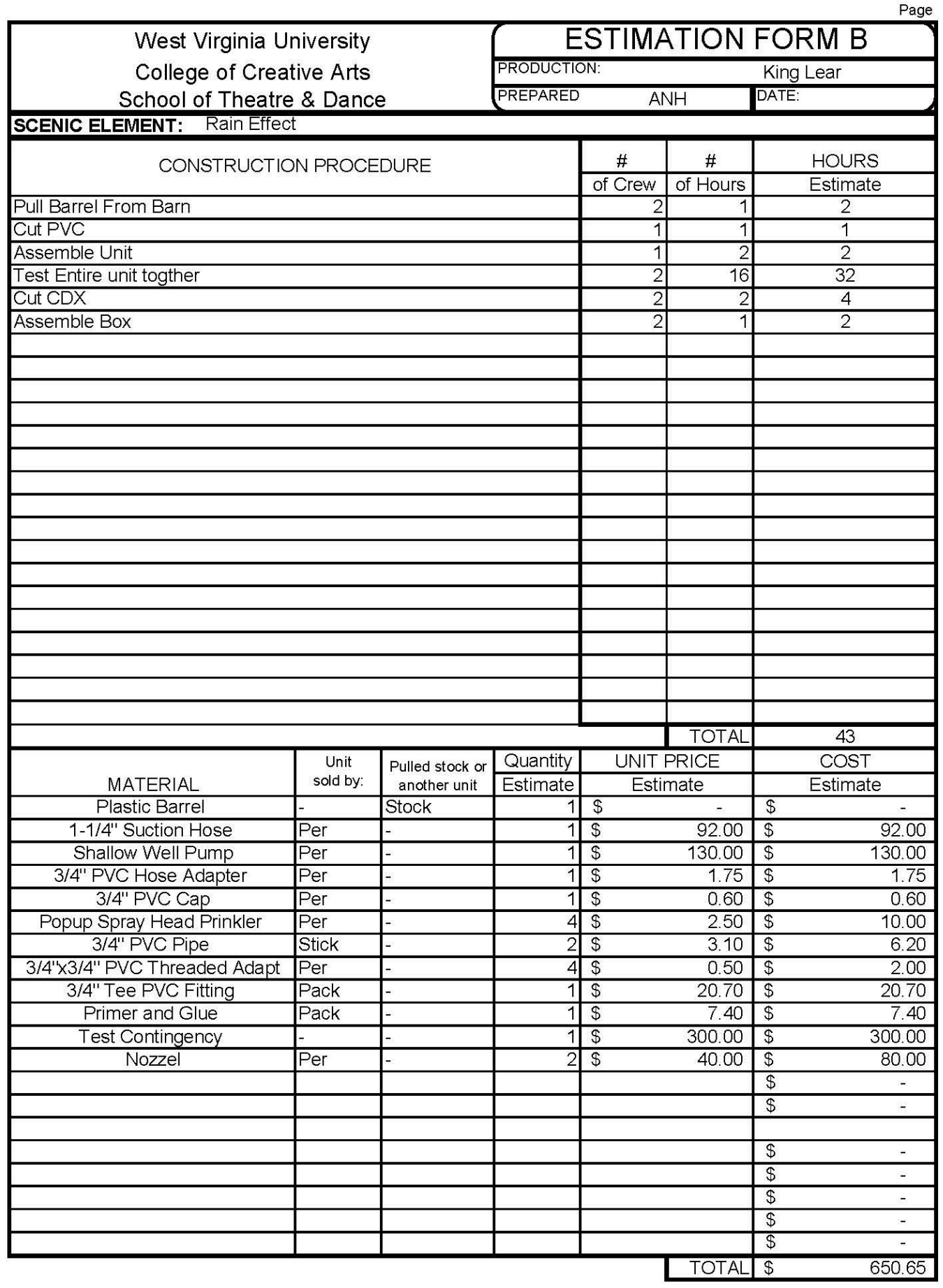




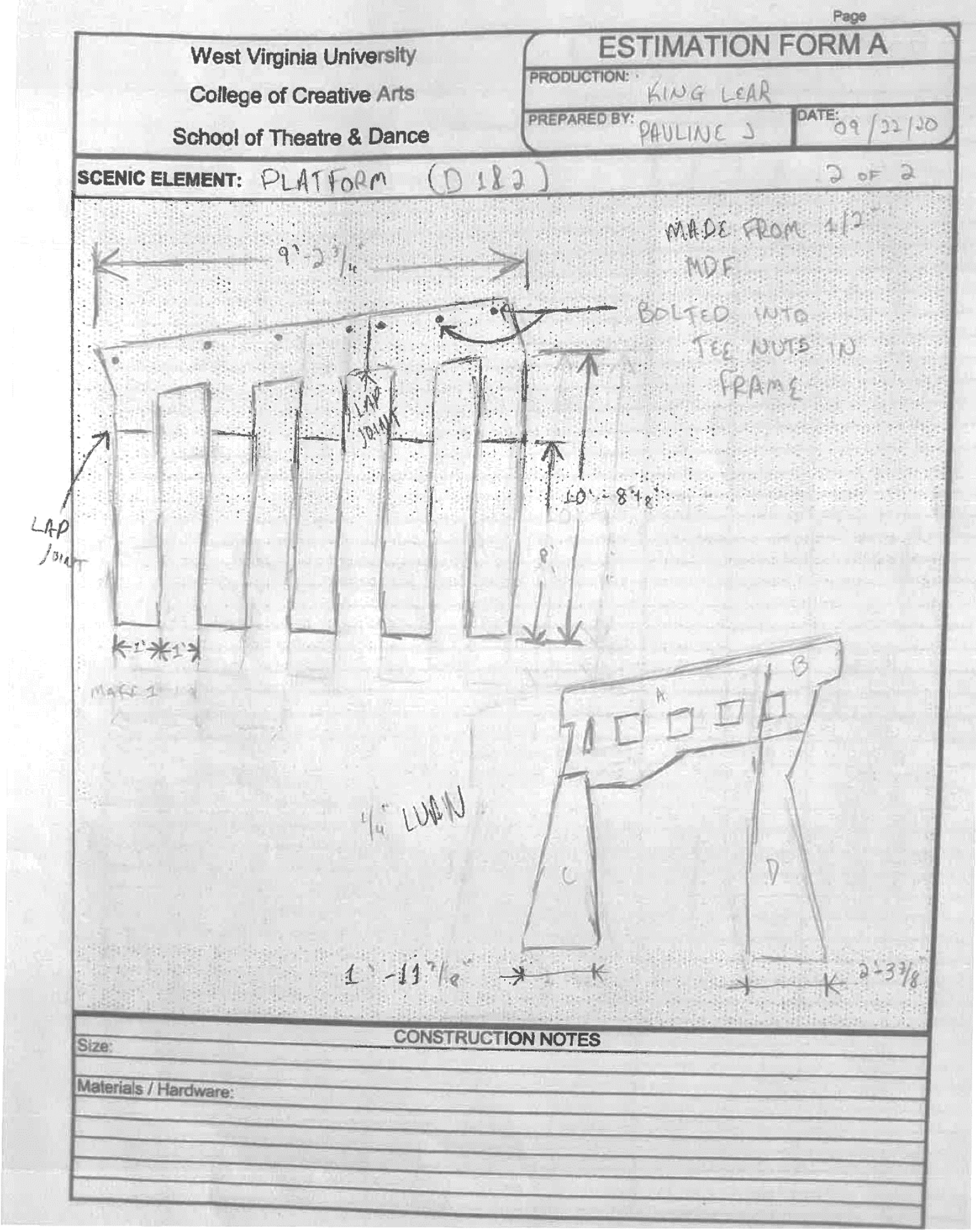


Page

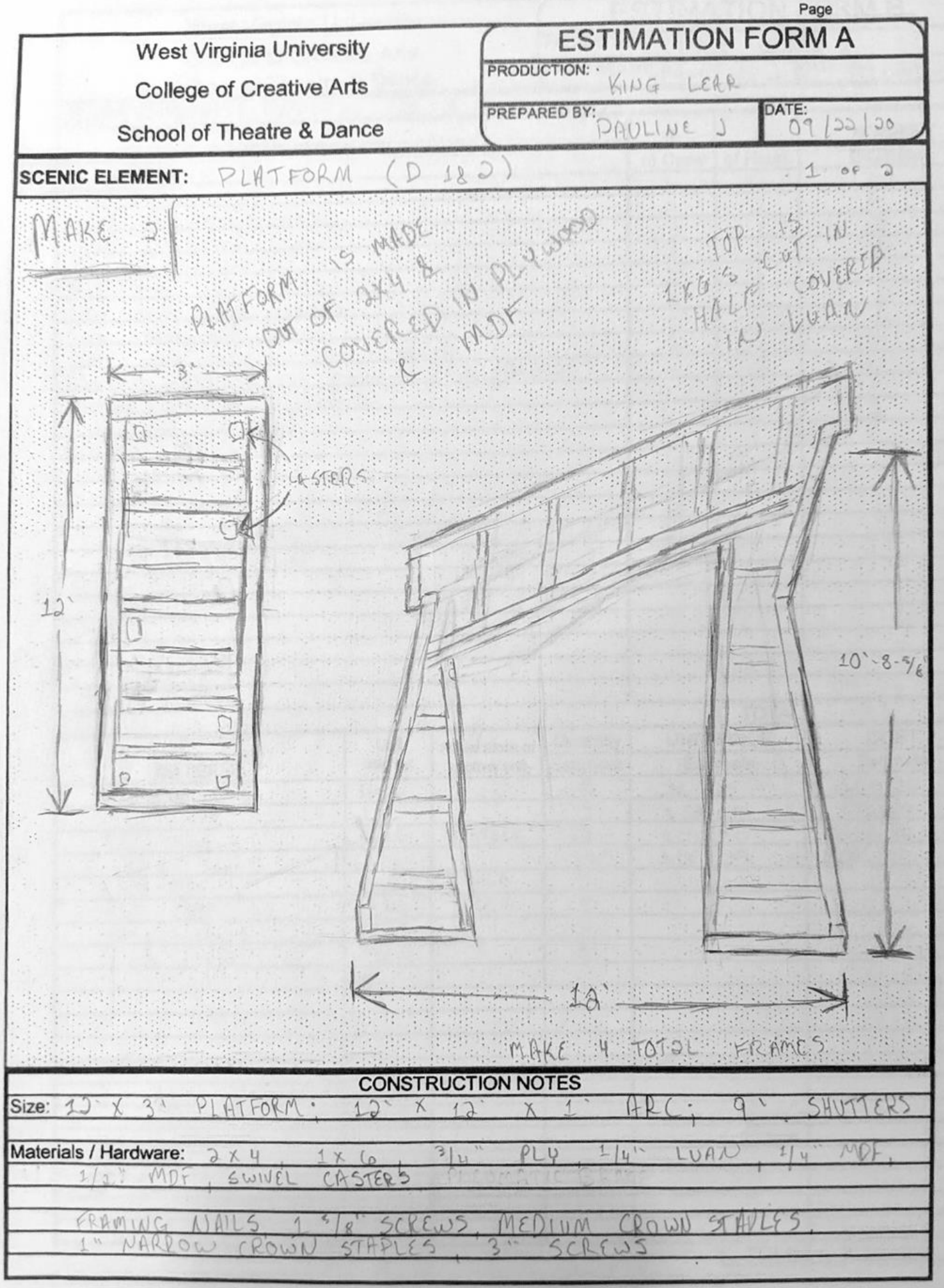




\begin{tabular}{|c|c|c|c|c|c|c|}
\hline \multirow{3}{*}{\multicolumn{3}{|c|}{$\begin{array}{l}\text { West Virginia University } \\
\text { College of Creative Arts } \\
\text { School of Theatre \& Dance }\end{array}$}} & \multicolumn{4}{|c|}{ ESTIMATION FORM B } \\
\hline & & & \multicolumn{3}{|c|}{ PRODUCTION: } & King Lear \\
\hline & & & PREPARED & \multicolumn{2}{|c|}{ Pauline Johnson } & DATE: \\
\hline \multicolumn{7}{|c|}{ SCENIC ELEMENT: Platforms D 1 \& 2} \\
\hline \multirow{2}{*}{\multicolumn{3}{|c|}{ CONSTRUCTION PROCEDURE }} & & $\#$ & $\#$ & HOURS \\
\hline & & & & of Crew & of Hours & Estimate \\
\hline \multicolumn{4}{|l|}{ Cut $2 \times 4$} & 1 & 1 & 1 \\
\hline \multicolumn{4}{|l|}{ Assemble Platform Frames } & 2 & 4 & 8 \\
\hline \multicolumn{4}{|l|}{ Cut Plywood } & 2 & 1 & \multirow{2}{*}{$\frac{2}{4}$} \\
\hline \multicolumn{4}{|l|}{ Attach Plywood } & 2 & 2 & \\
\hline \multicolumn{4}{|l|}{ Rip and Cut $1 x$} & 2 & 3 & 6 \\
\hline \multicolumn{4}{|l|}{ Assemble Frames } & 2 & 3 & 6 \\
\hline Cut Lauan & & & & 2 & 3 & 6 \\
\hline Attach Castors & & & & 2 & 3 & 6 \\
\hline Attach Arcs to platfroms & & & & 4 & 2 & 8 \\
\hline Cut MDF & & & & 2 & 1 & 2 \\
\hline Attach MDF & & & & 2 & 1 & 2 \\
\hline & & & & - & & \\
\hline & & & & & & \\
\hline & & & & & & \\
\hline & & & & & & \\
\hline & & & & & & \\
\hline & & & & & & \\
\hline & & & & & & \\
\hline & & & & & & \\
\hline & & & & & & \\
\hline & & & & & & \\
\hline & & & & & TOTAL & 51 \\
\hline & Unit & & Quantity & UNIT F & PRICE & COST \\
\hline MATERIAL & sold by: & another unit & Estimate & Estir & mate & Estimate \\
\hline $2 \times 4 \times 16$ & Stick & & 8 & $\$$ & 6.25 & 50.00 \\
\hline CDX & Sheet & & 3 & $\$$ & 28.00 & 84.00 \\
\hline 1/4" Lauan & Sheet & 5 Stock & 9 & $\$$ & 16.00 & 144.00 \\
\hline $1 \times 6 \times 16$ & Stick & & 12 & $\$$ & 14.25 & 171.00 \\
\hline $1 / 4^{\prime \prime} \mathrm{MDF}$ & Sheet & Stock & 5 & $\$$ & - & $\$$ \\
\hline $1 / 2^{\prime \prime} \mathrm{MDF}$ & Sheet & Stock & 3 & $\$$ & - & $\$$ \\
\hline Swivel Castors & Jer & Stock & 16 & $\$$ & - & $\$$ \\
\hline & & & & & & $\$$ \\
\hline & & & & & & $\$$ \\
\hline & & & & & & $\$$ \\
\hline & & & & & & $\$$ \\
\hline & & & & & & $\$$ \\
\hline & & & & & & $\$$ \\
\hline & & & & & & $\$$ \\
\hline & & & & & & $\$$ \\
\hline & & & & & & $\$$ \\
\hline & & & & & & $\$$ \\
\hline & & & & & & $\$$ \\
\hline & & & & & & $\$$ \\
\hline & & & & & TOTAL & 449.00 \\
\hline
\end{tabular}




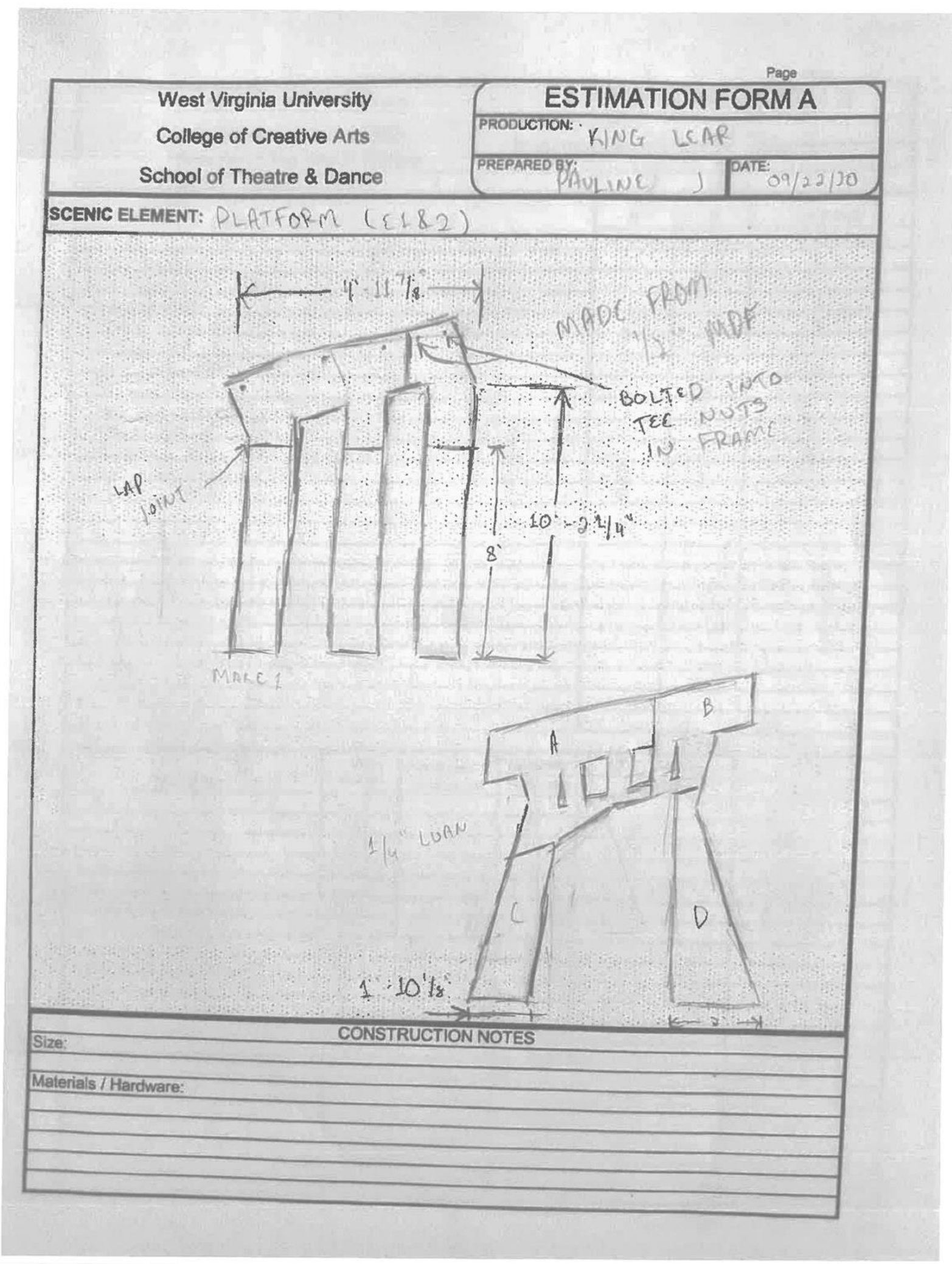




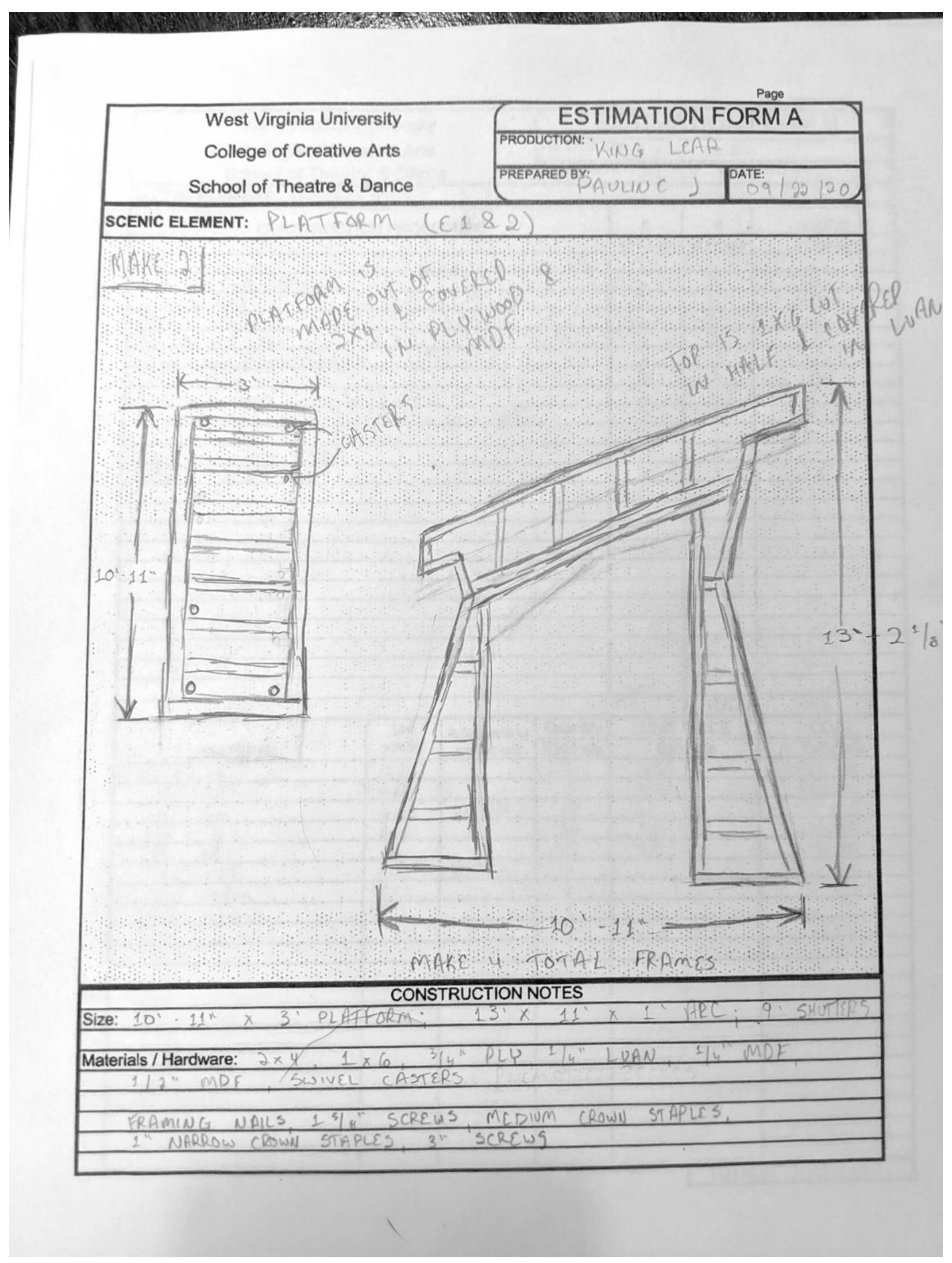




\begin{tabular}{|c|c|c|c|c|c|c|c|}
\hline \multirow{3}{*}{\multicolumn{3}{|c|}{$\begin{array}{c}\text { West Virginia University } \\
\text { College of Creative Arts } \\
\text { School of Theatre \& Dance }\end{array}$}} & \multicolumn{5}{|c|}{ ESTIMATION FORM B } \\
\hline & & & \multicolumn{3}{|c|}{ PRODUCTION: } & \multicolumn{2}{|c|}{ King Lear } \\
\hline & & & \multirow[t]{2}{*}{ PREPARED } & \multicolumn{2}{|c|}{ Pauline Johnson } & \multicolumn{2}{|c|}{ DATE: } \\
\hline \multicolumn{7}{|c|}{ SCENIC ELEMENT: Platforms E 1 \& 2} & \\
\hline \multirow{2}{*}{\multicolumn{3}{|c|}{ CONSTRUCTION PROCEDURE }} & & \# & \# & \multicolumn{2}{|r|}{ HOURS } \\
\hline & & & & of Crew & \begin{tabular}{|l|} 
of Hours \\
\end{tabular} & \multicolumn{2}{|r|}{ Estimate } \\
\hline \multicolumn{4}{|l|}{ Cut $2 \times 4$} & 1 & 1 & \multicolumn{2}{|r|}{1} \\
\hline \multicolumn{4}{|l|}{ Assemble Platform Frames } & 2 & 4 & \multicolumn{2}{|r|}{8} \\
\hline \multicolumn{4}{|l|}{ Cut Plywood } & 2 & 1 & \multicolumn{2}{|r|}{2} \\
\hline \multicolumn{4}{|l|}{ Attach Plywood } & 2 & 2 & \multicolumn{2}{|r|}{4} \\
\hline \multicolumn{4}{|l|}{ Rip and Cut $1 x$} & 2 & 3 & & 6 \\
\hline Assemble Frames & & & & 2 & 3 & & 6 \\
\hline Cut Lauan & & & & 2 & 3 & & 6 \\
\hline Attach Castors & & & & 2 & 3 & & 6 \\
\hline Attach Arcs to platfroms & & & & 4 & 2 & & 8 \\
\hline Cut MDF & & & & 2 & 1 & & 2 \\
\hline Attach MDF & & & & $\overline{2}$ & 1 & & 2 \\
\hline & & & & & & & \\
\hline & & & & & & & \\
\hline & & & & & & & \\
\hline & & & & & & & \\
\hline & & & & & & & \\
\hline & & & & & & & \\
\hline & & & & & & & \\
\hline & & & & & & & \\
\hline & & & & & & & \\
\hline & & & & & & & 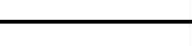 \\
\hline & & & & & TOTAL & & 51 \\
\hline & Unit & Pulled stock or & Quantity & UNITI & $\mathrm{PRICE}$ & & COST \\
\hline MATERIAL & sold by: & another unit & Estimate & Estir & nate & & Estimate \\
\hline $2 \times 4 \times 16$ & Stick & & 8 & $\$$ & 6.25 & $\$$ & 50.00 \\
\hline CDX & Sheet & & 3 & $\$$ & 28.00 & $\$$ & 84.00 \\
\hline 1/4" Lauan & Sheet & Stock & 14 & $\$$ & - & $\$$ & - \\
\hline $1 \times 6 \times 16$ & Stick & & 12 & $\$$ & 14.25 & $\$$ & 171.00 \\
\hline $1 / 4^{\prime \prime} \mathrm{MDF}$ & Sheet & & 5 & $\$$ & 11.00 & $\$$ & 55.00 \\
\hline $1 / 2^{\prime \prime} \mathrm{MDF}$ & Sheet & Stock & 2 & $\$$ & - & $\$$ & - \\
\hline Swivel Castors & Per & Stock & 16 & $\$$ & - & $\$$ & - \\
\hline & & & & & & $\$$ & - \\
\hline & & & & & & $\$$ & - \\
\hline & & & & & & $\$$ & - \\
\hline & & & & & & $\$$ & - \\
\hline & & & & & & $\$$ & - \\
\hline & & & & & & $\$$ & - \\
\hline & & & & & & $\$$ & - \\
\hline & & & & & & $\$$ & - \\
\hline & & & & & & $\$$ & - \\
\hline & & & & & & $\$$ & - \\
\hline & & & & & & $\$$ & - \\
\hline & & & & & & $\$$ & - \\
\hline & & & & & TOTAL & $\$$ & 360.00 \\
\hline
\end{tabular}




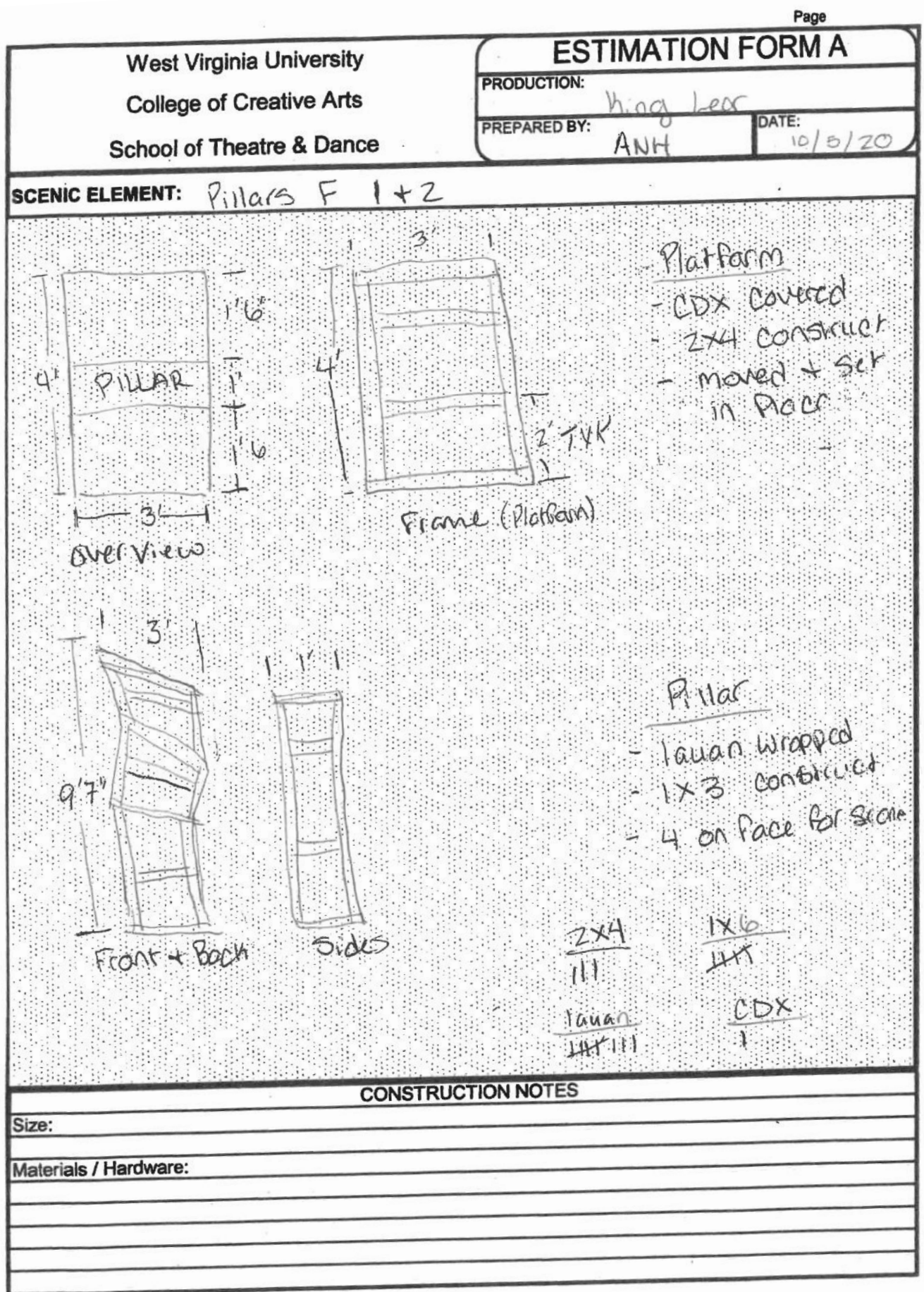




\begin{tabular}{|c|c|c|c|c|c|c|c|}
\hline \multirow{3}{*}{\multicolumn{3}{|c|}{$\begin{array}{c}\text { West Virginia University } \\
\text { College of Creative Arts } \\
\text { School of Theatre \& Dance }\end{array}$}} & \multicolumn{5}{|c|}{ ESTIMATION FORM B } \\
\hline & & & \multicolumn{3}{|c|}{ PRODUCTION: } & \multicolumn{2}{|c|}{ King Lear } \\
\hline & & & \multirow[t]{2}{*}{ PREPARED } & \multicolumn{2}{|c|}{ Pauline Johnson } & \multicolumn{2}{|c|}{ DATE: } \\
\hline \multicolumn{7}{|c|}{ SCENIC ELEMENT: Pillars F 1 \& 2} & \\
\hline \multirow{2}{*}{\multicolumn{3}{|c|}{ CONSTRUCTION PROCEDURE }} & & \# & $\#$ & \multicolumn{2}{|r|}{ HOURS } \\
\hline & & & & of Crew & of Hours & \multicolumn{2}{|r|}{ Estimate } \\
\hline \multicolumn{4}{|l|}{ Cut $2 \times 4$} & 1 & 1 & \multicolumn{2}{|r|}{1} \\
\hline \multicolumn{4}{|c|}{ Assemble Platform Frames } & $\overline{2}$ & $\overline{2}$ & \multicolumn{2}{|r|}{4} \\
\hline \multicolumn{4}{|l|}{ Cut Plywood } & 2 & 1 & \multicolumn{2}{|r|}{2} \\
\hline \multicolumn{4}{|l|}{ Attach Plywood } & 2 & 1 & \multicolumn{2}{|r|}{2} \\
\hline \multicolumn{4}{|l|}{ Cut $1 \mathrm{x}$} & 2 & 3 & & 6 \\
\hline Assemble Frames & & & & 2 & 3 & & 6 \\
\hline Cut Lauan & & & & 2 & 2 & & 4 \\
\hline Attach Lauan & & & & 2 & 2 & & 4 \\
\hline Attach Pillars to Platforr & & & & 2 & 2 & & 4 \\
\hline Cut MDF & & & & 2 & 1 & & 2 \\
\hline Staple MDF & & & & 2 & 1 & & 2 \\
\hline & & & & & & & \\
\hline & & & & & & & \\
\hline & & & & & & & \\
\hline & & & & & & & \\
\hline & & & & & & & \\
\hline & & & & & & & \\
\hline & & & & & & & \\
\hline & & & & & & & \\
\hline & & & & & & & \\
\hline & & & & & & & \\
\hline & & & & & TOTAL & & 37 \\
\hline & Unit & & Quantity & UNIT & PRICE & & COST \\
\hline MATERIAL & sold by: & another unit & Estimate & Esti & mate & & Estimate \\
\hline $2 \times 4 \times 16$ & Stick & & 3 & $\$$ & 6.25 & $\$$ & 18.75 \\
\hline CDX & Sheet & & 1 & $\$$ & 28.00 & $\$$ & 28.00 \\
\hline 1/4" Lauan & Sheet & Stock 6 & 2 & $\$$ & 16.00 & $\$$ & 32.00 \\
\hline $1 \times 6 \times 16$ & Stick & & 5 & $\$$ & 14.25 & $\$$ & 71.25 \\
\hline 1/4" MDF & Sheet & & 2 & $\$$ & 11.00 & $\$$ & 22.00 \\
\hline & & & & & & $\$$ & - \\
\hline & & & & & & $\$$ & - \\
\hline & & & & & & $\$$ & - \\
\hline & & & & & & $\$$ & - \\
\hline & & & & & & $\$$ & - \\
\hline & & & & & & $\$$ & - \\
\hline & & & & & & $\$$ & - \\
\hline & & & & & & $\$$ & - \\
\hline & & & & & & $\$$ & - \\
\hline & & & & & & $\$$ & - \\
\hline & & & & & & $\$$ & - \\
\hline & & & & & & $\$$ & - \\
\hline & & & & & & $\$$ & - \\
\hline & & & & & & $\$$ & - \\
\hline & & & & & TOTAL & $\$$ & 172.00 \\
\hline
\end{tabular}




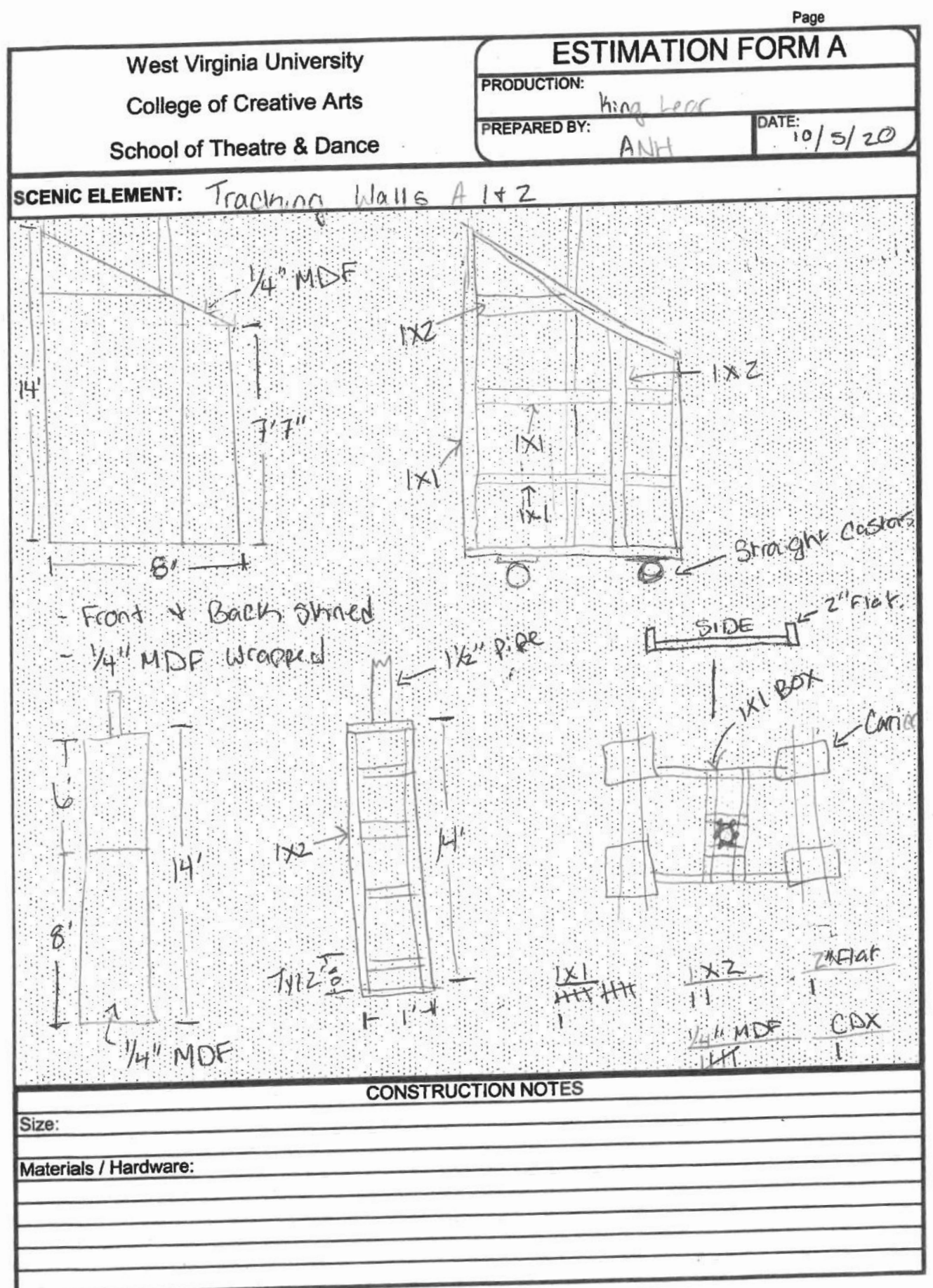




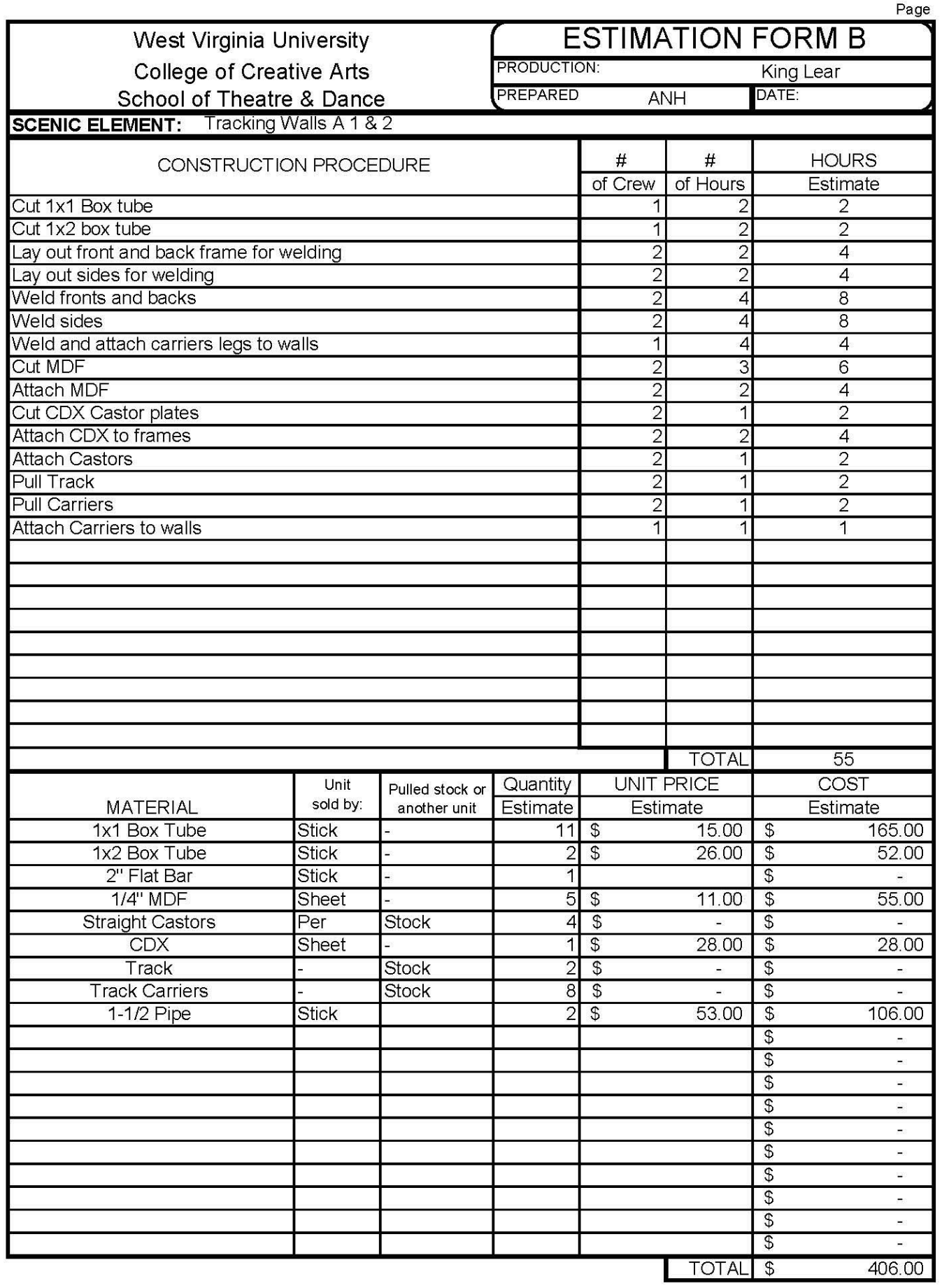




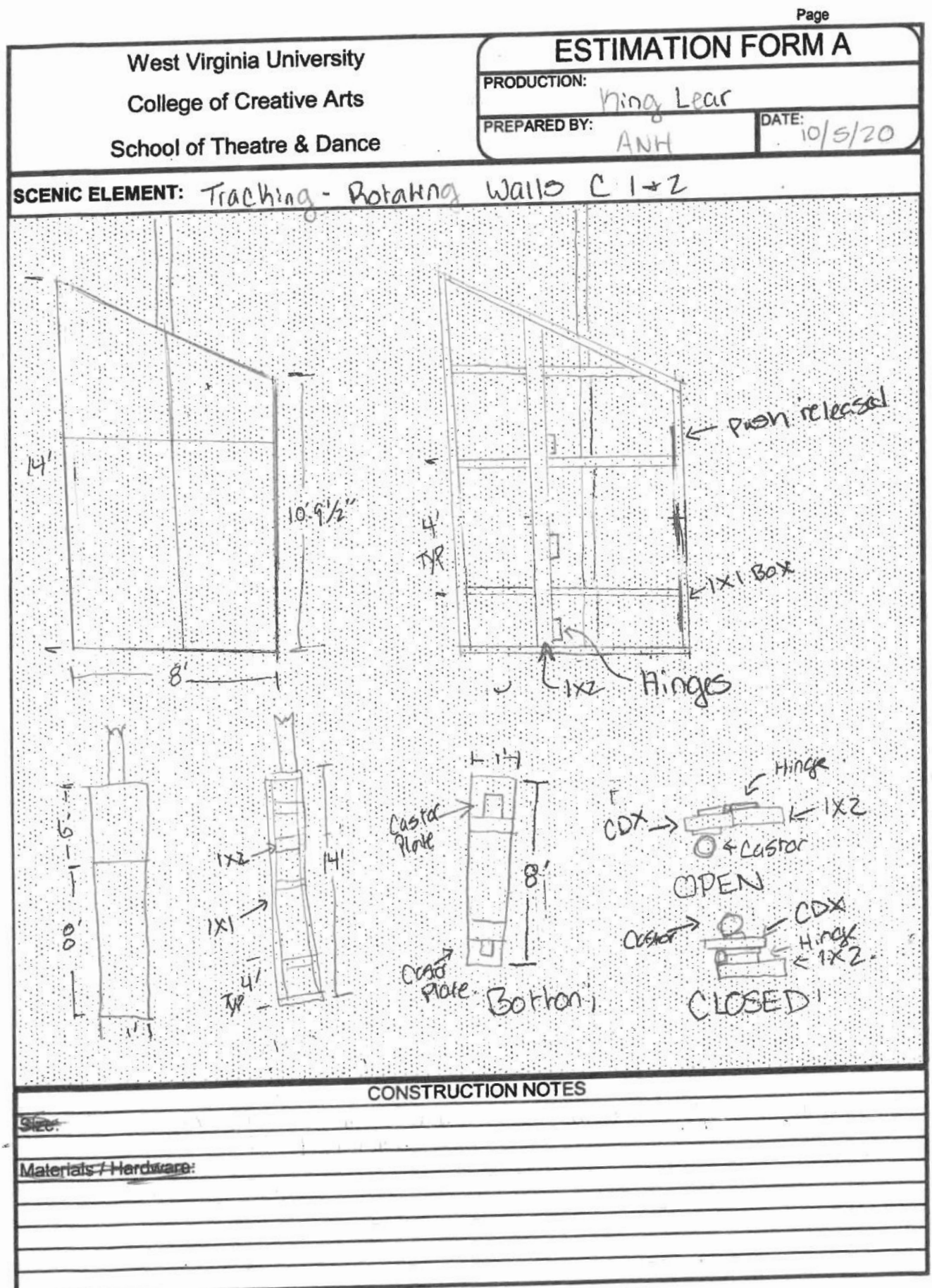




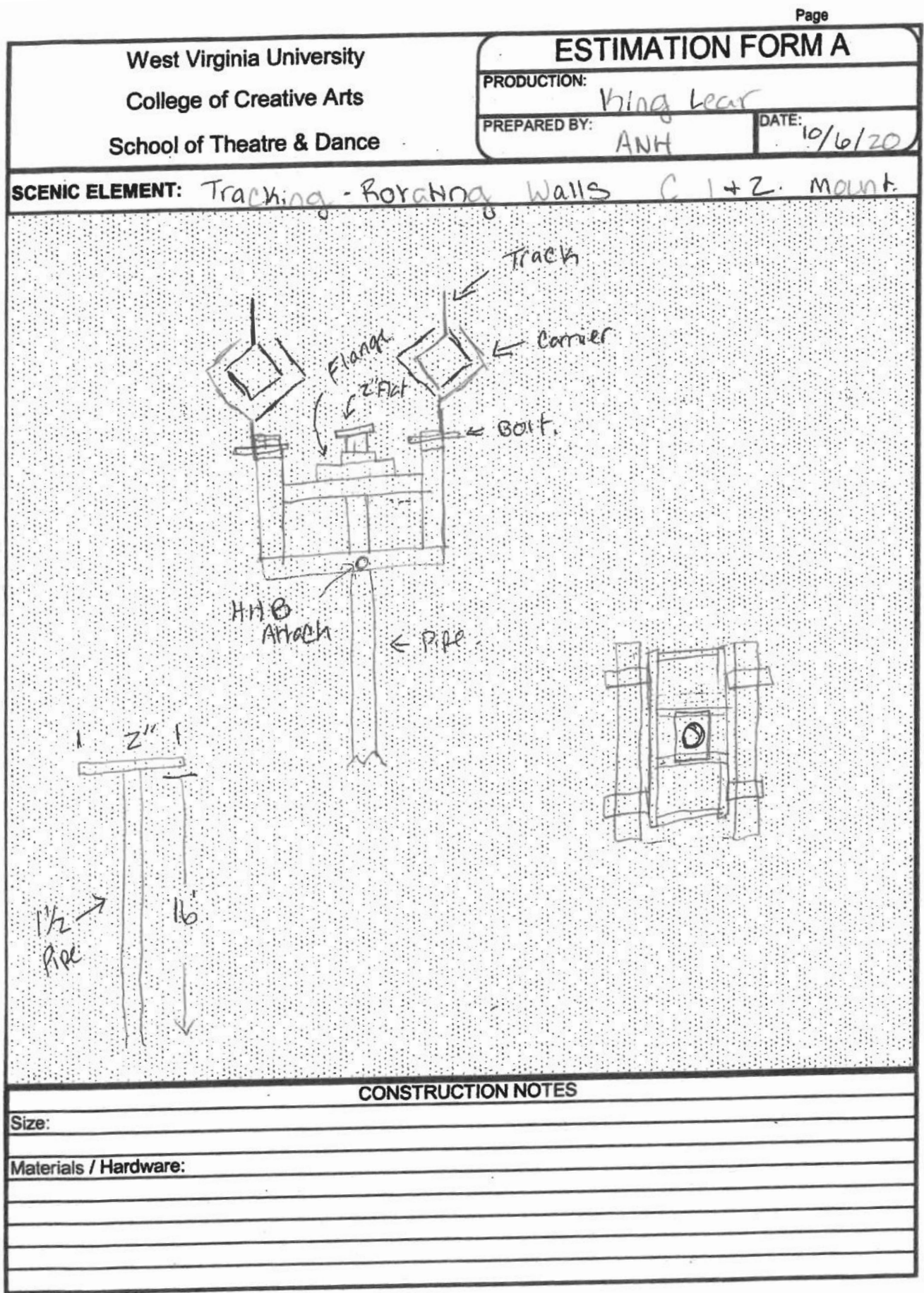




\begin{tabular}{|c|c|c|c|c|c|c|c|}
\hline \multirow{3}{*}{\multicolumn{3}{|c|}{$\begin{array}{c}\text { West Virginia University } \\
\text { College of Creative Arts } \\
\text { School of Theatre \& Dance }\end{array}$}} & \multicolumn{5}{|c|}{ ESTIMATION FORM B } \\
\hline & & & \multicolumn{3}{|c|}{ PRODUCTION: } & \multicolumn{2}{|c|}{ King Lear } \\
\hline & & & \multirow[t]{2}{*}{ PREPARED } & \multicolumn{2}{|c|}{$\overline{\mathrm{ANH}}$} & \multicolumn{2}{|c|}{ DATE: } \\
\hline \multicolumn{7}{|c|}{ SCENIC ELEMENT: Tracking-Rotating Walls C 1 \& 2} & \\
\hline \multirow{2}{*}{\multicolumn{3}{|c|}{ CONSTRUCTION PROCEDURE }} & & $\#$ & $\#$ & \multicolumn{2}{|r|}{ HOURS } \\
\hline & & & & of Crew & of Hours & \multicolumn{2}{|r|}{ Estimate } \\
\hline \multicolumn{4}{|l|}{ Cut $1 \times 1$ Box tube } & 1 & $\overline{2}$ & \multicolumn{2}{|r|}{2} \\
\hline \multicolumn{4}{|l|}{ Cut $1 \times 2$ box tube } & 1 & $\overline{2}$ & \multicolumn{2}{|r|}{2} \\
\hline \multicolumn{4}{|c|}{ Lay out front and back frame for welding } & $\overline{2}$ & $\overline{2}$ & \multicolumn{2}{|r|}{4} \\
\hline \multicolumn{4}{|l|}{ Lay out sides for welding } & 2 & $\overline{2}$ & \multicolumn{2}{|r|}{4} \\
\hline \multicolumn{4}{|l|}{ Weld fronts and backs } & $\overline{2}$ & $\overline{4}$ & & 8 \\
\hline Weld sides & & & & 2 & $\overline{4}$ & & 8 \\
\hline Weld and attach carriers legs to & alls & & & 1 & 4 & & 4 \\
\hline Cut MDF & & & & 2 & 3 & & 6 \\
\hline Attach MDF & & & & 2 & $\overline{2}$ & & 4 \\
\hline Cut CDX Castor plates & & & & 2 & 1 & & 2 \\
\hline Attach CDX to frames & & & & $\overline{2}$ & $\overline{2}$ & & 4 \\
\hline Attach Castors & & & & 2 & 1 & & 2 \\
\hline Pull Track & & & & 2 & 1 & & 2 \\
\hline Pull Carriers & & & & 2 & 1 & & 2 \\
\hline Attach Carriers to walls & & & & $\overline{1}$ & 1 & & 1 \\
\hline Test Weight and turning & & & & 2 & 4 & & 8 \\
\hline Attach spring action Panel & & & & 2 & 2 & & 4 \\
\hline Test Panel & & & & 2 & 2 & & 4 \\
\hline & & & & & & & \\
\hline & & & & & & & \\
\hline & & & & & & & \\
\hline & & & & & & & \\
\hline & & & & & TOTAL & & 71 \\
\hline & & & Quantity & UNIT & RICE & & COST \\
\hline MATERIAL & sold by: & another unit & Estimate & Esti & nate & & Estimate \\
\hline 1x1 Box Tube & Stick & - & 13 & $\$$ & 15.00 & $\$$ & 195.00 \\
\hline 1x2 Box Tube & Stick & 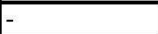 & 2 & $\$$ & 26.00 & $\$$ & 52.00 \\
\hline 2" Flat Bar & Stick & - & 1 & & & $\$$ & - \\
\hline $1 / 4^{\prime \prime} \mathrm{MDF}$ & Sheet & - & 5 & $\$$ & 11.00 & $\$$ & 55.00 \\
\hline Swivel Castors & Per & Stock & 4 & \$ & - & $\$$ & - \\
\hline $\mathrm{CDX}$ & Sheet & - & 1 & $\$$ & 28.00 & $\$$ & 28.00 \\
\hline Track & - & Stock & 1 & $\$$ & - & $\$$ & - \\
\hline Track Carriers & - & Stock & 2 & $\$$ & - & $\$$ & - \\
\hline Butt Hingers & Per & Stock & 4 & $\$$ & - & $\$$ & - \\
\hline Push to close \& open Catches & Per & & 6 & $\$$ & 12.50 & $\$$ & 75.00 \\
\hline European Style Hinges & Per & & 6 & $\$$ & 5.60 & $\$$ & 33.60 \\
\hline 1-1/2 Pipe & & & 2 & $\$$ & 53.00 & $\$$ & 106.00 \\
\hline & & & & & & $\$$ & - \\
\hline & & & & & & $\$$ & - \\
\hline & & & & & & $\$$ & - \\
\hline & & & & & & $\$$ & - \\
\hline & & & & & & $\$$ & - \\
\hline & & & & & & $\$$ & - \\
\hline & & & & & & $\$$ & - \\
\hline & & & & & TOTAL & $\$$ & 544.60 \\
\hline
\end{tabular}




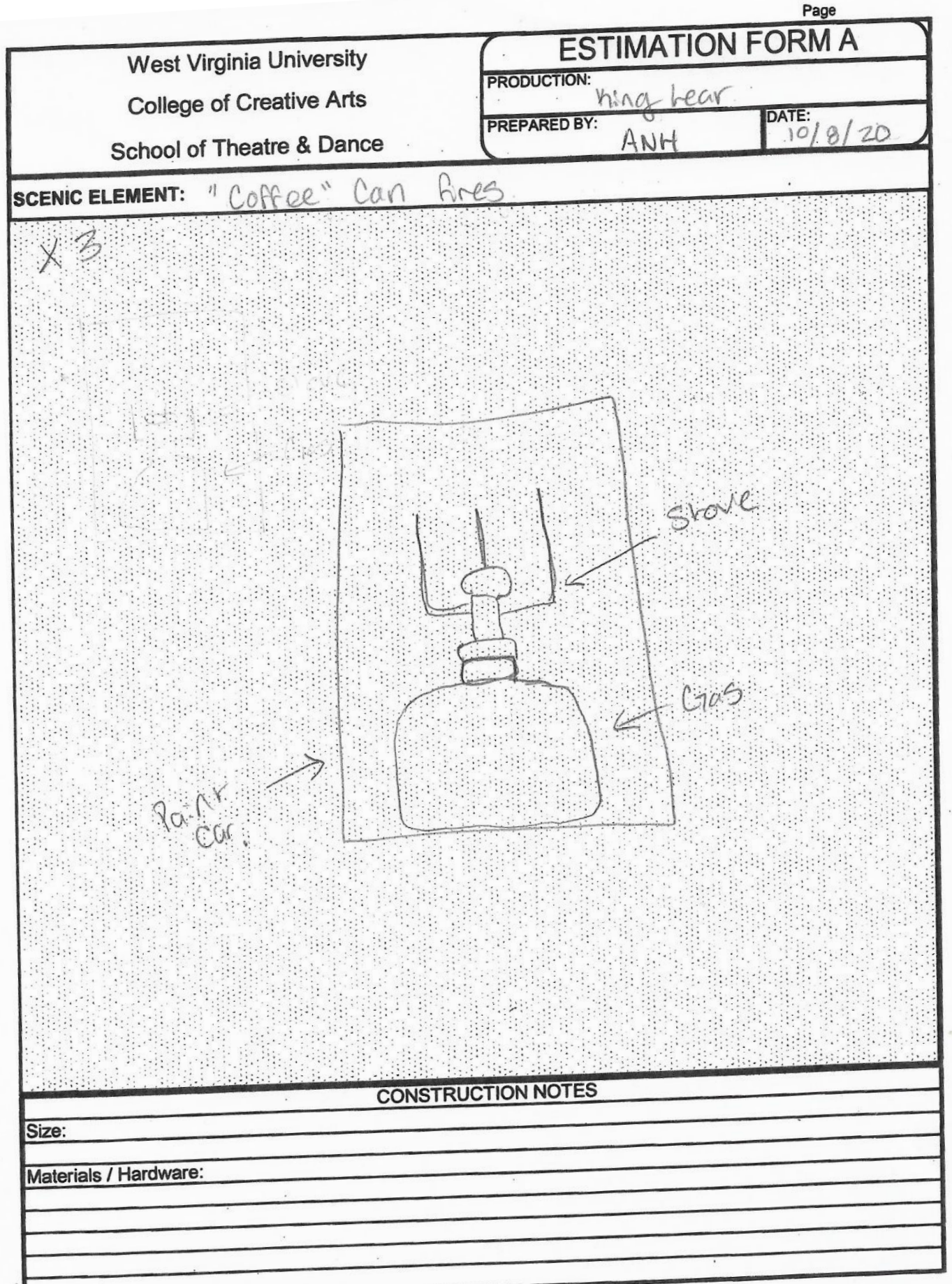




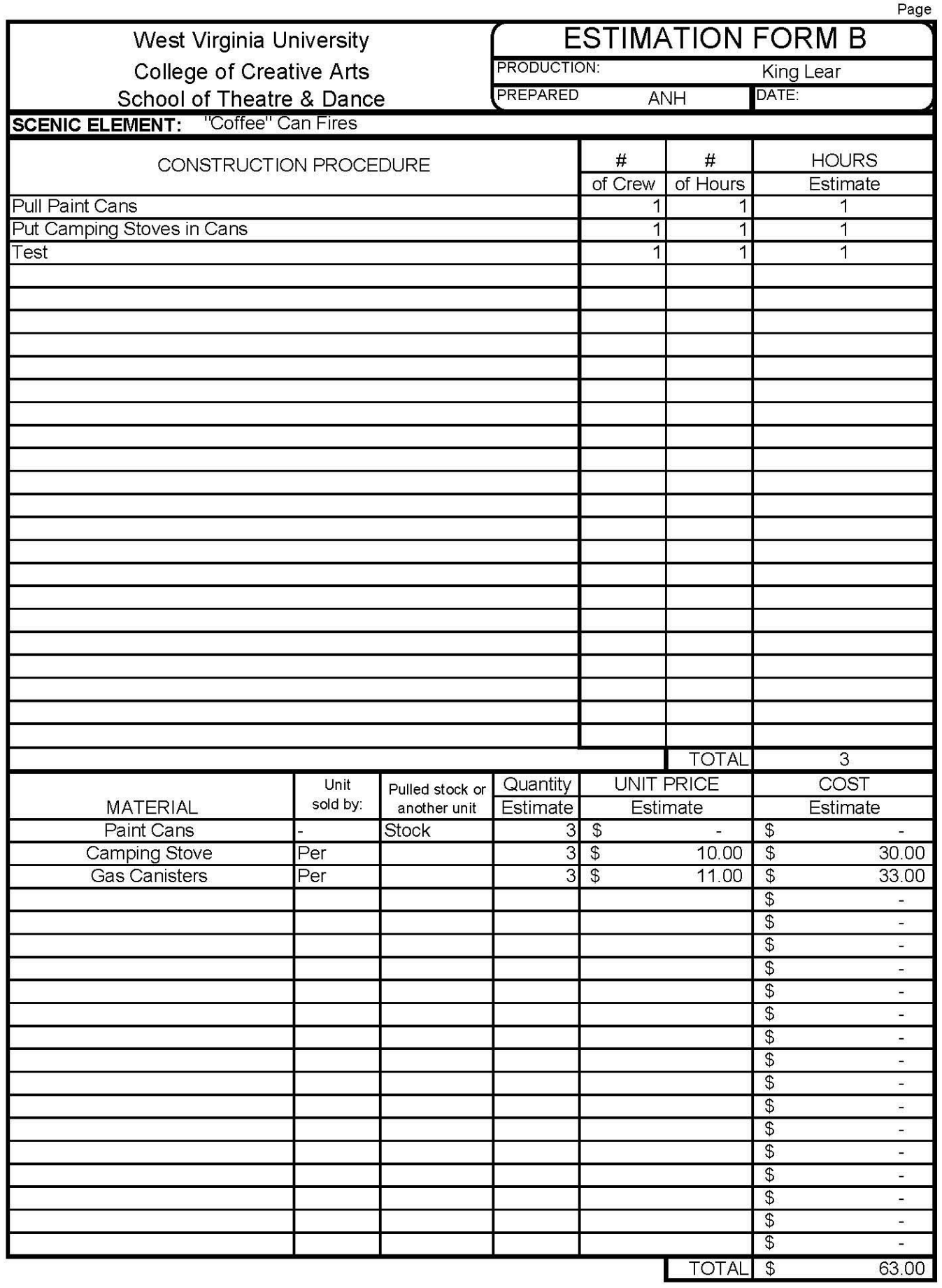


APPENDIX B: BUILD CALENDAR

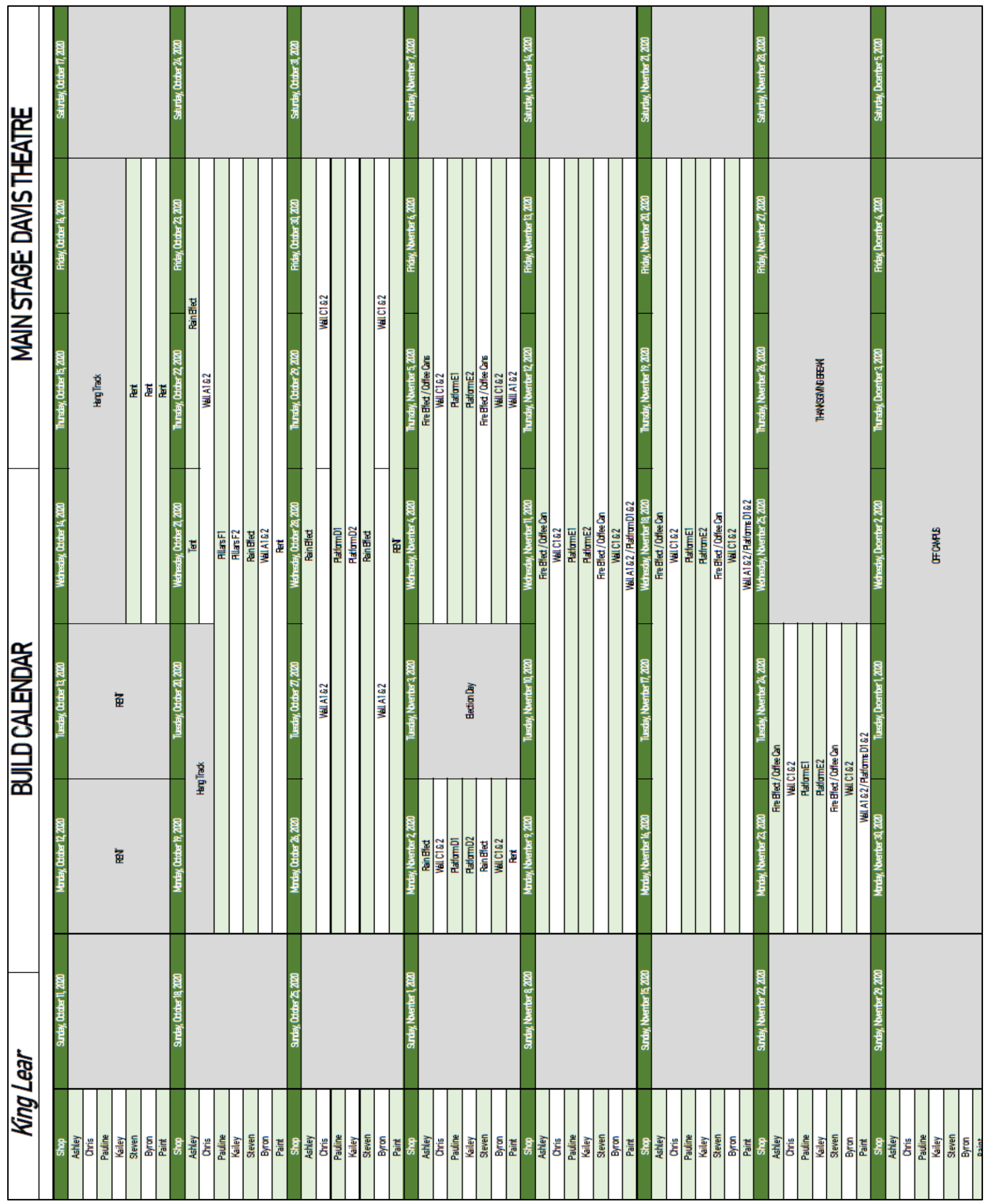




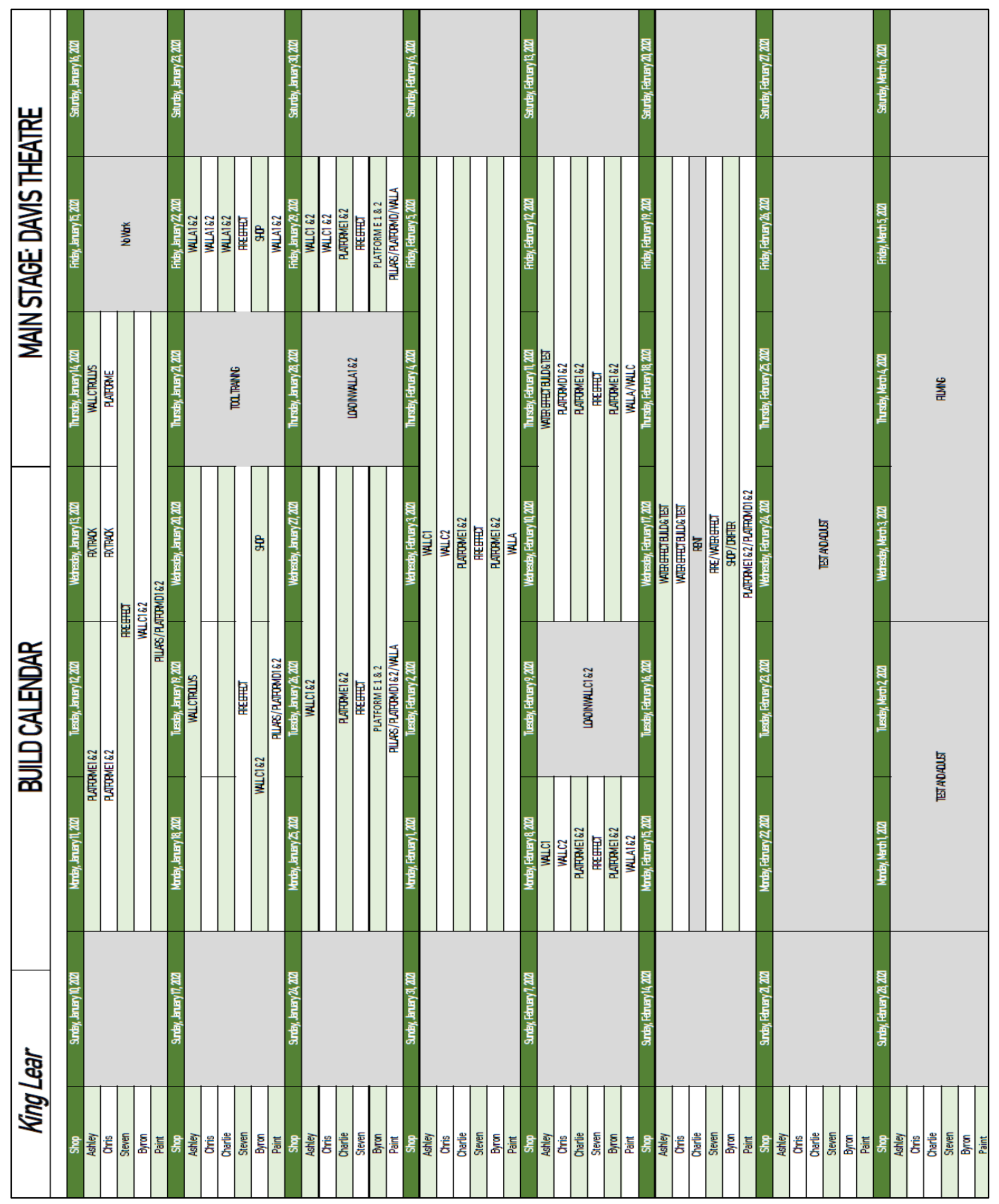




\section{APPENDIX C: PURCHASE ORDER FORM}

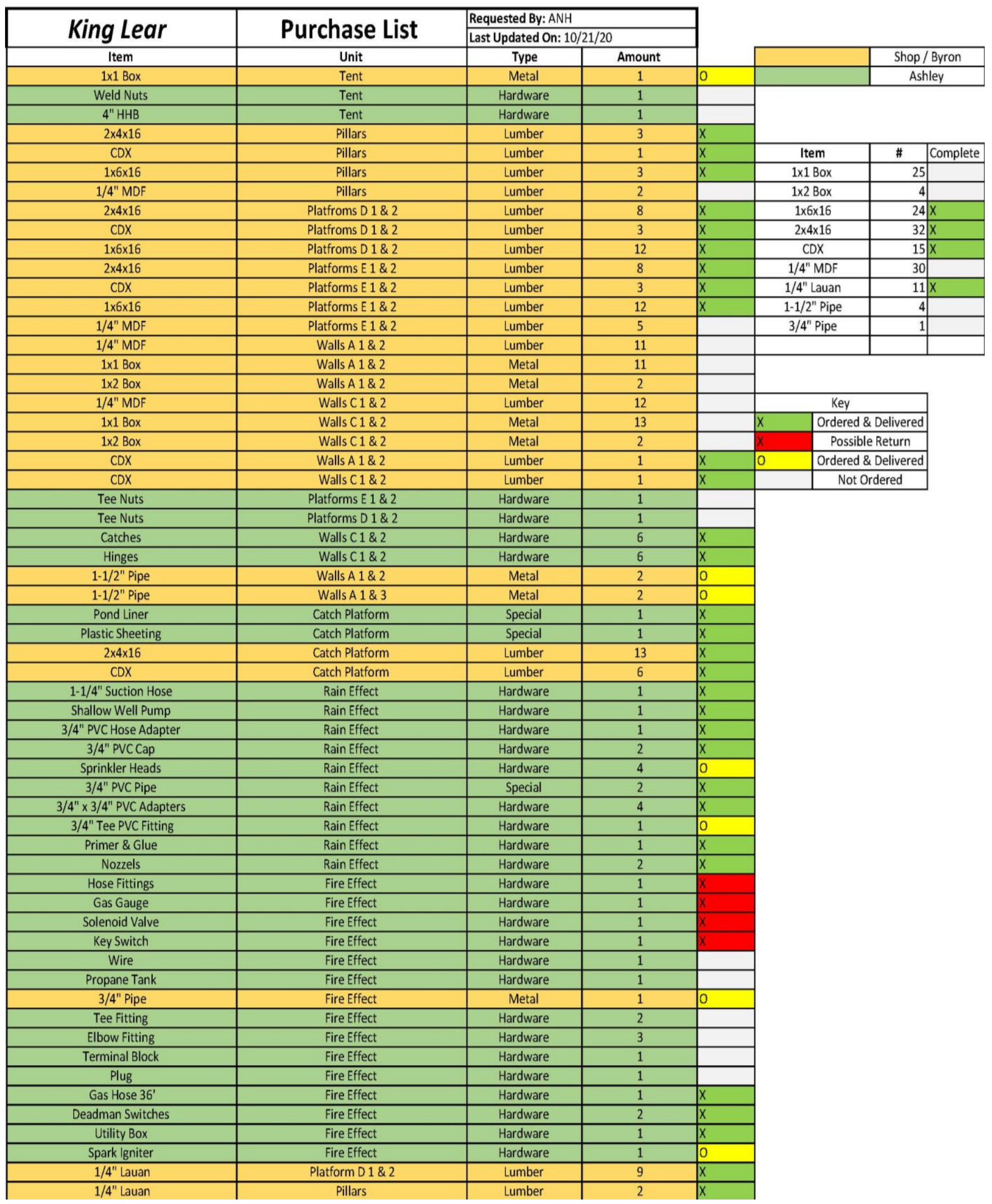




\section{APPENDIX D: DRAFTING}

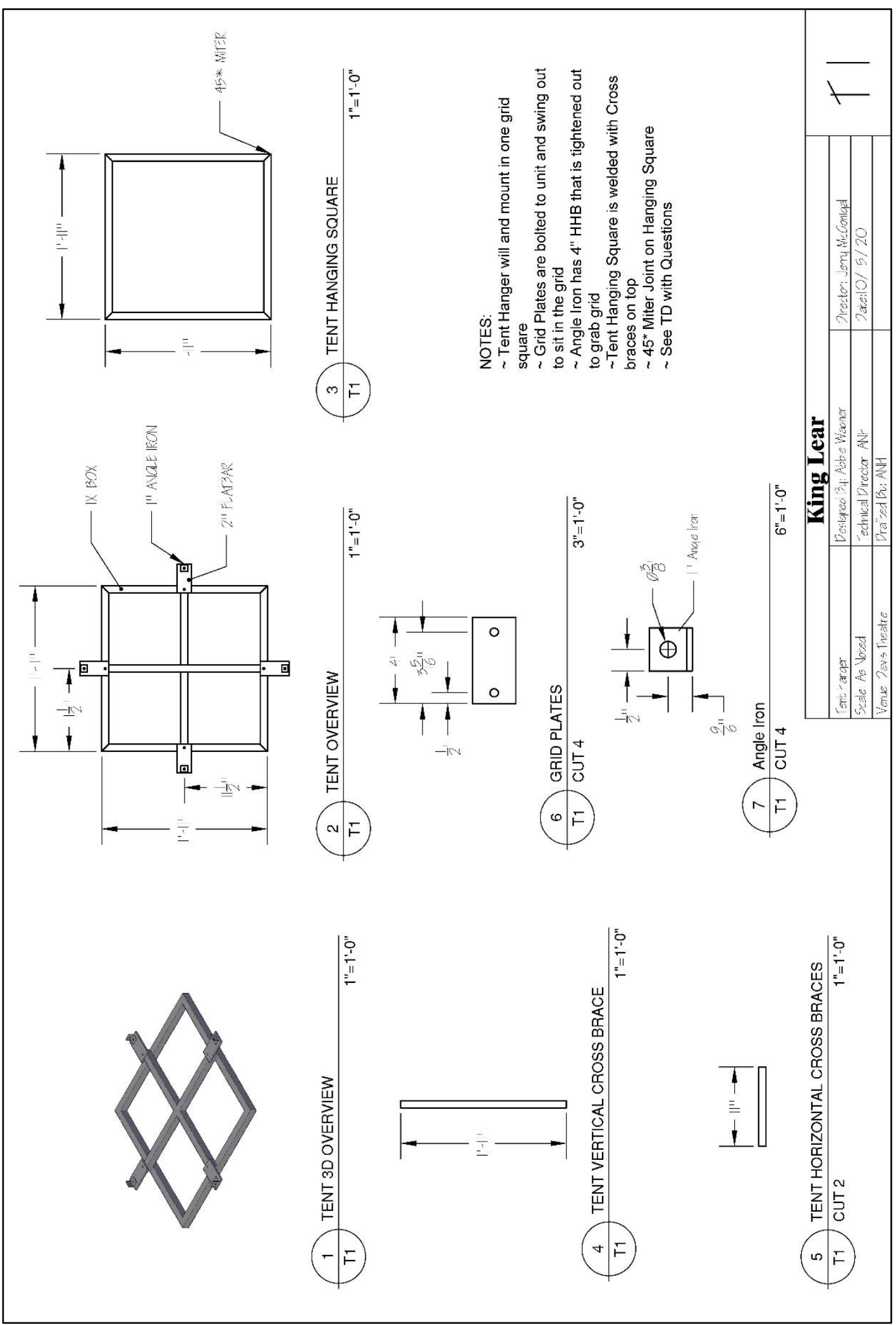



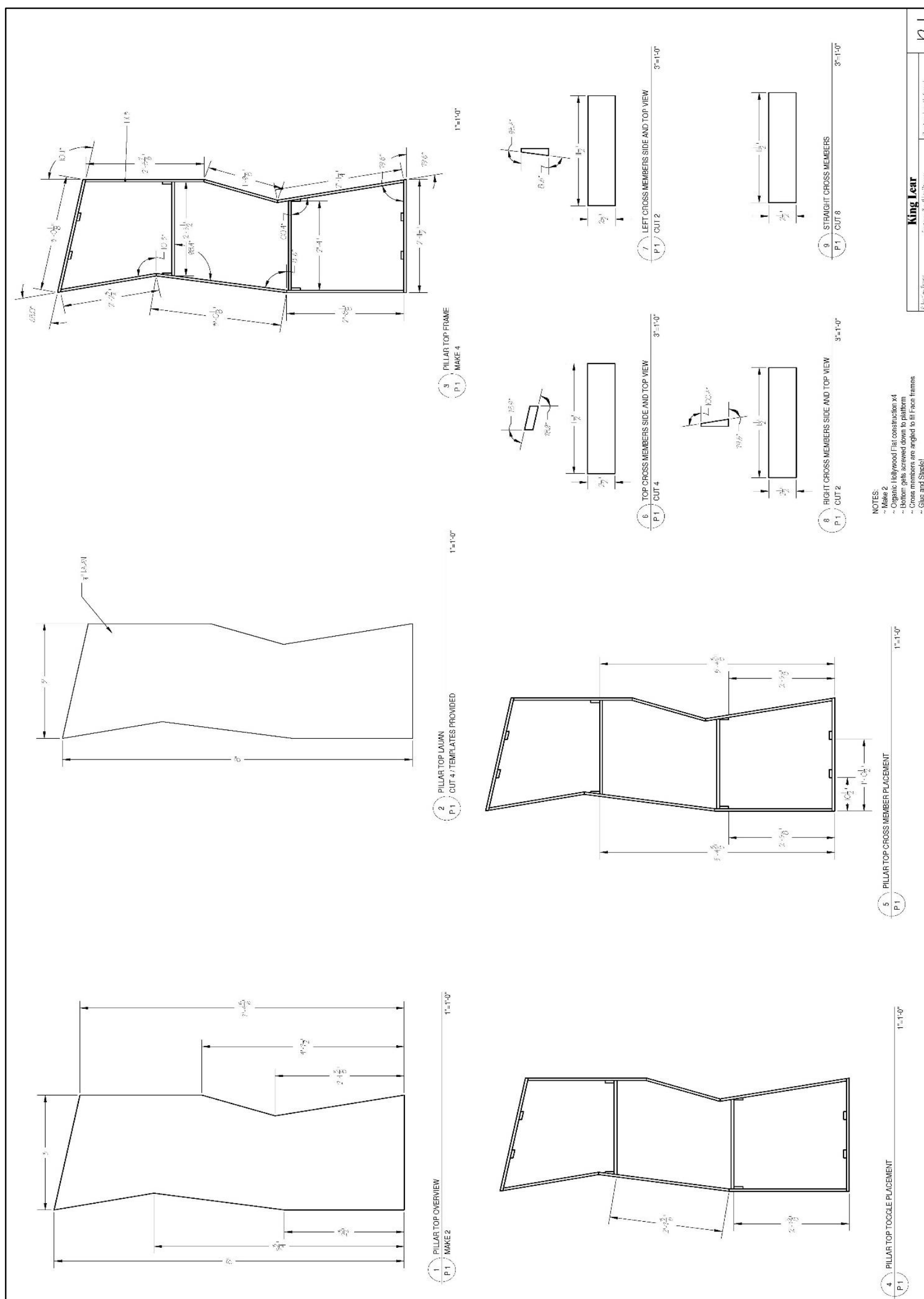

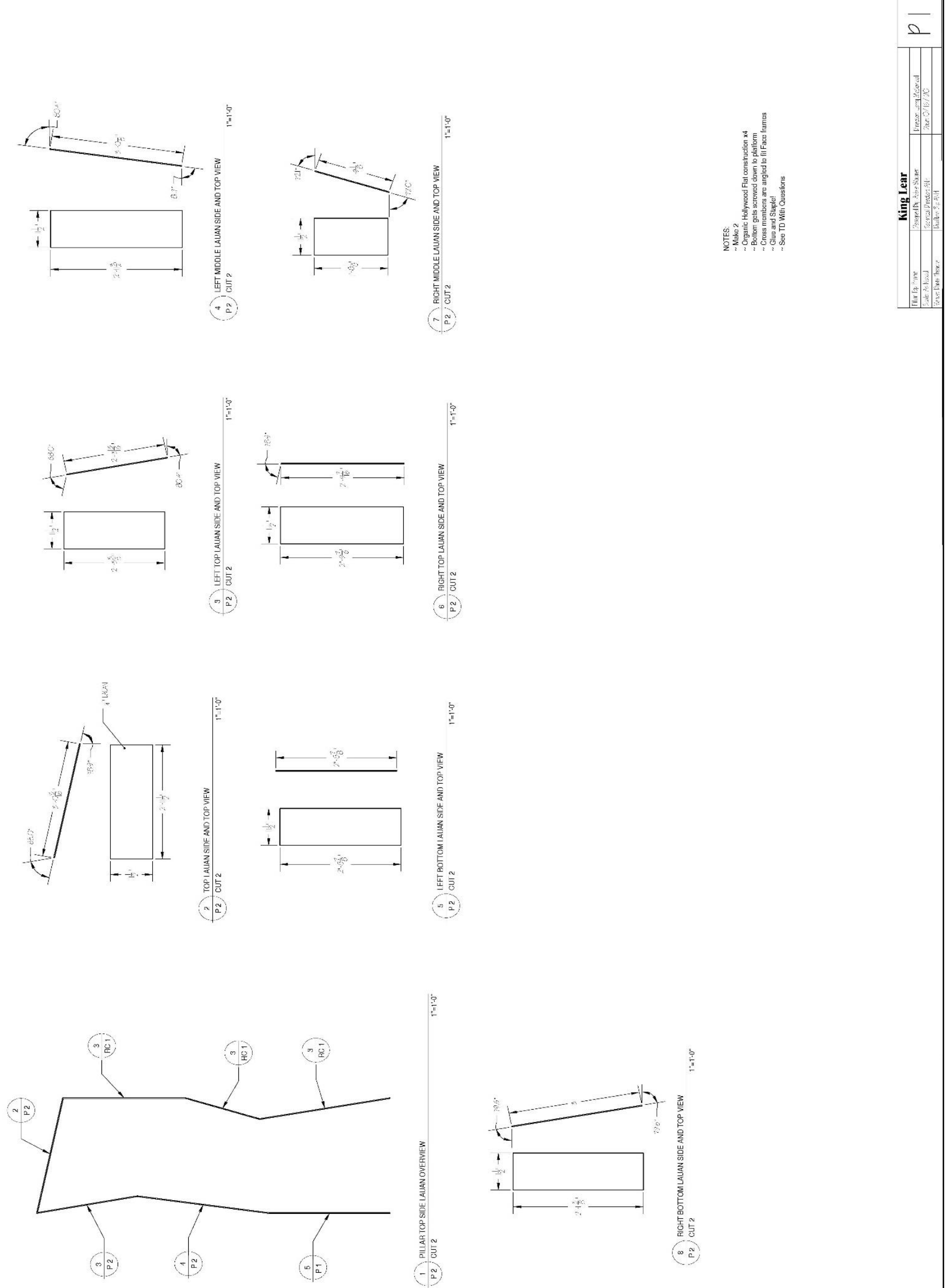


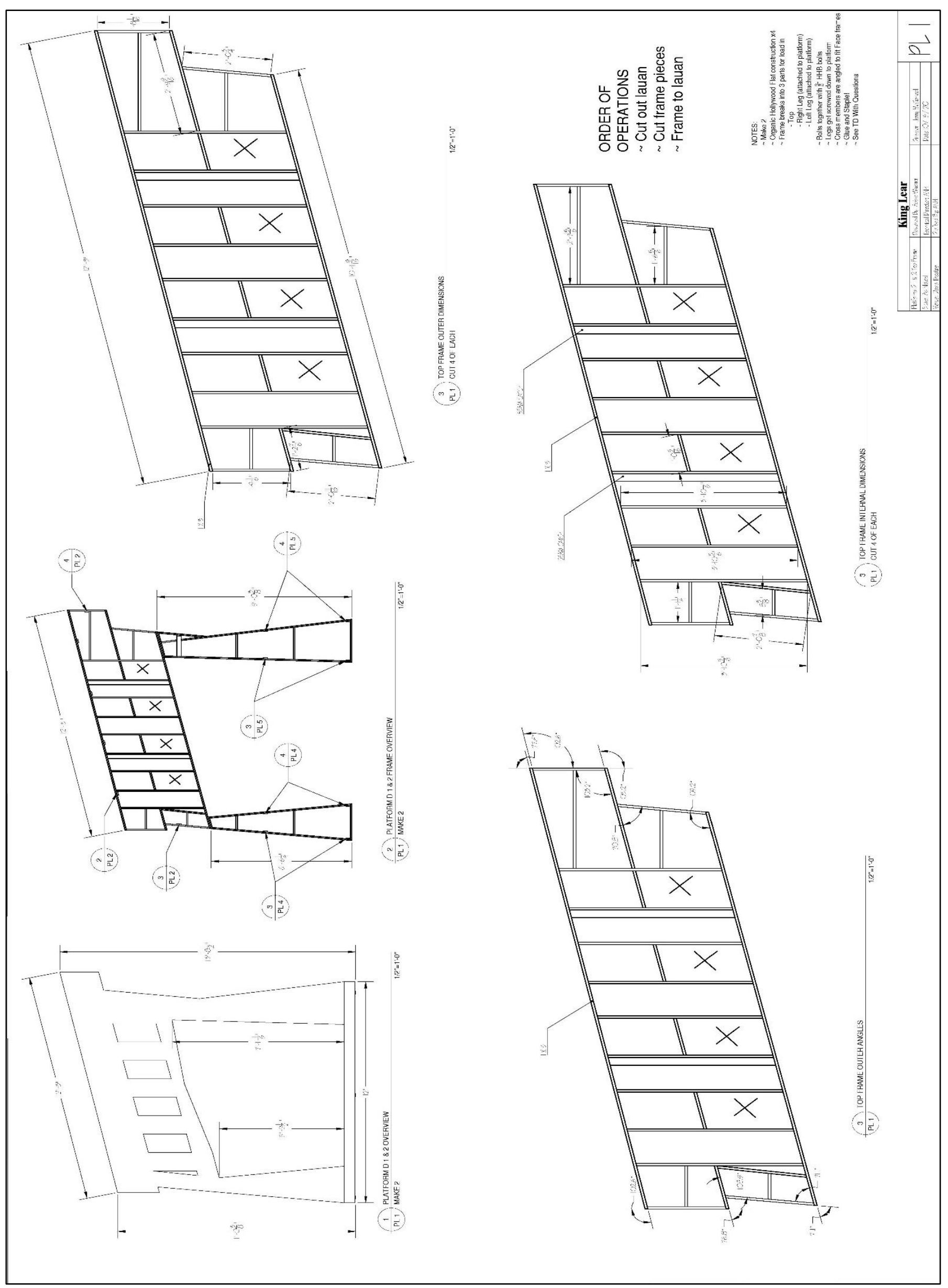



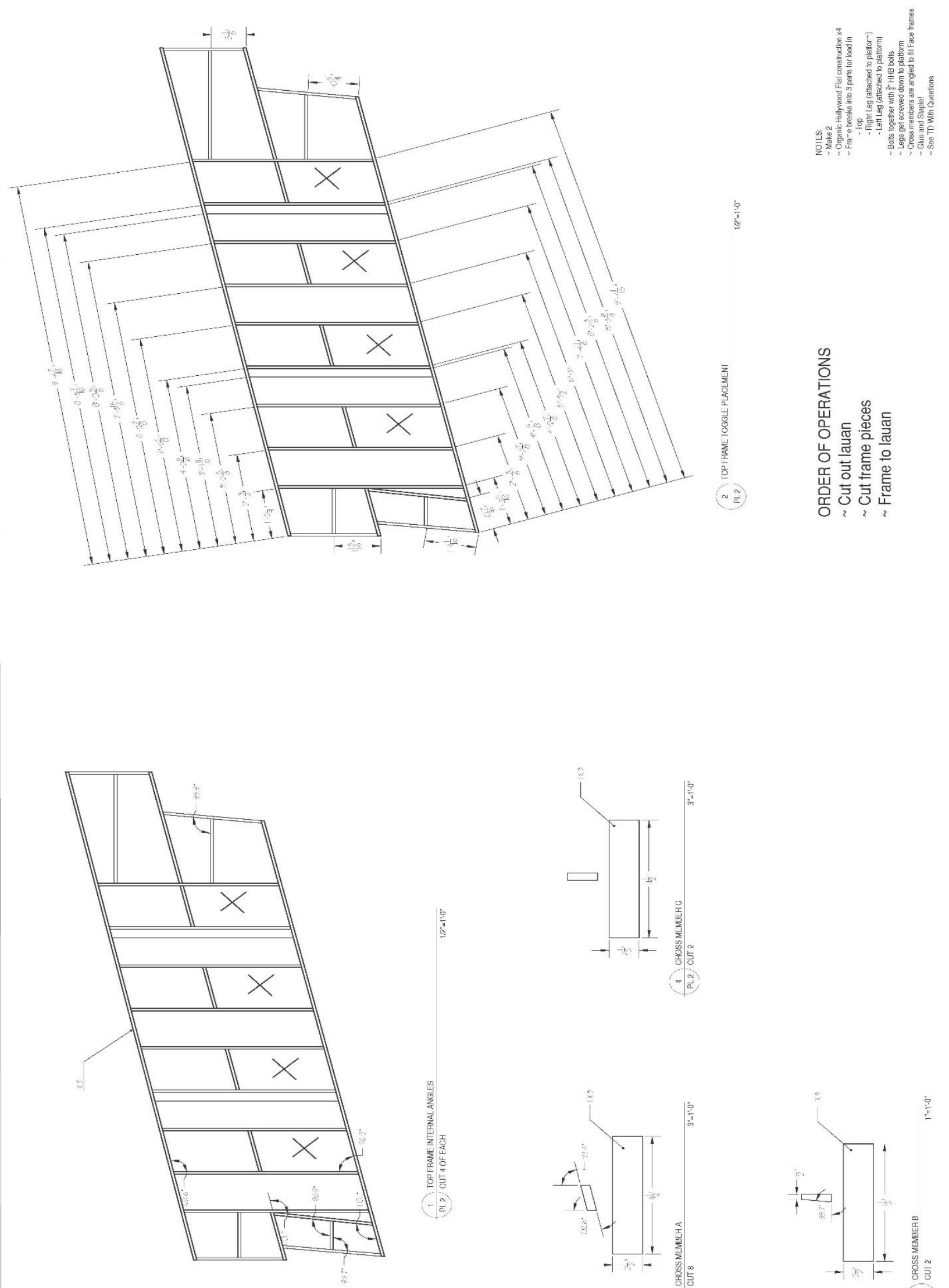

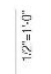
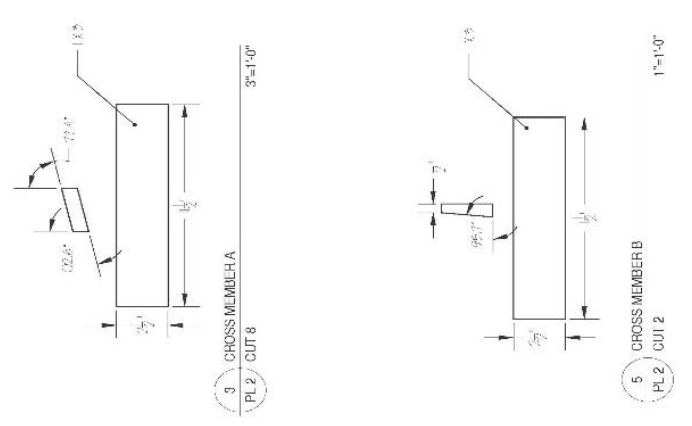


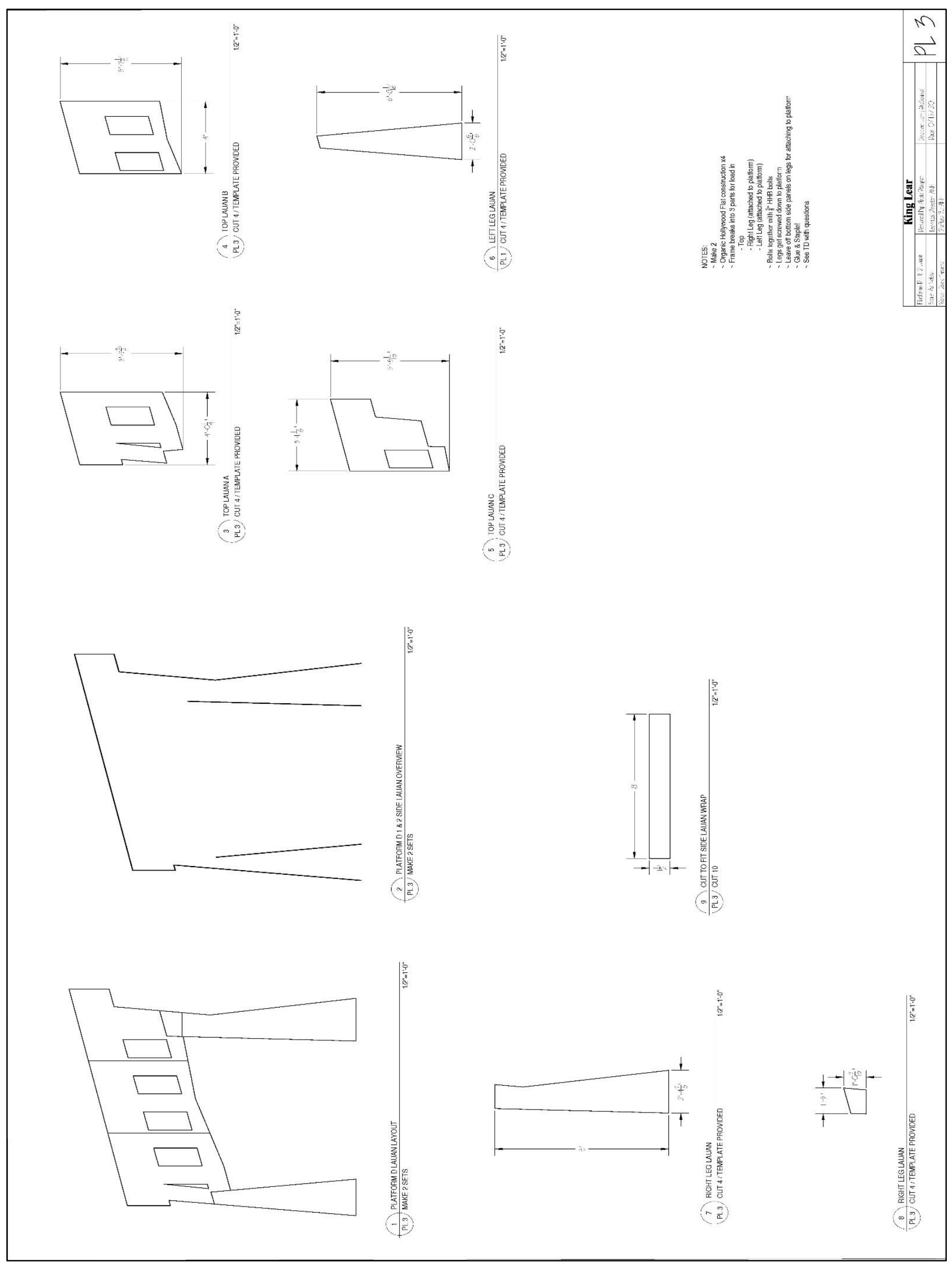




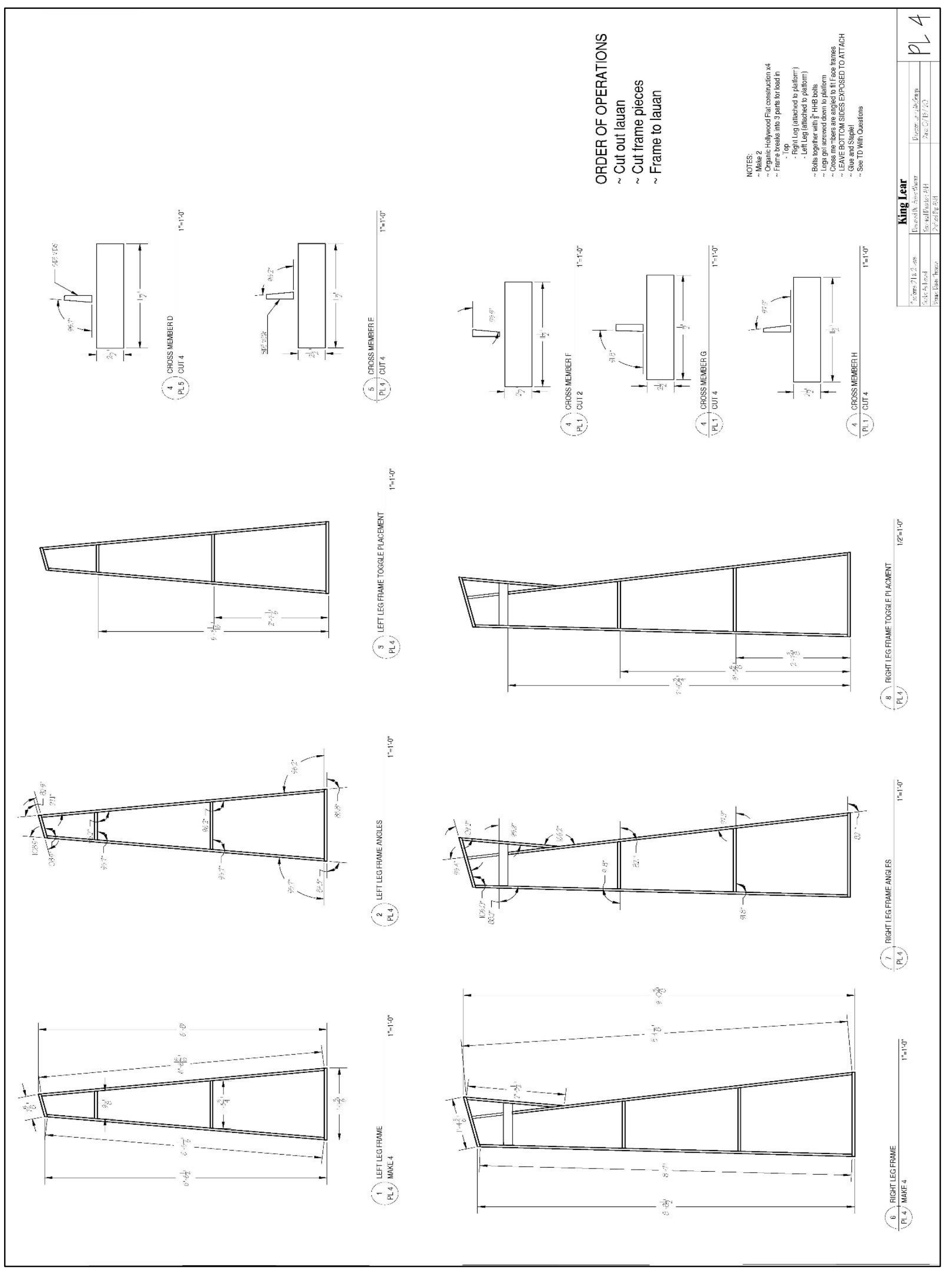




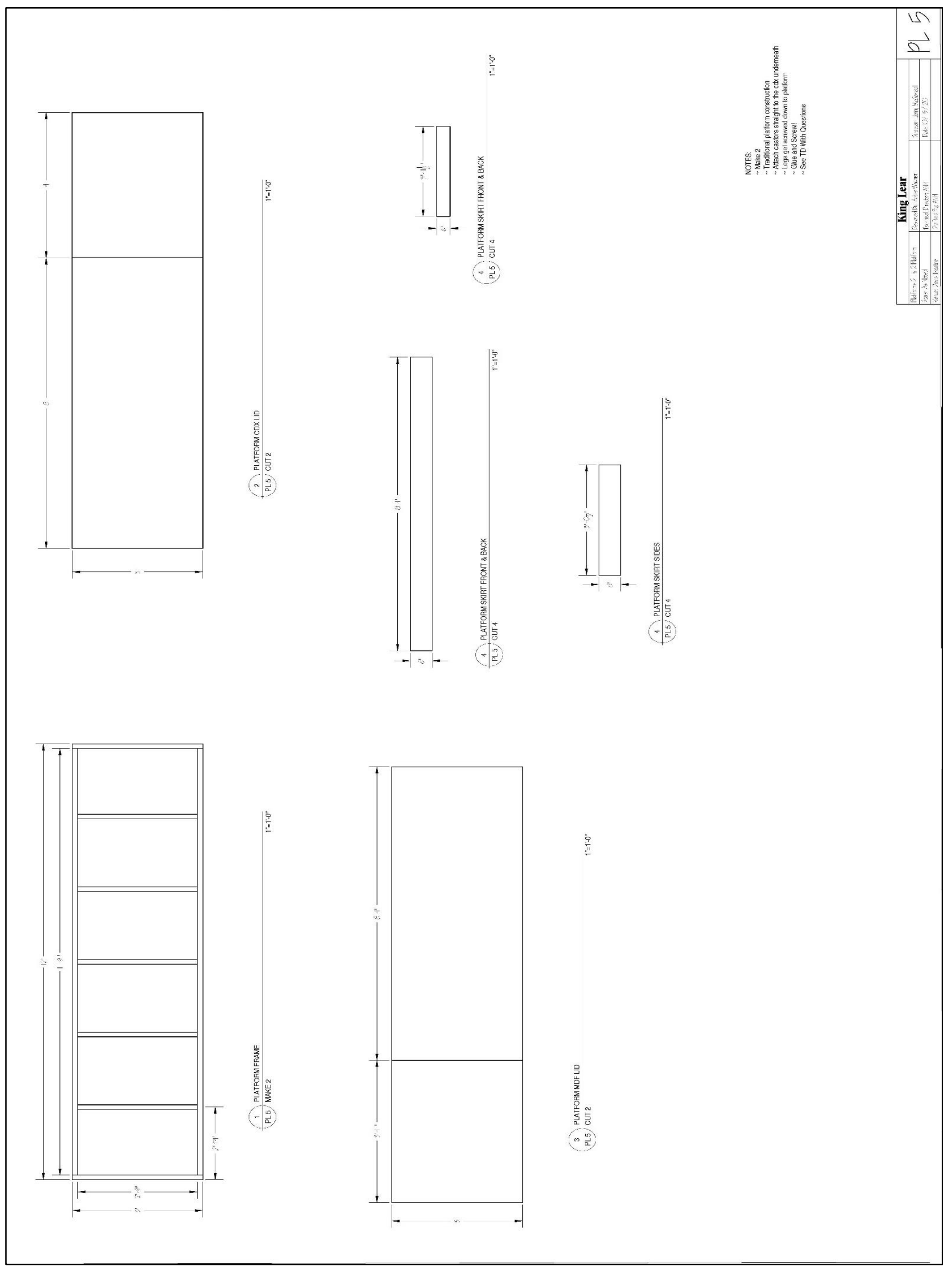



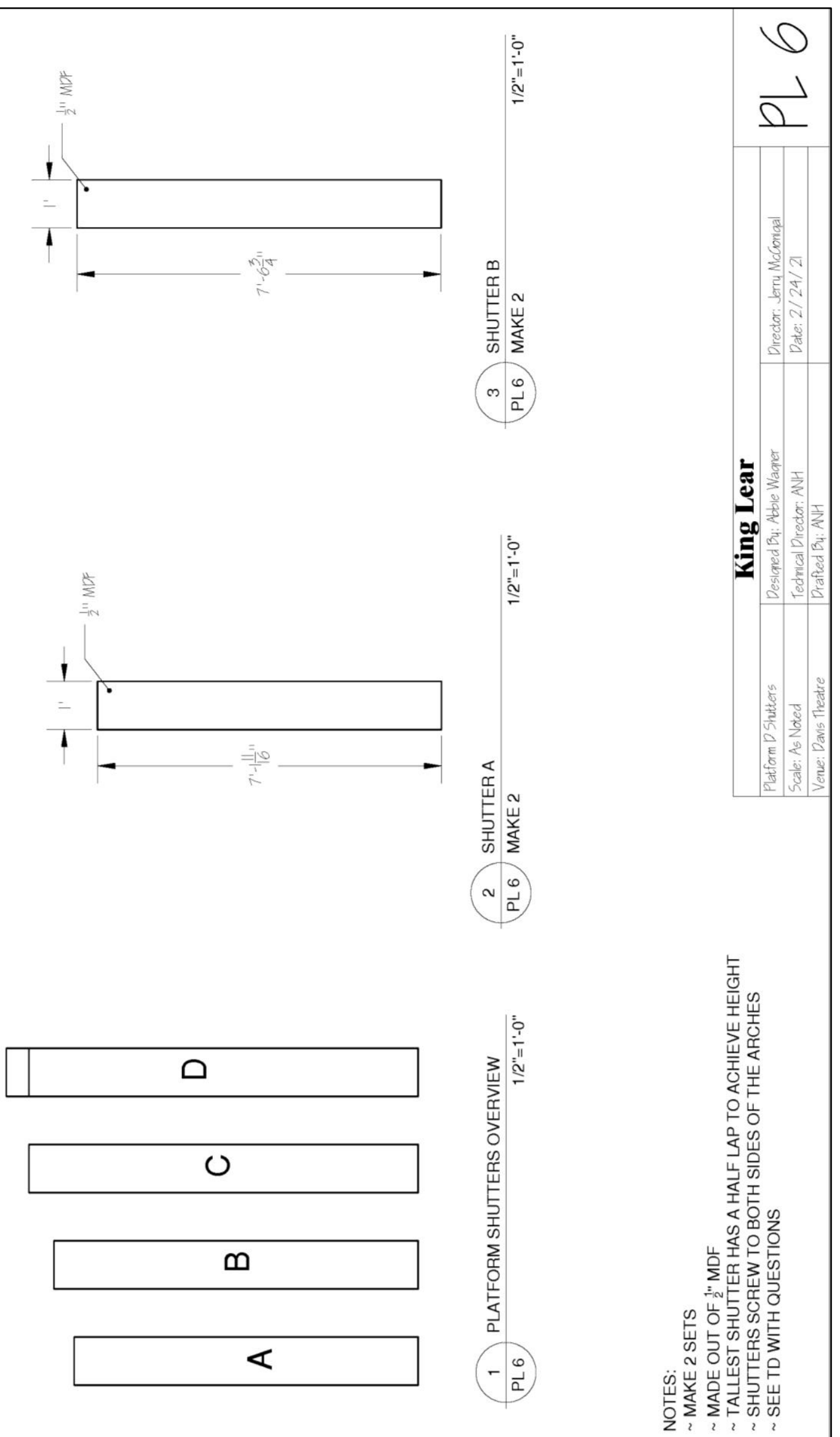


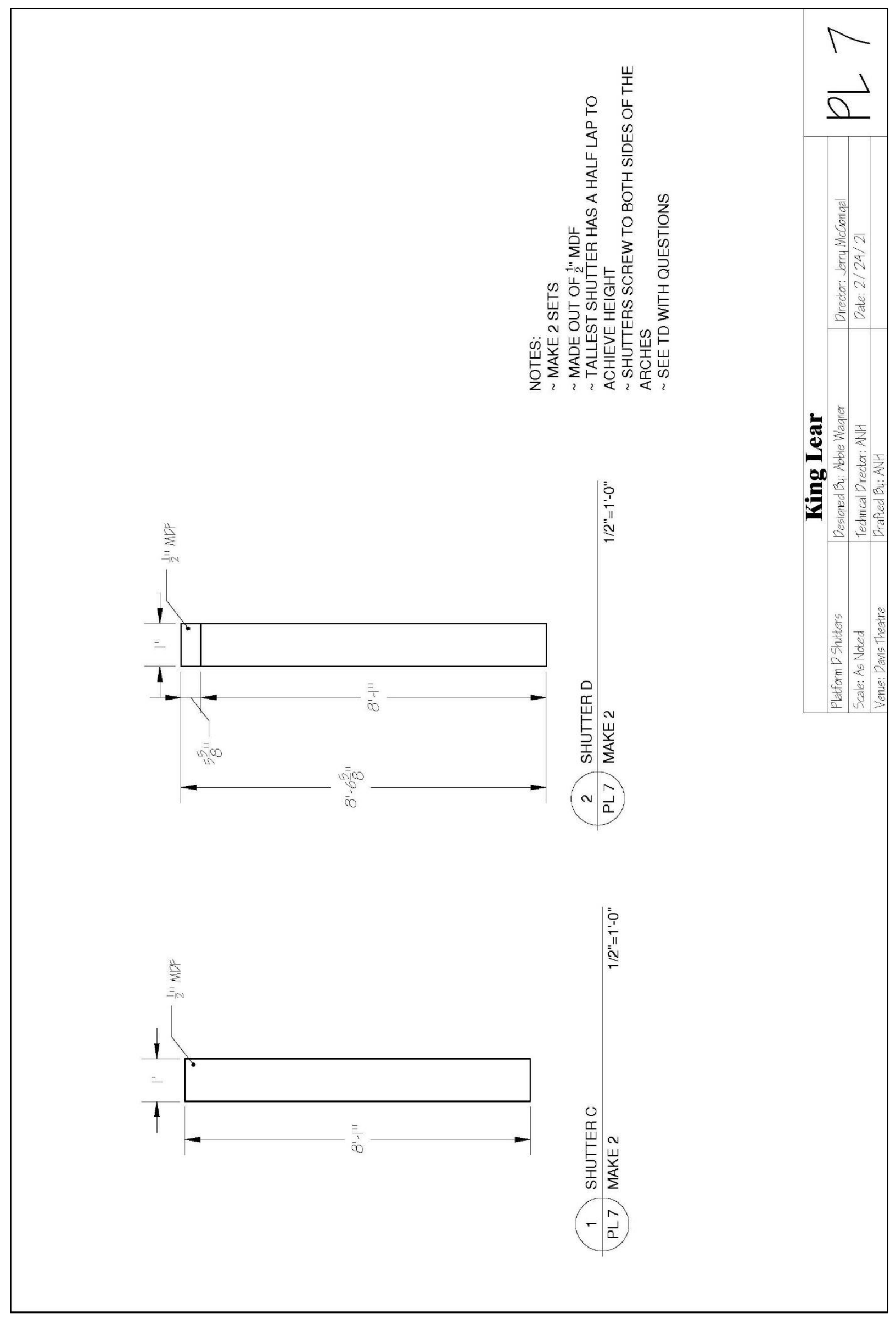




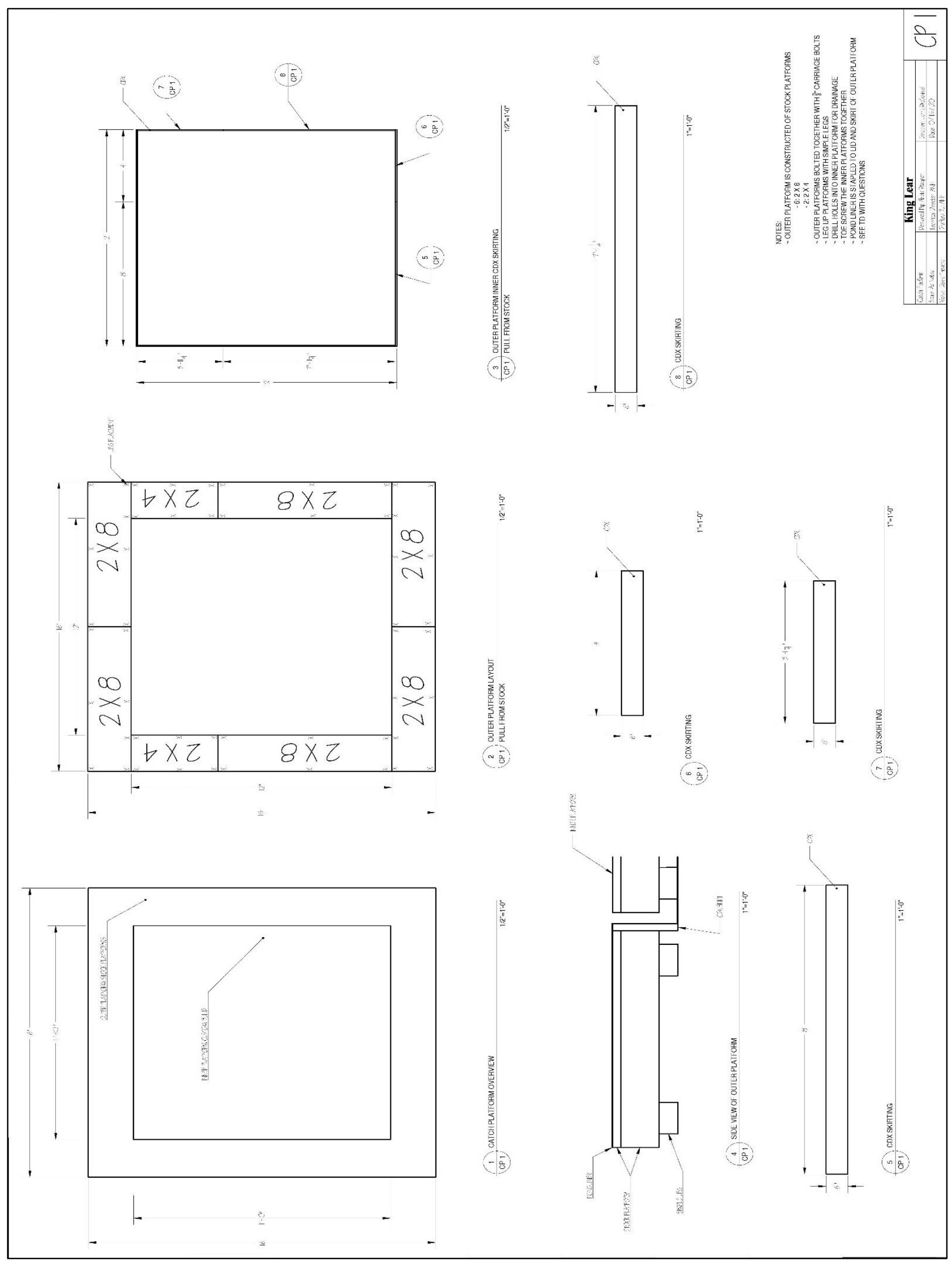




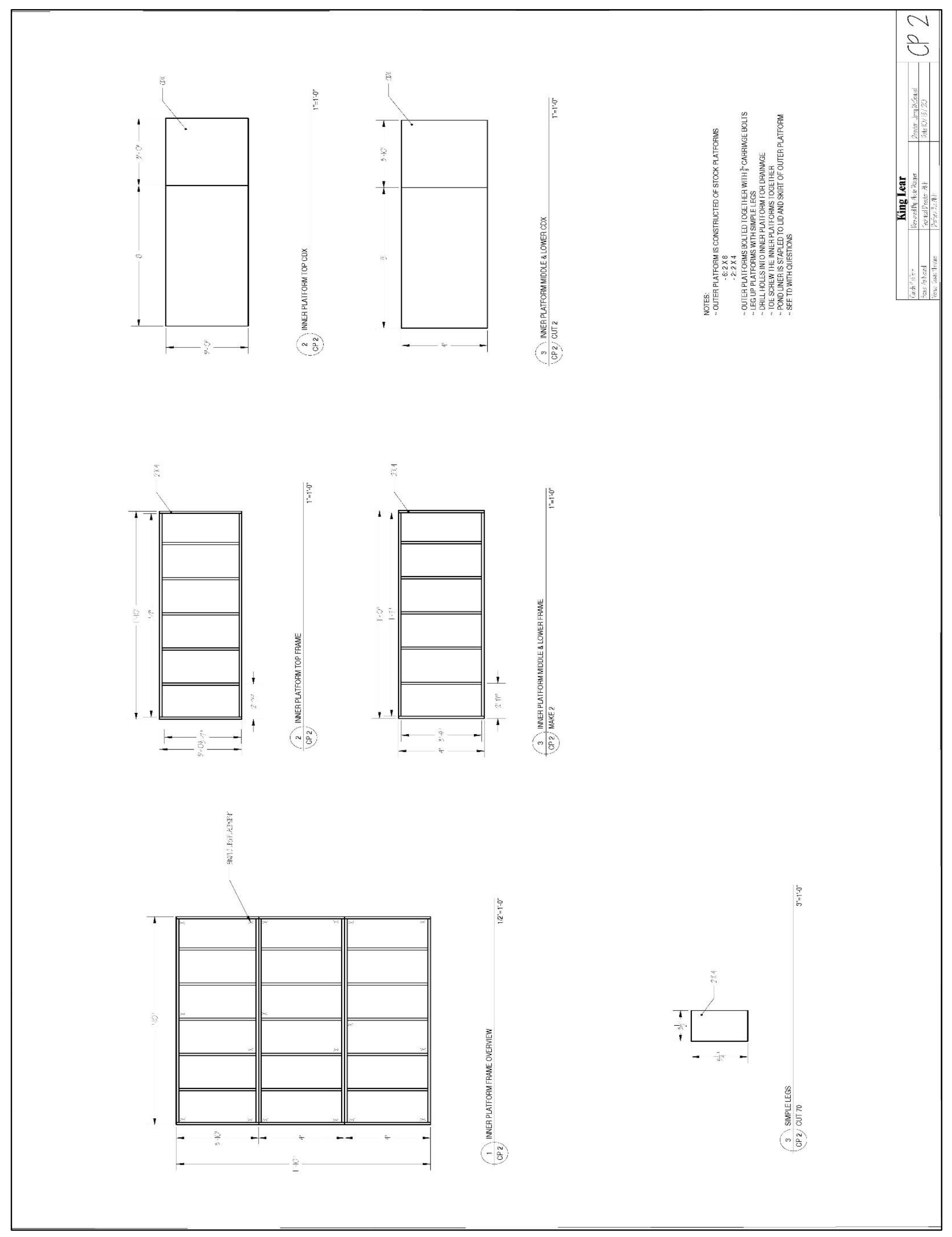




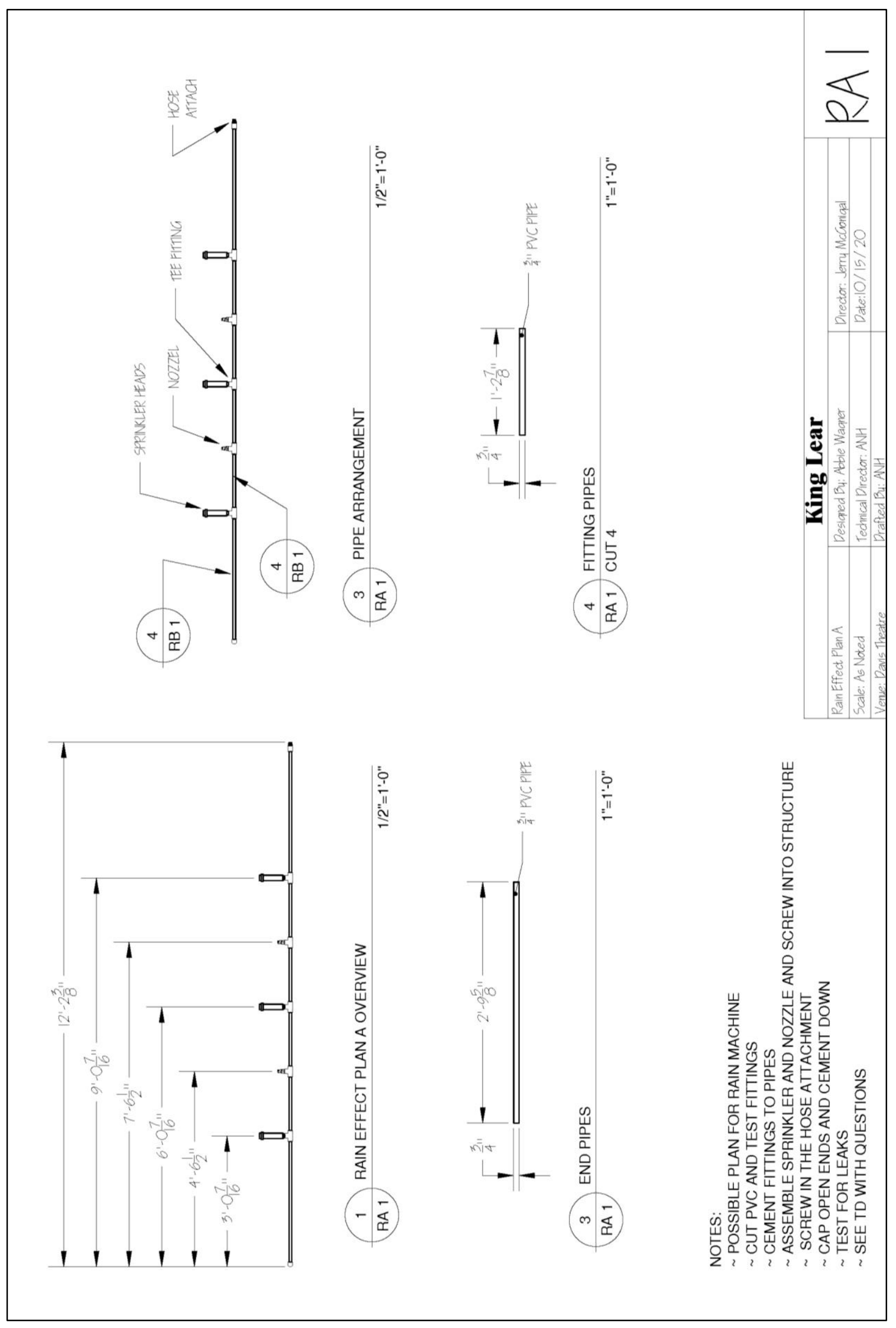




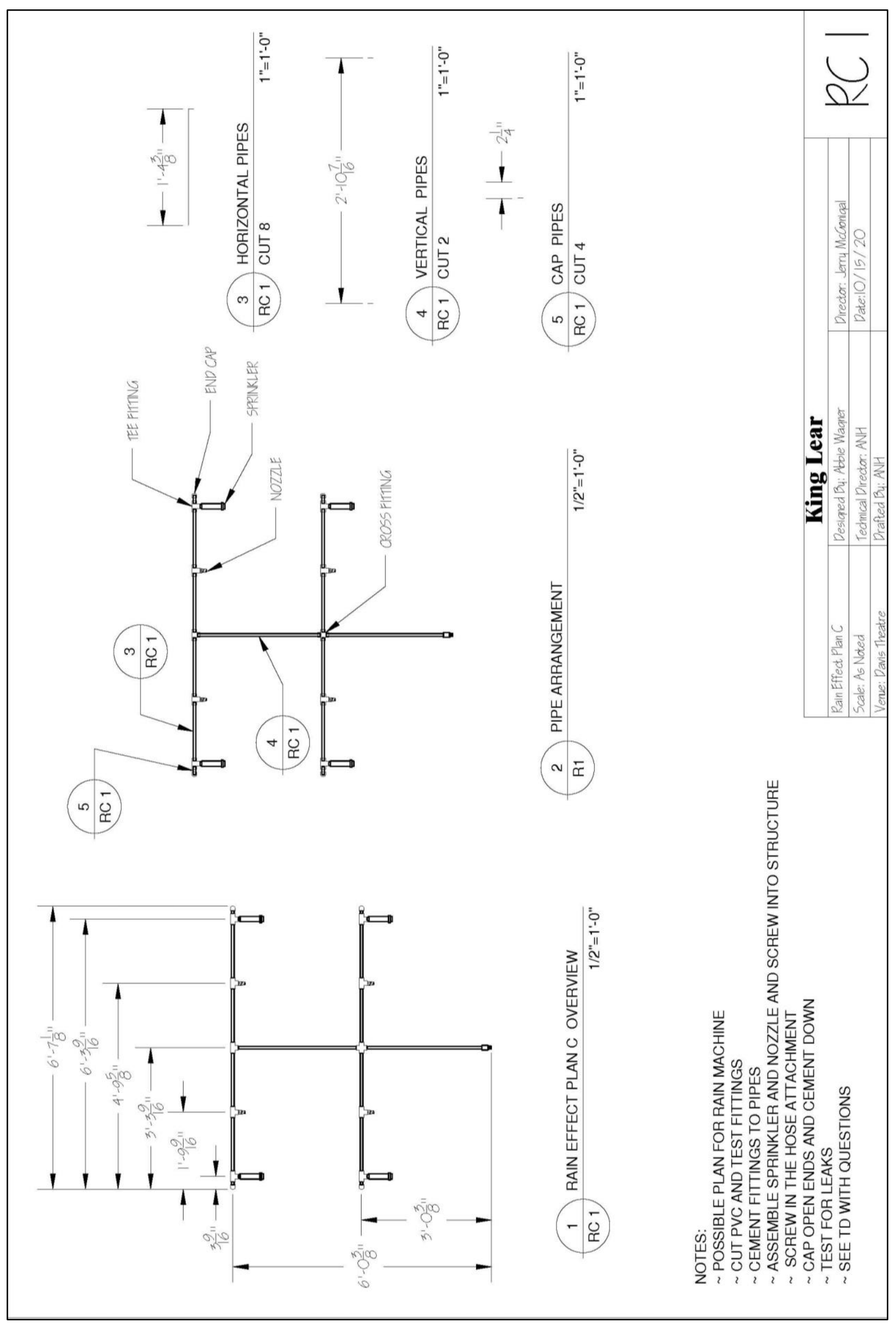




\section{APPENDIX E: DESIGNER RENDERINGS}

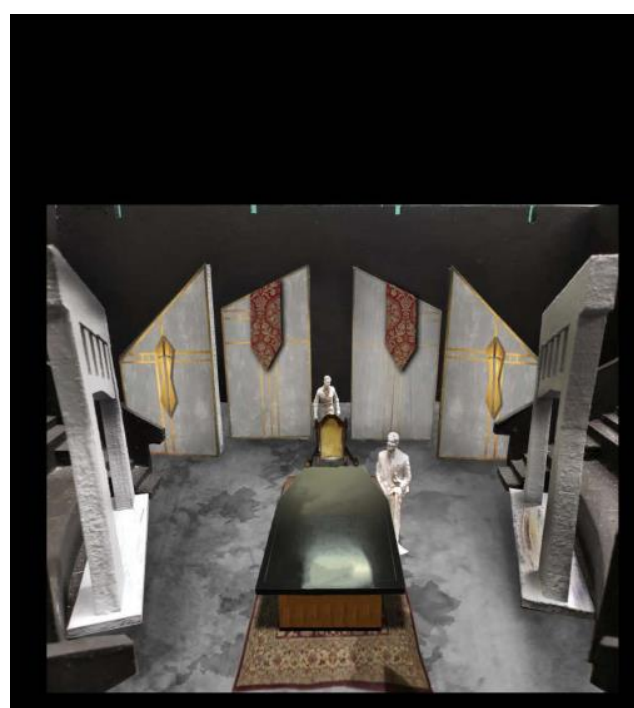

1.1 - Lear's Palace

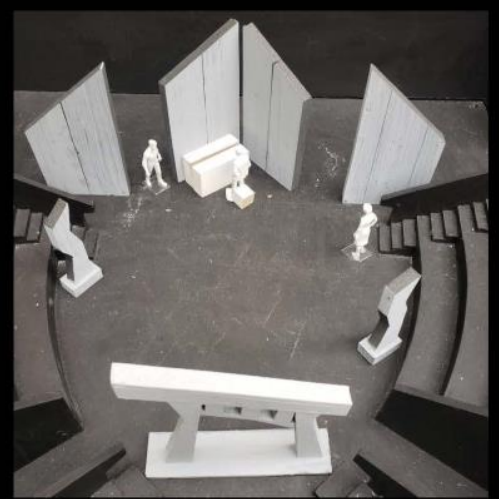

1.2 - Gloucester's Castle

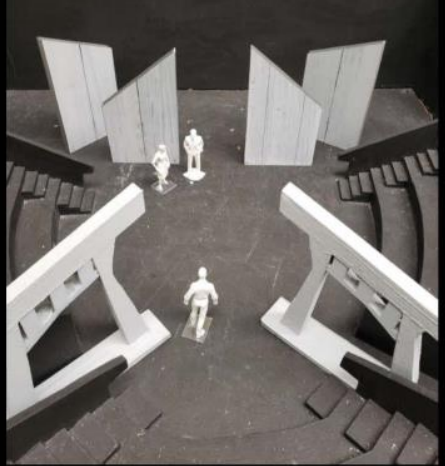

1.3-1.5 - Albany's Palace, Court, Hall

Act 2.1-2.4 - Outside Gloucester's Castle

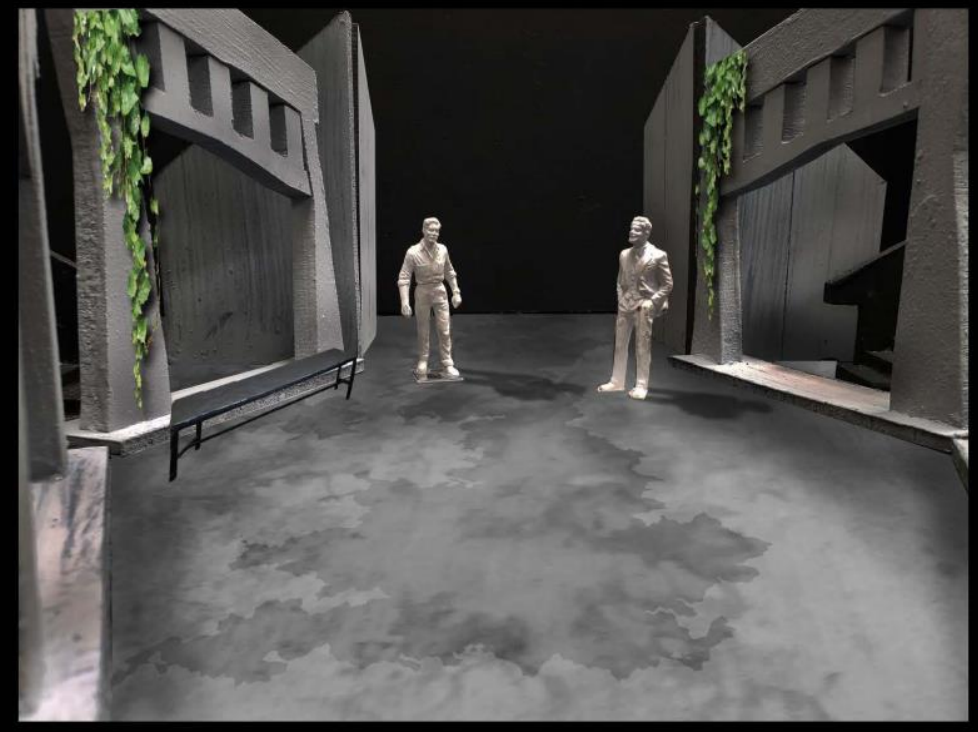




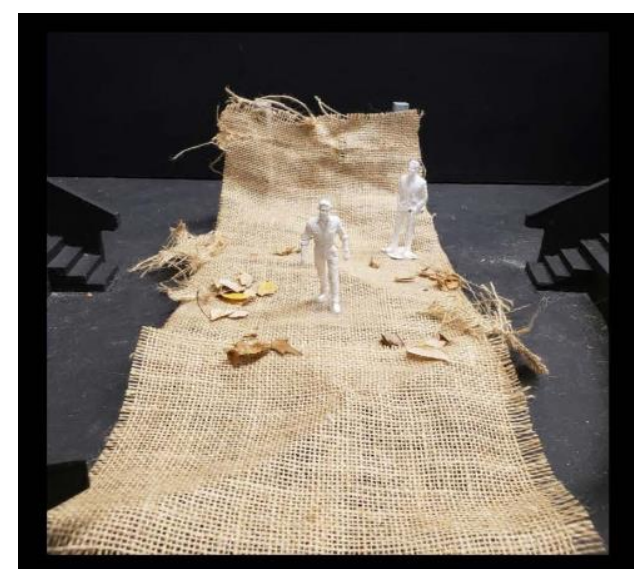

3.1-3.2 - Heath/Storm

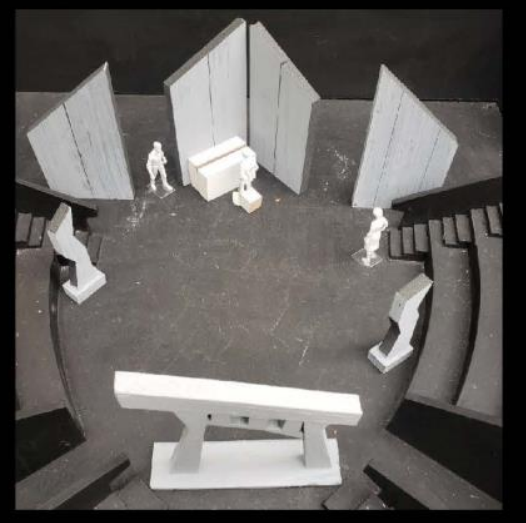

$3.3,3.5,3.7$

Gloucester's Castle

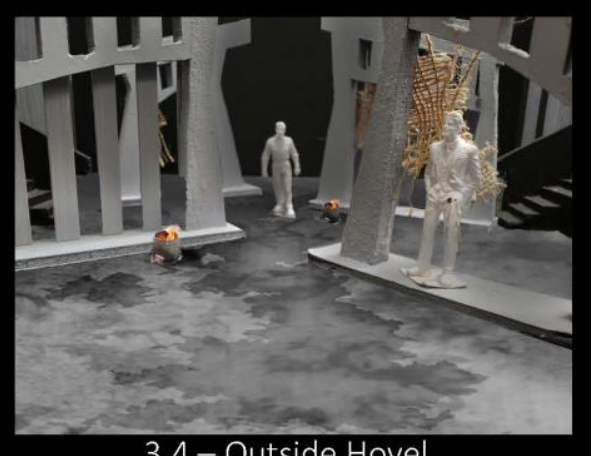

3.4 - Outside Hovel

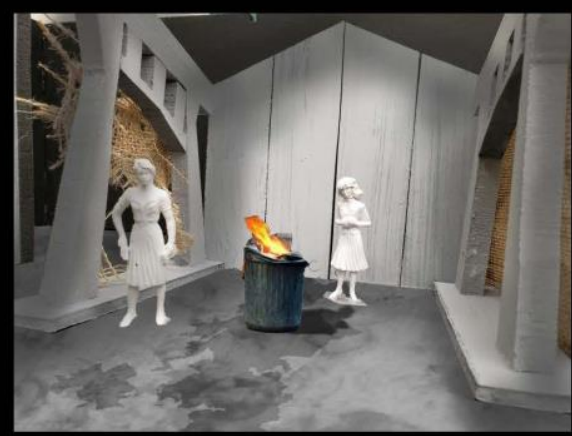

3.6 - Hovel Interior

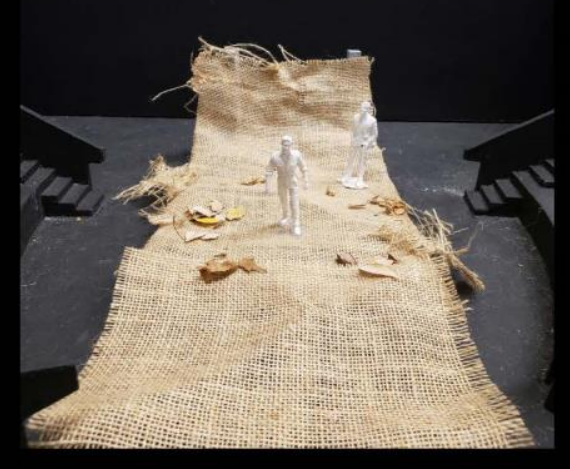

4.1- Heath

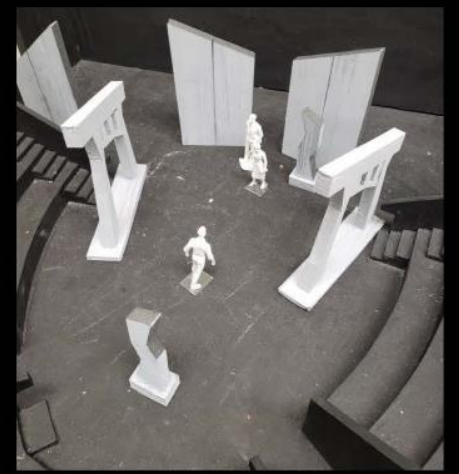

4.2 - Outside Albany's Palace

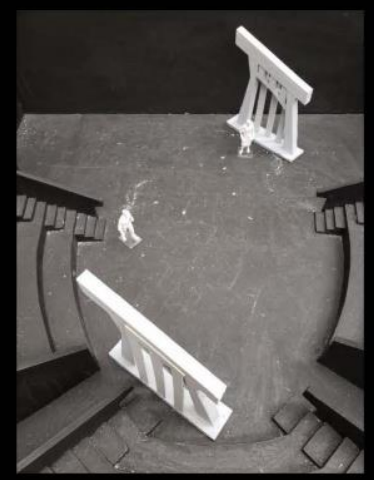

4.3 - French Camp

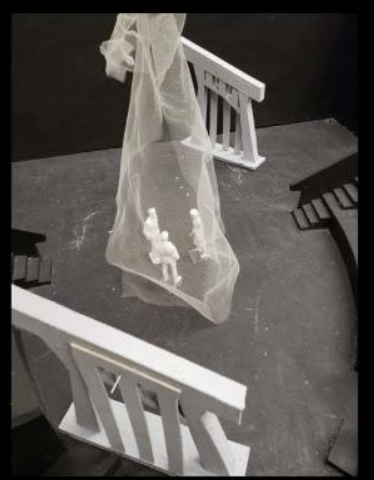

4.4 - French Tent 

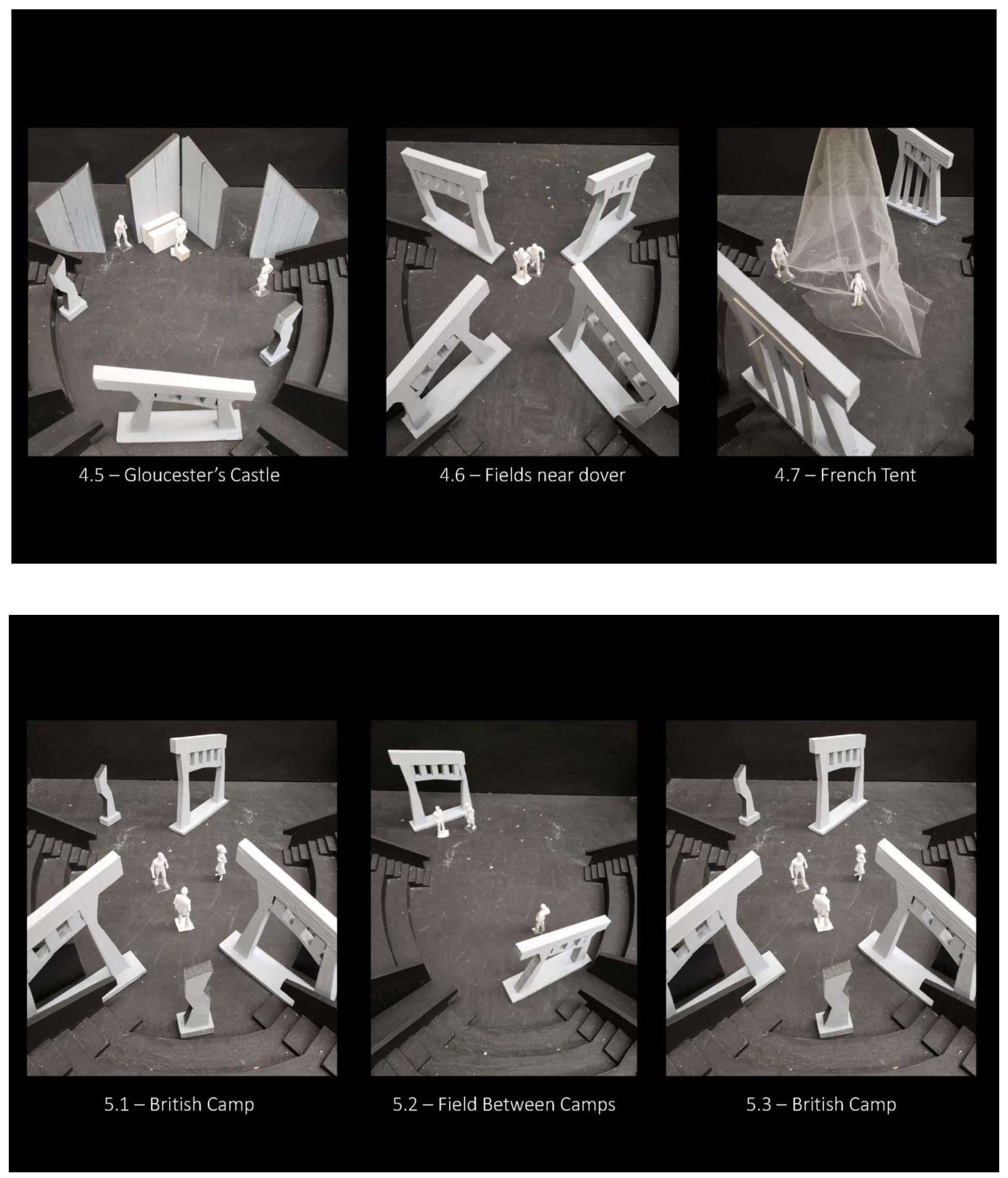


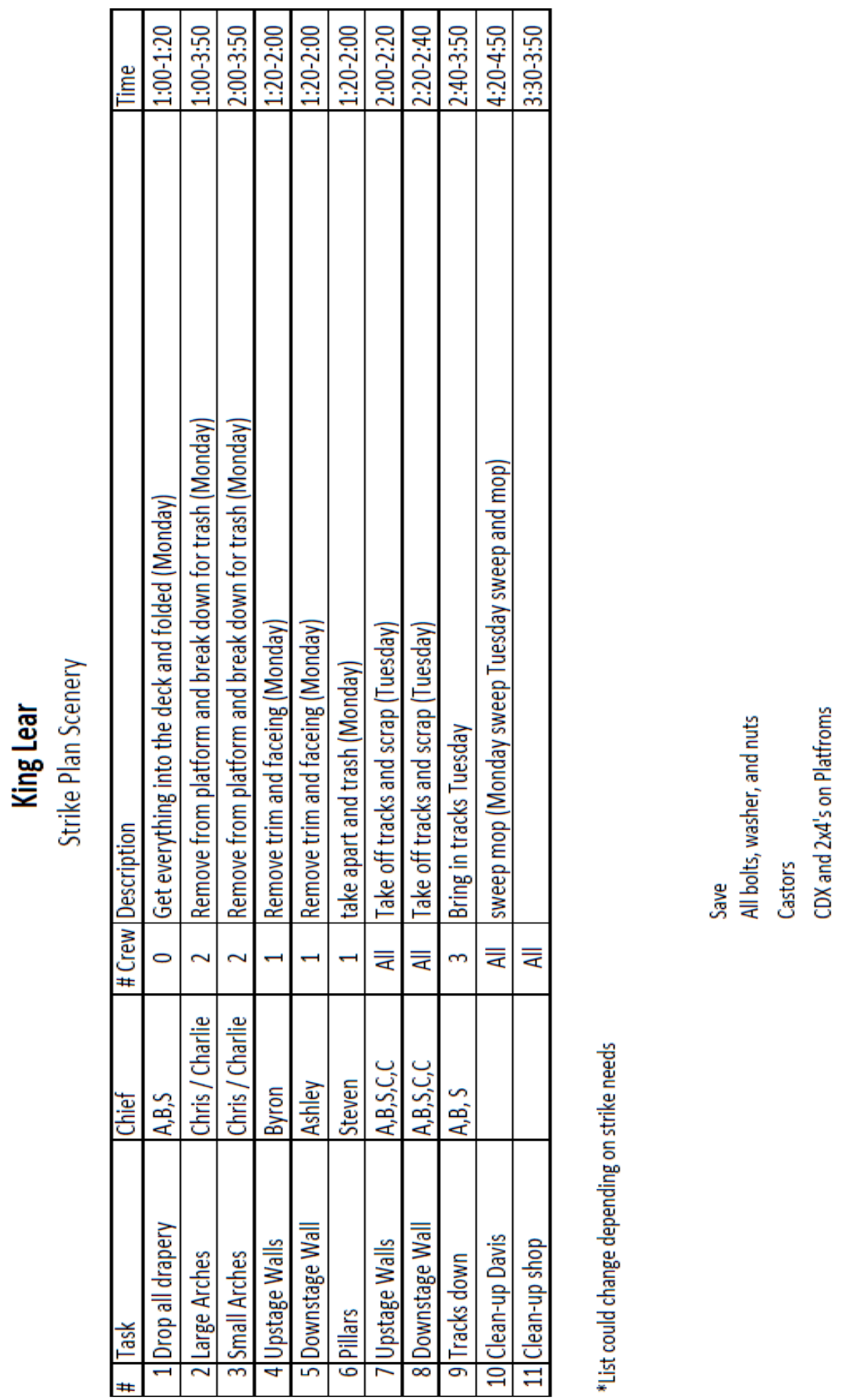

